\title{
Interspecific variation in the limb long bones among modern rhinoceroses - extent and drivers
}

\author{
Christophe Mallet $^{\text {Corresp., } 1}$, Raphaël Cornette ${ }^{2}$, Guillaume Billet $^{3}$, Alexandra Houssaye $^{1}$ \\ 1 Mécanismes adaptatifs et évolution (MECADEV), UMR 7179, MNHN, CNRS, Museum national d'Histoire naturelle, Paris, France \\ 2 Institut de Systématique, Evolution, Biodiversité (ISYEB), UMR 7205, MNHN, CNRS, SU, EPHE, UA, Museum national d'Histoire naturelle, Paris, France \\ ${ }^{3}$ Centre de Recherche en Paléontologie - Paris (CR2P), UMR CNRS 7207, MNHN, CNRS, SU, Museum national d'Histoire naturelle, Paris, France \\ Corresponding Author: Christophe Mallet \\ Email address: christophe.mallet@edu.mnhn.fr
}

Among amniotes, numerous lineages are subject to an evolutionary trend towards body mass and size increases. Large terrestrial species may face important constraints linked to weight bearing, and the limb segments are particularly affected by such constraints due to their role in body support and locomotion. Such groups showing important limb modifications related to high body mass have been called "graviportal". Often considered graviportal, rhinoceroses are among the heaviest terrestrial mammals and are thus of particular interest to understand the limb modifications related to body mass and size increase. Here, we present a morphofunctional study of the shape variation of the limb long bones among the five living rhinos to understand how the shape may vary between these species in relation with body size, body mass and phylogeny. We used 3D geometric morphometrics and comparative analyses to quantify the shape variation. Our results indicate that the five species display important morphological differences depending on the considered bones. The humerus and the femur exhibit noticeable interspecific differences between African and Asiatic rhinos, associated with a significant effect of body mass. The radius and ulna are more strongly correlated with body mass. While the tibia exhibits shape variation both linked with phylogeny and body mass, the fibula displays the greatest intraspecific variation. We highlight three distinct morphotypes of bone shape, which appear in accordance with the phylogeny. The influence of body mass also appears unequally expressed on the different bones. Body mass increase among the five extant species is marked by an increase of the general robustness, more pronounced attachments for muscles, and a development of medial parts of the bones. Our study underlines that the morphological features linked to body mass increase are not similar between rhinos and other heavy mammals such as elephants and hippos, suggesting that the weight bearing constraint can lead to different morphological responses. 


\section{Interspecific variation in the limb long bones among modern \\ 2 rhinoceroses - extent and drivers}

3 Christophe Mallet ${ }^{1}$, Raphaël Cornette ${ }^{2}$, Guillaume Billet ${ }^{3}$, Alexandra Houssaye $^{1}$

$4{ }^{1}$ Mécanismes adaptatifs et évolution (MECADEV), UMR 7179, MNHN, CNRS, Museum

5 national d'Histoire naturelle, Paris, France

62 Institut de Systématique, Evolution, Biodiversité (ISYEB), UMR 7205, MNHN, CNRS, SU,

7 EPHE, UA, Museum national d'Histoire naturelle, Paris, France

$8{ }^{3}$ Centre de Recherche en Paléontologie - Paris (CR2P), UMR CNRS 7207, MNHN, CNRS, SU,

9 Museum national d'Histoire naturelle, Paris, France

10

11 Corresponding author:

12 Christophe Mallet

1355 rue Buffon, CP 55, 75005, Paris, France

14 Email address: christophe.mallet@edu.mnhn.fr 


\section{Abstract}

Among amniotes, numerous lineages are subject to an evolutionary trend towards body mass and size increases. Large terrestrial species may face important constraints linked to weight bearing, and the limb segments are particularly affected by such constraints due to their role in body support and locomotion. Such groups showing important limb modifications related to high body mass have been called "graviportal". Often considered graviportal, rhinoceroses are among the heaviest terrestrial mammals and are thus of particular interest to understand the limb modifications related to body mass and size increase. Here, we present a morphofunctional study of the shape variation of the limb long bones among the five living rhinos to understand how the shape may vary between these species in relation with body size, body mass and phylogeny. We used 3D geometric morphometrics and comparative analyses to quantify the shape variation. Our results indicate that the five species display important morphological differences depending on the considered bones. The humerus and the femur exhibit noticeable interspecific differences between African and Asiatic rhinos, associated with a significant effect of body mass. The radius and ulna are more strongly correlated with body mass. While the tibia exhibits shape variation both linked with phylogeny and body mass, the fibula displays the greatest intraspecific variation. We highlight three distinct morphotypes of bone shape, which appear in accordance with the phylogeny. The influence of body mass also appears unequally expressed on the different bones. Body mass increase among the five extant species is marked by an increase of the general robustness, more pronounced attachments for muscles, and a development of medial parts of the bones. Our study underlines that the morphological features linked to body mass increase are not similar between rhinos and other heavy mammals such as elephants and hippos, suggesting that the weight bearing constraint can lead to different morphological responses.

\section{Keywords}

rhinoceros; limb bones; 3D geometric morphometrics; morphofunctional anatomy; body mass; body size; graviportality. 


\section{Introduction}

42 Many vertebrate lineages exhibit convergence towards a body mass increase through time (Depéret, 1907; Raia et al., 2012; Baker et al., 2015; Bokma et al., 2016). Size and mass augmentation implies metabolic and musculoskeletal modifications for the whole body to bear its own weight (McMahon, 1973). One of the most noticeable body changes related to weight bearing concern modifications of the appendicular skeleton; animals displaying such adaptive traits are said to be "graviportal" (Hildebrand, 1974). This concept introduced by Gregory (1912) and Osborn (1929) has been defined based on both anatomical and locomotion aspects: the commonly accepted criteria are, in addition to a body mass of several hundreds of kilograms, columnar limbs with stylopodium lengthening and autopodium shortening, robust bones (i.e. larger shaft for a given length), large feet with enlarged adipose cushions, reduced phalanges, long strides associated with the inability to gallop (Gregory, 1912; Osborn, 1929; Coombs, 1978). This condition was opposed to the "cursorial" one characterizing running animals (e.g. horses and many ungulates). Between these two extremes, intermediate categories tended to sharpen this tentative locomotor classification, with "subcursorial" for moderate cursorial adaptations with good running performances (e.g. felids and canids), and "mediportal" for animals with conformations meeting both the weight bearing aspect and running capacities (e.g. suids, tapirs) (Gregory, 1912; Coombs, 1978; Eisenmann \& Guérin, 1984). These categories remain extensively used in functional morphology and locomotion studies (e.g. Maynard Smith \& Savage, 1956; Coombs, 1978; Eisenmann \& Guérin, 1984; Prothero et al., 1986; Biewener, 1989a; Stein \& Casinos, 1997; Polly, 2007; Scherler et al., 2013; MacLaren \& Nauwelaerts, 2016). Hildebrand (1974) proposed an arbitrary body mass of $900 \mathrm{~kg}$ beyond which the species is considered as graviportal, but without justification for this threshold. Carrano (1999) tackled this problem by replacing these discrete categories by a multivariate continuum of locomotor habits ranging from graviportal to cursorial based on bone and muscular insertion measurements, chosen to be "biomechanically relevant" but performed only on the femur, tibia and third metatarsal.

As a consequence, the categorization of some taxa as graviportal may vary depending on authors. Among living mammals, elephants, rhinos and hippos are commonly considered as the three main graviportal taxa (Alexander \& Pond, 1992). Elephants obviously fulfil all the 
71 morphological and biomechanical criteria defining graviportality (Coombs, 1978; Langman et al., 1995). However, the peculiar morphology of hippos (barrel-like body and shortened limbs) linked to semi-aquatic habits (Mazza, 2014) has been considered alternately as mediportal (Coombs, 1978; Ross, 1984) or graviportal (Alexander \& Pond, 1992; Carrano, 1999; MacFadden, 2005; Stilson, Hopkins \& Davis, 2016). The graviportal condition in rhinoceroses is surely the least consensual: Gregory (1912) and Osborn (1929) considered rhinos as mediportal whereas later works assigned them a graviportal condition (Prothero and Sereno, 1982; Eisenmann and Guérin, 1984). Becker (2003) and Becker et al. (2009) dug into this question and developed a "gracility index" based on the work of Guérin (1980) to categorize modern and fossil rhinos, but only based on third metacarpal and metatarsal proportions. The use of this index refined the classification of modern rhinos distinguishing mediportal and graviportal species instead of a single class attribution for the whole family (Table 1).

Regardless of the locomotor type to which they belong, the family Rhinocerotidae includes some of the heaviest land mammal species after elephants, displaying adaptations to support their high body mass (Alexander \& Pond, 1992). There are five remaining species of rhinos on Earth nowadays: the White Rhinoceros (Ceratotherium simum Burchell, 1817) and the Black Rhinoceros (Diceros bicornis Linnaeus, 1758) both live in sub-Saharan Africa, whereas the Indian Rhinoceros (Rhinoceros unicornis Linnaeus, 1758), the Javan Rhinoceros (Rhinoceros sondaicus Desmarest, 1822) and the Sumatran Rhinoceros (Dicerorhinus sumatrensis Fischer, 1814) survive in India and Nepal, Java and Sumatra, respectively (Dinerstein, 2011). These species exhibit an important variation in body mass and size (Table 1), ranging from less than a ton for Dicerorhinus sumatrensis to more than three tons for the biggest known specimens of Ceratotherium simum. They are all good walkers and runners, able to gallop and reach an elevated speed $(27 \mathrm{~km} / \mathrm{h}$ for Ceratotherium simum, Alexander \& Pond, 1992; $45 \mathrm{~km} / \mathrm{h}$ for Diceros bicornis, Blanco, Gambini \& Fariña, 2003). However, important ecological differences also exist (Groves, 1967a,b, 1972; Groves \& Kurt, 1972; Laurie, Lang \& Groves, 1983; HillmanSmith \& Groves, 1994; Dinerstein, 2011; Groves \& Leslie, 2011): the three Asiatic rhinos are excellent swimmers and very familiar with an aquatic environment whereas the two African ones are easily stopped by a relatively deep river (Guérin, 1980). While Ceratotherium simum is a pure grazer, Rhinoceros unicornis can both graze and browse small shrubs, leafy material and fruits, the three other species being mainly leaf browsers. Before the drastic decrease of their 
102 natural habitats under human pressure, rhinos occupied a wide geographic range across Africa 103 and Asia (Dinerstein, 2011; Rookmaaker \& Antoine, 2013). Moreover, the fossil record of the

104

105

106

107

108

109

110

111

112

113

114

115

116

117

118

119

120

121

122

123

124

125

126

127

128

129

130

131

superfamily Rhinocerotoidea contains many lineages displaying evolutionary convergence towards an increase of body mass (Prothero \& Schoch, 1989; Prothero, 1998; Antoine, 2002; Becker, 2003; Scherler et al., 2013). However, despite the importance of rhino species for understanding evolution towards large body mass and the fact that they are some of the heaviest surviving land mammals, only a few studies really explore the variation of their limb bone morphology in relation to their body proportions (Guérin, 1980; Eisenmann \& Guérin, 1984). After the pioneering works of Cuvier (1812) and de Blainville \& Nicard (1839) describing the postcranial anatomy of modern rhinos, almost no work tried to broadly analyse and compare the morphology of their limb bones. Guérin (1980) published a substantial comparative anatomy work on the whole skeleton of the five extant species. This study emphasized anatomical descriptions with a direct application on the determination of fossil forms. Despite considerations on inter- and intraspecific osteological variation in modern rhinos, this work did not fully explore the patterns of shape variation in this group. Furthermore, most of the previous studies used a classic morphometric approach with linear measurements on bones, an approach which cannot precisely take into consideration the whole shape of the bone in three dimensions (3D). To our knowledge, no morphofunctional analyses have been carried out on limb long bones of modern rhinos taking into consideration their whole shape.

Here we hypothesize that modern rhinoceroses exhibit a large amount of interspecific variation of the shape of each bone that would be essentially associated with a strong effect of body mass on bone morphology. We predict that this effect will be more pronounced on the stylopodium (humerus and femur) than on the zeugopodium (radius, ulna, tibia and fibula) bones. This would be in accordance with previous works on changes of limb shape between graviportal and cursorial taxa (Biewener, 1989b; Campione \& Evans, 2012). In addition, we expect an effect of phylogenetic heritage and different species' ecologies on bone shape. To test these hypotheses, we propose to explore the variation in the shape of the limb long bones among the five modern rhino species using a 3D geometric morphometrics approach. We describe interspecific patterns of morphological variation for the six bones composing the stylopodium and the zeugopodium, taking into account the intraspecific variation.

Peer) reviewing PDF | (2019:05:37815:2:0:NEW 6 Aug 2019) 
132 Material and Methods

\section{Sample}

134 We selected 62 dry skeletons in different European museums belonging to the five extant rhino

135

136

137

138

139

140

141

142

143

144

145

146

147

148

149

150

151

152

153

154

155

156

157

158

159 species: Ceratotherium simum, Dicerorhinus sumatrensis, Diceros bicornis, Rhinoceros sondaicus and Rhinoceros unicornis (Table 2). We followed the taxonomic attribution given by each institution for most of the specimens, except for three individuals determined or reattributed by ourselves on osteological criteria and later confirmed by our morphometric analysis (see Table 2). We studied altogether 53 humeri, 49 radii, 46 ulnae, 56 femora, 52 tibiae and 50 fibulae, with 37 skeletons being complete. We included only mature specimens with fully fused epiphyses (adults) or specimens where the line of the epiphyseal plates was still visible on some bones (subadults). Bones showing breakages or unnatural deformations were not considered in our analysis. It has been proved that feet bones are subject to important osteopathologic deformations in rhinos (Regnault et al., 2013). However, in accordance with the observations of Guérin (1980), we did not notice any major difference between the long bones of captive and wild animals, neither through visual and osteological observations nor in our morphometric analyses; we therefore did not take into account this parameter. Sexual dimorphism occurs among rhinos but has been mostly investigated regarding the external morphology of the animals (Dinerstein, 1991, 2011; Berger, 1994; Zschokke \& Baur, 2002). The few studies that have explored the osteological variations between sexes indicated only slight absolute metric divergences depending on species (Guérin, 1980; Groves, 1982). This suggests that intraspecific variation due to sex may be marginal when compared to interspecific variation, and probably more related to the size of the bone than to the shape. Furthermore, since almost half of our sample lacked sex information and that we had twice as many males than females, we could not carefully address sex in our study (see Results).

\section{D models}

Bones were mostly digitized with a structured-light three-dimensional scanner (Artec Eva) and reconstructed with Artec Studio Professional software (v12.1.1.12 - Artec 3D, 2018).

Complementarily, 19 bones were digitized with a photogrammetric approach, following Mallison 
160 \& Wings (2014) and Fau, Cornette \& Houssaye (2016). Sets of photos were taken all around the

161 bones and aligned to reconstruct a 3D model with Agisoft Photoscan software (v1.4.2 - Agisoft, 162 2018). Previous studies indicated no significant difference between 3D models obtained with 163 these two methods (Petti et al., 2008; Remondino et al., 2010; Fau, Cornette \& Houssaye, 2016). 164 Five bones were digitized using medical computed tomography scanners at the Royal Veterinary 165 College, London (Equine Hospital) and at the University of California, San Francisco

166 (Department of Radiology \& Biomedical Imaging). Bone surfaces were extracted as meshes 167 using Avizo software (v9.5.0 - Thermo Fisher Scientific, 2018). Each mesh was decimated to 168 reach 250,000 vertices and 500,000 faces using MeshLab software (v2016.12 - Cignoni et al., 169 2008). We mainly selected left bones during acquisition; when this was impossible, right bones 170 were selected and then mirrored before analysis.

\section{Anatomical terminology}

172 All anatomical terms used to describe bones come from classic references: the Nomina 173 Anatomica Veterinaria (World Association of Veterinary Anatomists \& International Committee 174 on Veterinary Gross Anatomical Nomenclature, 2005) and anglicized terms of Barone (2010a)

175 for general osteology and bone orientation, Guérin (1980) for specific rhino anatomy, 176 complemented by the contributions of Colyn (1980), Antoine (2002) and Heissig (2012). Despite 177 these previous works, one anatomical feature remained unnamed, leading us to use our own 178 designation: we called "palmar process" the process facing the coronoid process on the palmar 179 border of the radius proximal epiphysis. Muscle insertions were described after the general 180 anatomy of horses (Barone, 2010b), complemented by the work of Beddard \& Treves (1889) and 181 some complementary information from Guérin (1980) on rhino myology, Bressou (1961) on that 182 of tapirs and Fisher, Scott \& Naples (2007) and Fisher, Scott \& Adrian (2010) on that of hippos.

\section{Geometric Morphometrics}

184 To analyse shape variation in our sample, we performed 3D geometric morphometrics, a widely 185 used approach allowing quantification of morphological differences between objects using 186 landmark coordinates (Adams, Rohlf \& Slice, 2004; Zelditch et al., 2012). 
188 Following the procedure described by Gunz, Mitteroecker \& Bookstein (2005), Gunz \&

189 Mitteroecker (2013) and Botton-Divet et al. (2016), we defined the bones' shape using

190

191

192

193

194

195

196

197

198

199

200

201

202

203

204

205

206

207

208

209

210

211

212

213

214

215 anatomical landmarks and curve and surface sliding semi-landmarks. Each curve is bordered by anatomical landmarks as recommended by Gunz \& Mitteroecker (2013). We placed all landmarks and curves using the IDAV Landmark software (v3.0 - Wiley et al., 2005). We used 35 anatomical landmarks on the humerus, 23 on the radius, 21 on the ulna, 27 on the femur, 24 on the tibia and 12 on the fibula. Details of landmark numbers and locations used for each bone are given in Supplemental Table S1 and Figure S1.

Following the procedure detailed by Botton-Divet et al. (2016), we created a template to place surface semi-landmarks for each bone: a specimen (Ceratotherium simum RMCA 1985.32-M0001) was randomly chosen on which all anatomical landmarks, curve and surface sliding semilandmarks were placed. We then used this template for the projection of surface sliding semilandmarks on the surface of the other specimens. Projection was followed by a relaxation step to ensure that projected points matched the actual surface of the meshes. Curve and surface sliding semi-landmarks were then slid to minimize the bending energy of a Thin Plate Spline between each specimen and the template at first, and then two times between the result of the preceding step and the Procrustes consensus of the complete dataset. Therefore, all landmarks can be treated at the end as geometrically homologous (Gunz, Mitteroecker \& Bookstein, 2005) and analysed with classic procedure such as Generalized Procrustes Analysis (see below). Projection, relaxation and sliding processes were conducted using the Morpho package in the $\mathrm{R}$ environment (R Core Team, 2014). Details of the process are provided in the documentation of the package (Schlager, 2018).

\section{Repeatability tests}

For each bone, we tested the repeatability of the anatomical landmark digitization taking measurements ten times on three specimens of the same species, Ceratotherium simum, chosen to display the closest morphology and size. We superimposed these measurements using a Generalized Procrustes Analysis and visualized the results using a Principal Component Analysis (PCA). Results showed a variation within specimens clearly smaller than the variation between 
216 specimens (see Supplemental Fig. S2) and allowed us to consider our anatomical landmarks as

217 precise enough to describe shape variation.

After the sliding of all semi-landmarks, we performed Generalized Procrustes Analyses (GPA) (Gower, 1975; Rohlf \& Slice, 1990) to remove the effects of size and of the relative position of the points and to isolate only the shape information. As our dataset contained more variables than observations, we used a Principal Component Analysis (PCA) to reduce dimensionality as recommended by Gunz \& Mitteroecker (2013) and visualize the specimen distribution in the morphospace. We computed theoretical consensus shape of our sample and used it to calculate a TPS deformation of the template mesh. We then used this newly created consensus mesh to compute theoretical shapes associated with the maximum and minimum of both sides of each PCA, as well as mean shapes of each bone for each species. GPA, PCA and shape computations were done using the "Morpho" and "geomorph" packages (Adams \& Otárola-Castillo, 2013; Adams, Collyer \& Kaliontzopoulou, 2018; Schlager, 2018) in the R environment (R Core Team, 2014). Neighbour Joining method was used to construct trees based on relative Euclidian distances between individuals based on all principal component scores obtained with the PCA, allowing a global visualisation of the relationships between all the specimens. Trees were computed with the "ape" package (Paradis et al., 2018).

\section{Allometry effect}

235

We tested the effect of allometry, defined as "the size-related changes of morphological traits" (Klingenberg, 2016). Pearson's correlation tests were performed to look for correlation between the principal components and the centroid size $\left(\log _{10}\right)$ for each bone. We also used the function procD.allometry of the "geomorph" package to perform a Procrustes ANOVA (a linear regression model using Procrustes distances between species instead of covariance matrices - see Goodall, 1991) to quantify the shape variation related to the centroid size, and to visualize theoretical shapes associated with minimal and maximal sizes of our sample (Adams \& Otárola-Castillo, 2013; Adams, Collyer \& Kaliontzopoulou, 2018). This test was performed taking into account group affiliation (e.g. species) to highlight respective roles of centroid size and species determination on the shape variation. In the absence of individual body mass for the 
245 majority of our sample, we also performed a Procrustes ANOVA with the cube root of the mean 246 mass attributed to each species (Table 1), each species being associated with the mean mass of

247 its species. As for the centroid size, theoretical shapes associated with minimal and maximal

248 mean mass were computed using the predicted Procrustes residuals (details on the procedure are

249 given in the "geomorph" documentation). Plots of the multivariate regressions of shape scores

250 (i.e. regression of shape on size; see Drake \& Klingenberg, 2008) against log-transformed

251 centroid size were also computed.

\section{Results}

\section{Shape analysis}

254 We describe here the results of our PCA for each bone and focus on the theoretical shape

255 variations along the two main axes. For each bone, we chose to represent relevant views and 256 anatomical features. Complete visualizations of the different theoretical shapes for the two first 257 axes are available in Supplemental Figure S3. Analysis of shape relations among our sample is 258 completed by the Neighbour Joining trees provided in Supplemental Figure S4.

Humerus

260 The first two axes of the PCA computed on the humerus represent $60.6 \%$ of the total variance 261 (Fig. 1A). The first axis represents more than half of the global variance (53\%) and the five 262 species appear clearly sorted along it, opposing D. sumatrensis on the positive side to C. simum on the negative one, i.e. the lightest and heaviest species, respectively. D. bicornis is grouped with $C$. simum on the negative part of the axis, whereas $R$. sondaicus is on the positive part. $R$. unicornis occupies the centre of the axis, between D. bicornis and $R$. sondaicus. Points distribution in the morphospace and Neighbour Joining trees indicate a clear separation between African and Asiatic rhinos (Fig. S4A). The theoretical shape at the PC1 minimum (Fig. 1B, D, F, H) shows a massive morphology, with mediolaterally and craniocaudally broad epiphyses and shaft; a wide humeral head, with very little overhanging of the diaphysis in the caudal direction; a lesser tubercle more strongly developed than the greater tubercle, with an intermediate tubercle separating a widely open bicipital groove into unequal parts, the lateral one being the largest; a

272 lesser tubercle convexity medially extended whereas the greater tubercle one is quite reduced in 
273 this direction; a broad and diamond-shaped $m$. infraspinatus imprint on the lateral side; a broad

274 deltoid tuberosity not extending beyond the lateral border of the bone; a shaft with its maximal

275 width situated between the humeral head and the deltoid tuberosity; a distinct but very smooth

276 and flat $m$. teres major tuberosity; a very large distal epiphysis because of the development of the

277 lateral epicondyle; a smooth epicondylar crest; a mediolaterally wide and craniocaudally

278 compressed medial epicondyle; shallow and proximodistally compressed olecranon fossa and

279 trochlea; a wide trochlea displaying a main axis tilted in the dorsoventral direction; and a

280 capitulum with a relatively small surface area. At the opposite, the theoretical shape at the PC1

281 maximum (Fig. 1C, E, G, I) shows a slender and thin aspect; a more rounded humeral head

282 overhanging the diaphysis caudally; a greater tubercle more strongly developed than the lesser

283 one and extending medially, conferring a more closed aspect to the bicipital groove, where the

284 intermediate tubercle is almost absent; a poorly developed lesser tubercle convexity whereas the

285 greater tubercle one is massive; a rounded and reduced $m$. infraspinatus insertion; a deltoid

286 tuberosity strongly protruding laterally; a straight and thin shaft; no visible m. teres major

287 tuberosity; a narrow distal epiphysis, with a small development of the lateral epicondyle; a sharp

288 epicondylar crest; a craniocaudally developed medial epicondyle overhanging the olecranon

289 fossa; a deep and wide olecranon fossa; a far less compressed trochlea, with a less dorsoventrally

290 tilted axis; and a very reduced capitulum.

291 Along the second axis (7.6\%), we observe this time that C. simum and D. sumatrensis are

292 grouped together on the negative part of the axis, with the three other species on the positive

293 part, whereas they are opposed along the first axis. This second axis expresses the separation

294 between the lightest and the heaviest rhino species on the one hand and the three other species on

295 the other hand. The theoretical shape at the PC2 minimum displays a humeral head stretched in

296 the caudal direction; a lesser tubercle more developed than the greater one, delimiting an open

297 bicipital groove; a proximodistally extended distal epiphysis, with an epicondylar crest starting

298 almost on the middle of the shaft; a rounded and wide olecranon fossa. At the opposite, the

299 theoretical shape at the PC2 maximum shows a rounded humeral head; a strong development of

300 both tubercles and a more closed bicipital groove; a mediolaterally stretched distal epiphysis,

301 with the epicondylar crest starting at the distal third of the shaft; an olecranon fossa

302 proximodistally compressed and more rectangular; and a well-developed lateral epicondyle. 


\section{Radius}

304 305

306

307

308

309

310

311

312

313

314

315

316

317

318

319

320

321

322

323

324

325

326

327

328

329

330

331

332

333

The first two axes of the PCA performed on the radius express $52.3 \%$ of the total variance (Fig. 2A). The first axis (36.4\%) opposes D. sumatrensis and D. bicornis to R. unicornis and $C$. simum. $R$. sondaicus overlaps both $R$. unicornis and $D$. bicornis clusters. The specimens of $D$. sumatrensis are split in two discrete clusters along the first axis, but no clear explanation linked to age, sex or geographic origin was associated with this distribution. Point dispersion along this axis indicates an important intraspecific variation for D. sumatrensis, and to a lesser extent for $D$. bicornis and $R$. sondaicus. Unlike for the humerus, phylogenetically related species are not grouped together on PCA and Neighbour Joining trees (Fig. S4B). The theoretical shape at the PC1 minimum (Fig. 2B, D, F, H) shows a massive morphology with large shaft and epiphyses; an asymmetrical proximal articular surface (constituting the ulnar notch), with a medial portion appearing nearly twice as large as the lateral one; a protruding lateral insertion relief (distally to the lateral coronoid process sensu Budras, Sack \& Röck, 2009) (i.e. insertion area of the $m$. extensor digitorum communis) whereas the radial tuberosity is little prominent; a mediolaterally reduced lateral synovial articulation surface for the ulna; a rectangular and thin medial synovial articulation surface for the ulna; a triangular proximal articular surface for the ulna as wide mediolaterally as proximodistally; a thick shaft with an interosseous space opening close to the proximal epiphysis: consequently, the interosseous crest runs along the diaphysis to the distal articular surface for the ulna; a broad distal epiphysis in the mediolateral direction, with a strong medial tubercle developed on the dorsal face; a distal articular surface compressed in the dorsoventral direction; an articular surface for the scaphoid little extended proximally; a trapezoidal and wide articular surface for the semilunar (i.e. lunate bone or lunatum); a welldeveloped radial styloid process. The theoretical shape at the PC1 maximum (Fig. 2C, E, G, I) displays a more slender morphology; a less asymmetrical proximal articular surface, despite the development of the medial part; an almost absent lateral insertion relief; a completely flat radial tuberosity; a mediolaterally reduced lateral synovial articulation surface for the ulna; a rectangular and thin medial synovial articulation for the ulna; a triangular proximal articular surface for the ulna, mediolaterally short and proximodistally stretched; a thin and slender shaft, with an interosseous space opening at the proximal third of the total length; a poorly visible interosseous crest; a less dorsoventrally compressed distal epiphysis and a poorly developed lateral tubercle (on the dorsal side); a dorsoventrally wide distal articular surface, with a 
334 proximally extended articular surface corresponding to the scaphoid; a trapezoidal and reduced

335 articular surface for the semilunar; a less developed radial styloid process with a rounded border.

336 The second axis (15.9\%) discriminates mainly $R$. sondaicus from the four other species. $R$.

337 unicornis displays little extension along this axis; neither does D. bicornis, only driven on the

338 negative side by a single individual. Extension of $R$. unicornis morphospace occupation along

339 the second axis is very limited, contrary to that of $C$. simum and D. sumatrensis clusters. As on

340 the first axis, D. sumatrensis is split in two clusters, one in the negative part and the other around

341 null values. The theoretical shape at the PC2 minimum displays a slender morphology, with a

342 strongly asymmetrical proximal articular surface; a proximally reduced palmar process, opposed

343 to the coronoid process; a distal epiphysis dorsoventrally broad, with a developed lateral

344 prominence; a little developed radial styloid process; a slight proximal extension of the articular

345 surface for the scaphoid. The theoretical shape at PC2 maximum displays a more massive shape;

346 a deeper and more symmetrical proximal articular surface with a well-developed palmar process;

347 a dorsoventrally compressed distal epiphysis with a more developed styloid process.

Ulna

349

350

351

352

353

354

355

356

357

358

359

360

361

362

363

The first two axes of the PCA performed on the ulna express $41.5 \%$ of the total variance (Fig. 3A). The first axis (22.1\%) separates D. sumatrensis and D. bicornis on the positive part and $R$. sondaicus, $R$. unicornis and $C$. simum on the negative part. However, the clusters of $C$. simum and $R$. unicornis overlap along this axis. The general pattern on both PCA and Neighbour Joining trees is close to the one observed for the radius (Fig. S4C). The theoretical shape at the PC1 minimum (Fig. 3B, D, F, H) displays a thick morphology with large epiphyses; a massive olecranon tuberosity with a medial tubercle - where inserts the medial head of the $m$. triceps brachii, as well as the mm. flexor carpi ulnaris and flexor digitorum superficialis - oriented dorsally; an anconeal process poorly developed dorsally and mediolaterally wide, as is the articular surface constituting the trochlear notch (receiving the humeral trochlea); a medially stretched medial part of the articular surface for the humerus; a short interosseous crest ending at the shaft half, with the interosseous space; a broad shaft with a triangular cross-section; a straight palmar border whereas the shaft is medially curved; a massive distal epiphysis with a wide insertion surface for the radius; a mediolaterally wide and little concave articular surface for the triquetrum (i.e. triquetral, pyramidal or cuneiform bone), while the one responding to the 
364 pisiform is crescent-shaped and little extended proximally. The theoretical shape for the PC1

365 maximum (Fig. 3C, E, G, I) displays a more gracile morphology; a slender olecranon tuberosity

366 with a medial tubercle where inserts the medial head of the m. triceps brachii oriented in the

367 palmar direction; a dorsally developed and mediolaterally narrow anconeal process, as is the

368 articular surface of the trochlear notch; a slightly medially stretched medial part of the articular

369 surface; a sharp interosseous crest; a thin and straight shaft; a mediolaterally compressed and

370 little concave distal epiphysis; a mediolaterally narrow articular surface for the triquetrum; a

371 triangular and proximally well-developed articular surface for the pisiform.

372 The second axis (19.4\%) separates quite clearly the three Asian species from the African ones.

373 The theoretical shape at the PC2 minimum displays a slender and straight morphology with a

374 high square-shaped olecranon process, mediolaterally flattened, more stretched in the palmar

375 direction; a wide and squared anconeal process; a straight and regular shaft; a mediolaterally

376 compressed distal epiphysis with a concave articular surface for the triquetrum and a distally

377 developed styloid process; a proximally extended articular facet for the pisiform. The theoretical

378 shape at the PC2 maximum displays a more massive and medially concave shape with an

379 olecranon process mediolaterally inflated and rounded in the palmar direction; an anconeal

380 process little developed dorsally and laterally tilted; a proximodistally compressed and extending

381 medially articular surface constituting the trochlear notch; a mediolaterally wide articular surface

382 for the triquetrum; a little developed styloid process; a poorly extended proximally and square-

383 shaped articular surface for the pisiform.

Femur

385

386

387

388

389

390

391

392

393

The first two axes of the PCA performed on the femur express $45.0 \%$ of the global variance (Fig. 4A). The first principal component (36.1\%) clearly isolates D. sumatrensis on the positive part from the other species. The clusters of D. bicornis, R. sondaicus and R. unicornis overlap on the negative part of the axis. D. bicornis and R. unicornis specimens overlap a substantial part of the cluster of $C$. simum too. The general pattern observed on the Neighbour Joining tree is closer to the humerus one, with African and Asiatic species grouped together, respectively (Fig. S4D). The theoretical shape at the PC1 minimum (Fig. 4B, D, F, H) shows a massive morphology with large epiphyses and a curved medial border, conferring a concave aspect to the diaphysis; a large femoral head, off-centred relatively to the shaft main axis, supported by a very large neck; a 
394

395

396

397

398

399

400

401

402

403

404

405

406

407

408

409

410

411

412

413

414

415

416

417

418

419

420

421

422

423

424

small and shallow fovea capitis mediocaudally oriented; a greater trochanter convexity expanding strongly laterodistally; the absence of trochanteric notch between the convexity and the top of the trochanter (Fig. 4F); a proximodistally reduced trochanteric fossa; a sharp lesser trochanter running along the medial edge, which is craniocaudally flattened below the humeral head; a third trochanter extending strongly laterally, cranially and proximally towards the greater trochanter convexity, and much curved towards the medial direction; a quite irregular shaft section along the bone - flattened below the proximal epiphysis and more trapezoidal towards the distal epiphysis; a broad distal epiphysis with developed medial and lateral epicondyles; a shallow supracondylar fossa; a wide trochlea, with a main rotation axis aligned with the shaft axis; a large and cranially expanded medial ridge of the trochlea separated from the lateral one by a deep trochlear groove; a medial condyle surface area larger than the lateral condyle one, both being separated by a narrow intercondylar space. At the opposite, the theoretical shape at the PC1 maximum (Fig. 4C, E, G, I) is more slender with a straight and regular shaft; a rounded femoral head aligned with the shaft main axis and supported by a thinner neck; a more pronounced and rounded fovea capitis oriented almost completely caudally; a greater trochanter convexity little developed laterodistally; a more pronounced trochanter top despite the absence of trochanteric notch; a thin lesser trochanter situated on the caudal border of the medial side; a rounded third trochanter more developed laterally than cranially; a quite regular and trapezoidal shaft section; a mediolaterally broader and medially oriented distal epiphysis; an almost absent supracondylar fossa; a less developed medial trochlear ridge separated from the lateral one by a shallow trochlear groove; a lateral condyle more oblique and divergent relatively to the medial one, increasing the intercondylar space; symmetrical medial and lateral condylar surfaces.

The second axis (8.9\%) clearly opposes D. sumatrensis, C. simum and D. bicornis on the positive part to the two Rhinoceros species on the negative part, the cluster of $D$. sumatrensis being driven towards negative values by a single individual. The theoretical shape at the PC2 minimum is mainly characterized by a flattened femoral head with a strong neck; a rounded and large fovea capitis mediocaudally oriented; a laterodistally expanded greater trochanter convexity; a long and thin lesser trochanter; an extremely developed third trochanter in lateral, cranial and proximal directions; a straight and regular shaft; a broad distal epiphysis with important development of both epicondyles; a trochlea rotation axis aligned with the main axis of the shaft. The theoretical shape at the PC2 maximum displays a more rounded head, with a more stretched 
425

426

427

428

429

430

431

432

433

434

435

436

437

438

439

440

441

442

443

444

445

446

447

448

449

450

451

452

453

454

neck; no fovea capitis at all but a little groove on the head border; a greater trochanter convexity little expanded laterodistally; a short and more medially developed lesser trochanter; a rounded third trochanter little developed in cranial and proximal directions; a straight shaft; a distal epiphysis less mediolaterally broad; a narrower intercondylar space; a more inflated medial condyle.

\section{Tibia}

The first two axes of the PCA performed on the tibia express $50.0 \%$ of the global variance (Fig. 5A). The first axis (29.1\%) separates roughly D. bicornis and D. sumatrensis on the positive part and $C$. simum, $R$. sondaicus and $R$. unicornis on the negative part. D. bicornis shows an important intraspecific variation along both axes. Neighbour Joining tree structure is less clear than for previous bones: both Rhinoceros species isolate from most of the other specimens, $C$. simum appears also separated from D. bicornis and D. sumatrensis. However, one C. simum and three D. sumatrensis specimens are closer from the Rhinoceros group than from their own respective species (Fig. S4E). The theoretical shape at the PC1 minimum (Fig. 5B, D, F, H) shows a massive morphology with broad shaft and epiphyses, both in craniocaudal and mediolateral directions; medial and lateral intercondylar tubercles having the same height and a reduced central intercondylar area; a broad cranial intercondylar area; a medial articular surface larger than the lateral one, with a caudally extended sliding surface for the $m$. popliteus tendon; a U-shaped popliteal notch; a rounded tibial tuberosity, laterally deflected and medially bordered by a shallow groove; a shallow extensor groove; a regularly triangular and distally extended proximal articular surface for the fibula; a thick tibial crest disappearing at the middle of the shaft, where the bone section is the smallest; a mediolaterally broad and rectangular in section distal epiphysis; a triangular-shaped distal articular surface for the fibula reduced in height, surmounted by a smooth interosseous crest running towards the middle of the shaft; a roughly rectangular distal articular surface for the talus, with a lateral groove larger and shallower than the medial one, separated by a prominent intermediate process without synovial fossa; an articular surface with a rotation axis aligned with the bone main axis; a prominent medial malleolus. The theoretical shape at the PC1 maximum (Fig. 5C, E, G, I) displays a relatively gracile morphology with a thin shaft; a lateral intercondylar tubercle more proximally extended than the medial one and a relatively large central intercondylar area; a cranially extended lateral 
455 condylar surface, reducing the cranial intercondylar area; roughly equal medial and lateral 456 articular surface areas; a V-shaped popliteal notch; a tibial tuberosity slightly more laterally 457 deflected; a deeper tuberosity groove; a nail-shaped proximal articular surface for the fibula; a 458 sharper tibial crest disappearing just before the first half of the shaft; a distal epiphysis more 459 compressed craniocaudally; a distal articular surface for the fibula displaying a large triangle 460 synostosis area occupying a third of the shaft and prolonged by a sharp interosseous crest. There 461 is no major difference in the distal articular shape between PC1 maximum and minimum, except 462 that the caudal apophysis is less prominent in the distal direction.

463 The second axis (20.9\%) clearly separates the two African species (C. simum and D. bicornis) on 464 the positive part from the three Asian species (D. sumatrensis, R. sondaicus and R. unicornis) on 465 the negative part. The theoretical shape at the PC2 minimum displays a slightly more slender 466 morphology; a proximal plateau higher cranially than caudally and forming a closer angle with 467 the diaphysis axis; a high intercondylar eminence; a lateral articular surface more caudally 468 extended than the medial one; a tibial tuberosity well separated from the condyles by deep 469 tuberosity and extensor grooves; a straight shaft ending with divergent borders forming a large 470 and rectangular distal epiphysis; a distal articular surface for the fibula forming a regular triangle 471 surmounted by a sharp interosseous crest; a medially extended medial malleolus, resulting in a 472 rectangular articular surface with the talus, where the medial groove is narrow and deep, 473 occupying a third of the area, whereas the lateral groove is shallow and broad. The theoretical 474 shape at the PC2 maximum displays a more massive morphology, with a craniocaudal inflation 475 of the epiphyses; a proximal plateau almost perpendicular to the diaphysis axis; a lower 476 intercondylar eminence; a lateral condyle surface almost twice less large than the medial one, 477 which is more developed caudally; a massive tibial tuberosity strongly deviated laterally, 478 delimited by very shallow tuberosity and extensor grooves and resulting in a very large cranial 479 intercondylar area; a straight shaft ending with almost parallel medial and lateral borders and a 480 square-shaped distal epiphysis; a less medially deflated medial malleolus; a squared distal 481 articular surface for the talus with medial and lateral grooves showing similar surface area and 482 depth. 
484 The first two axes of the PCA performed on the fibula express 55.9\% of the global variance (Fig.

485

486

487

488

489

490

491

492

493

494

495

496

497

498

499

500

501

502

503

504

505

506

507

508

509

510

511

512

6). Contrary to the five previous analyses, the first axis $(40.7 \%)$ here seems particularly driven by a strong intraspecific variation. The clusters of $C$. simum and D. sumatrensis are stretched along the PC1 and overlap with almost every other specimens. The cluster of D. bicornis is quite stretched along the axis too and only the two Rhinoceros species display less intraspecific variation. This pattern does not seem linked to sex, age class or condition (wild or captive): despite the presence of slightly more females and subadults on the negative part of the component, we did not consider this observation as robust enough to state on this question. This cluster distribution along the PC1 seems linked to the presence of irregular crests along the shaft, associated with an important variation of the outline of the crests running along the diaphysis, and a slight rotation of the fibular head (see Supplemental Figure S3). Consequently, we chose to display and analyse the specimen distribution along the second and third components instead. Theoretical shapes associated with the PC1 are available in Supplemental Figure S3.

PC2 and PC3 express $22.9 \%$ of the global variance (Fig. 7A). The second component (15.2\%) opposes $C$. simum on the negative side to $D$. sumatrensis on the positive side, whereas $D$. bicornis, $R$. sondaicus and $R$. unicornis have a more central disposition. As for the tibia, the Neighbour Joining tree structure appears less clearly sorted by species than for other bones. If Rhinoceros species group together and African ones as well, D. sumatrensis sample is split in two subgroups mixed with $R$. unicornis and African rhinos respectively (Fig. S4F). The theoretical shape at the PC2 minimum (Fig. 7B, D, F, H, J) displays a broad morphology with large epiphyses and a straight shaft; a rounded head with a craniomedially oriented proximal articular surface for the tibia; a head width similar to the shaft one; a robust shaft with two strong craniolateral and caudolateral lines running down the distal epiphysis and enlarging craniocaudally towards the distal epiphysis; a sharp and irregular interosseous crest; a mediolaterally compressed distal epiphysis with little development of the two distal tubercles at the end of the lateral crests; a shallow lateral groove; a triangular distal articular surface for the tibia, occupying only the last distal quarter of the bone length; a short and ovoid articular surface for the talus with a sharp distal ridge. The theoretical shape at the PC2 maximum (Fig. 7C, E, G, I, K) displays a slender morphology with a strongly curved shaft; a mediolaterally flat head 
513 extending craniocaudally and overhanging strongly the diaphysis; a thin shaft with two sharp

514 lateral crests running along it: these crests end with two developed tubercles surrounding a deep

515 lateral groove; a distal articular surface for the tibia extending from the distal third of the shape

516 and forming a stretched triangle; a wider and kidney-shaped articular surface for the talus,

517 forming two distal tips corresponding to the two lateral tubercles: between them on the distal

518 face, a large groove is visible, ending at the centre of the face.

519 The third component (7.7\%) mainly opposes $D$. bicornis on the positive part to $R$. sondaicus on 520 the negative part. However, this opposition is mainly driven by a small number of individuals

521 (two for D. bicornis and four for $R$. sondaicus). The specimens of $R$. sondaicus are divided into

522 two clusters, with three individuals overlapping notably with $D$. sumatrensis. The theoretical

523 shape at the PC3 minimum shows a massive morphology, with broad shaft and epiphyses; a

524 craniocaudally broad head, overhanging the shaft laterally; a proximal articular surface for the

525 tibia almost completely medially oriented; a straight shaft displaying a constant width along the

526 bone; craniolateral and caudolateral crests running almost parallel towards the distal end of the

527 bone, forming two developed tubercles surrounding a deep groove; an interosseous space

528 covered by irregular reliefs and bordered by a sharp interosseous crest; a distal articular surface

529 for the tibia forming a cranially deviated triangle; a kidney-shaped distal articular surface for the

530 talus, with a distal border separated from the lateral tubercles by a groove stopping at the middle

531 of the distal face. The theoretical shape at the PC3 maximum shows an extremely thin

532 morphology with a flattened and poorly developed head; a proximal articular surface oriented

533 almost completely in the cranial direction; a torsion of almost 90 degrees between the orientation

534 of the proximal and distal articular surfaces for the tibia; a very thin and flat shaft; craniolateral

535 and caudolateral crests running along the diaphysis ending on the distal epiphysis with few

536 developed tubercles; a distal articular surface for the tibia forming a slender triangle; a relatively

537 small distal articular surface for the talus, with a less pronounced kidney-shape; a groove on the

538 distal face mediolaterally compressed.

\section{Interspecific morphological variation}

540 In addition to global interspecific patterns of shape, we shortly describe the main morphological

541 features characterizing each species. Mean shapes of each bone for the five species are available

542 in Supplemental Figure S5. 
543 Limb long bones of $C$. simum present a general massive and robust aspect. The humerus is thick

544 and shows a strong development of the lesser tubercle and the lateral epicondyle, as well as a

545 proximal broadening in the craniocaudal direction. The radius and ulna are robust and display an

546 important medial development of the articular parts constituting the trochlear notch. The ulna

547 bears a strong olecranon tubercle. The distal articular surface for the carpals constituted by the

548 two bones is mediolaterally wide and compressed in the craniocaudal direction. The hind limb

549 bones are robust as well, this robustness being mainly expressed in the mediolateral direction for

550 the femur. This bone displays a rounded and thick head, strong greater and third trochanters, and

551 a distal trochlea laterally oriented. The tibia and fibula are robust as well, with a wide tibial

552 plateau supporting the knee articulation and a squared distal articulation for the talus.

553 For D. bicornis, the general aspect of the humerus is close to the one observed on C. simum, 554 particularly for the epiphyses (e.g. the shape of the bicipital groove, the development of the

555 lesser tubercle and of the lateral epicondyle), though its degree of robustness is less intense. The

556 radius is relatively slender but the proximal articular surface displays a cranial border with a

557 marked groove under the coronoid process, also observed on $C$. simum. The ulna is slender as

558 well with a thin olecranon process and limited medial development. Both distal epiphyses form a

559 mediolaterally wide articular surface for the carpals, poorly craniocaudally compressed. As for

560 hind limb bones, the femur is only slightly robust, with poorly developed trochanters and a

561 slender diaphysis. Tibia and fibula are less thick too, with a squared articular surface for the talus

562 as well. D. bicornis displays noticeable morphological similarities with C. simum.

563 The bone general morphology is very similar between both $R$. sondaicus and $R$. unicornis, being

564 often more robust in $R$. sondaicus. For these two species, the humerus displays an important

565 development of both lesser and greater tubercles, resulting in an asymmetrical bicipital groove.

566 The greater tubercle is even sometimes higher than the lesser one in R. sondaicus, which is not

567 the case in $R$. unicornis. The distal epiphysis is wide but with a medial epicondyle less developed

568 than in C. simum and D. bicornis, and a rectangular olecranon fossa. The radius exhibits

569 mediolaterally large epiphyses and a quite robust diaphysis, with a proximal articular surface

570 similar in both Rhinoceros species, with a straight cranial border unlike in African rhinos. The

571 distal epiphysis is rectangular and craniocaudally compressed. $R$. unicornis distinguishes from $R$.

572 sondaicus in having a more robust radius, with a more asymmetrical proximal epiphysis, a 
573 deeper radial tuberosity and a larger distal articular surface. The ulna is also very similar, the one

574 of $R$. unicornis being slightly more robust. The general aspect remains extremely close, with a

575 developed olecranon, a medial development of the articular surface constituting the trochlear

576 notch and a quite wide distal articular surface. On the hind limb, the femur appears different, the

577 R. unicornis one showing important development of the greater and third trochanters, sometimes

578 fused by a bony bridge as previously stated by Guérin (1980). The femur of $R$. sondaicus appears

579 slightly less robust, and the greater and third trochanters are less developed and never fused. On

580 the tibia, the proximal plateau is as wide as for the African taxa but the tibial tuberosity is more

581 detached from the condyles by deep tuberosity and extensor grooves. The diaphysis is relatively

582 thick and the distal articular surface is clearly rectangular. The fibula is very similar as well in

583 the two species, with a distal epiphysis curved in the caudal direction and a kidney-shaped

584 articular surface for the talus.

585 D. sumatrensis clearly differs from the other species. Despite clear rhinocerotid features, limb

586 long bones display unique morphological traits, with a more pronounced slenderness. On the

587 humerus, the development of the greater tubercle results in a more closed and asymmetrical

588 bicipital groove. The distal epiphysis is mediolaterally narrow with a straight trochlea axis. The

589 thin radius possesses a proximal articular surface almost symmetrical despite a medial glenoid

590 cavity slightly more developed. The ulna is thin as well, and forms with the radius a rectangular

591 articular surface for the carpals. The femur shows a high and rounded head and a poorly

592 developed third trochanter. The distal trochlea axis is more medially oriented. On the tibia, the

593 plateau is far less wide than in other species and the distal articular surface for the talus is

594 rectangular. The thin fibula displays a large head caudally bordered by a thin crest and the

595 diaphysis is strongly curved medially towards the tibia. The kidney-shape of the distal articular

596 surface for the talus resembles the Rhinoceros ones.

\section{Correlation with the centroid size}

598 Table 3 provides the results of the Pearson's correlation tests between the centroid size and the

599 two first principal components for each bone (and the third component for the fibula). There is a

600 significant correlation in each case between the first component and the centroid size, with

601 higher correlation coefficient values for the radius and ulna, and smaller values for the humerus

602 and fibula. The second principal component is also significantly correlated with the centroid size 
603 for the humerus, femur and fibula, with smaller correlation coefficient values than for PC1, 604 except for the humerus.

\section{Allometry}

606

607

608

609

610

611

612

613

614

615

616

617

618

619

620

621

622

623

624

625

626

627

628

629

630

631

Table 4 and Table 5 provide the main anatomical differences observed between theoretical shapes associated with minimal and maximal centroid size for the forelimb and hind limb bones respectively. Theoretical shapes associated with minimal and maximal log centroid size are provided in Supplementary Figures S6. In the case of the fibula, we found a pattern very close to the one observed along the second axis of the PCA. Replacing the log centroid size by the cube root of the mean mass of each species results in almost identical theoretical shapes for each bone (Fig. 8 and Figure S7), only distinguishable by minor shape differences: towards body mass maximum, the radius and ulna appear slightly more robust than for centroid size maximum (Fig. $8 \mathrm{D}, \mathrm{F})$; the greater and third trochanters of the femur are slightly less developed towards each other (Fig. 8H). Theoretical shapes associated with minimum and maximum of log centroid size are slightly more massive than the ones obtained with the cube root of the body mass for the humerus, the tibia and the fibula. All theoretical shapes associated with minimal and maximal cube root of the mean mass are provided in Supplementary Figures S7.

Table 6 and Table 7 provide the results of the two Procrustes ANOVAs performed on shape data, where the log centroid size and the cube root of the mean body mass were respectively the independent variable. Log centroid size is significantly correlated with shape for the six bones, with a determination coefficient varying between 0.10 for the fibula and 0.18 for the ulna. In every case, the determination coefficient is more than twice as high for species affiliation as for $\log$ centroid size, indicating a more important influence of group affiliation than of allometry. This is especially the case for the humerus, with a determination coefficient of 0.53 for species affiliation and of only 0.13 for log centroid size. Cube root of mean body mass is also significantly correlated with shape for the six bones, with slightly higher determination coefficient values than those obtained with the log centroid size. The humerus, the radius and the femur display the highest coefficients, between 0.33 and 0.26 . These higher values may be due to the use of a same mean body mass for each rhino species instead of individual mass. Moreover, group affiliation could not be used in this case because of the mean body mass redundancy. 
632 Multivariate regressions of shape scores against log-transformed centroid size (Fig. 9) show that 633 D. sumatrensis has the smallest centroid size and is well separated from the other rhino species 634 in most cases, except for the tibia and fibula. R. unicornis possesses the highest centroid size in 635 most of the cases, except for the radius and ulna, where it shares similar centroid size values and 636 shape scores as C. simum (Table 8). Different tendencies can be observed: for the humerus, 637 Asiatic rhinos have lower shape scores than African ones for a given size. Radius and ulna data 638 display a point pattern similar to each other, with the isolation of $D$. sumatrensis towards low 639 values, a second cluster formed by D. bicornis and $R$. sondaicus at average values, and a third 640 cluster with $C$. simum and $R$. unicornis showing the highest values. This separation in three 641 groups can be observed at a lesser extent for the femur, where D. bicornis and R. sondaicus share 642 almost the same centroid size and shape score variations, whereas $C$. simum and $R$. unicornis are 643 separated by their respective centroid size despite similar shape scores. Finally, tibia and fibula 644 display rather similar patterns with an important intraspecific shape variation, notably for $D$. 645 sumatrensis and D. bicornis. There is a more important continuity between the different clusters 646 for the tibia and the fibula than for other bones, where clusters are more separated from each 647 other.

\section{Discussion}

\section{Identification of morphotypes and phylogenetic influence}

651 Morphological variation isolates each rhino species from the others, more or less clearly depending on the bone considered. The shape analysis of the six bones allows for clear isolation of three general bone morphotypes: the African morphotype grouping C. simum and D. bicornis, the Rhinoceros morphotype grouping the two Rhinoceros species, and the D. sumatrensis morphotype. The congruence of these morphotypes with the phylogeny indicates that the phylogenetic signal on long bone shape is strong, although it fluctuates among bones. In addition, body mass also appears as an important factor, depending on the considered bones. The phylogeny is clearly the main effect driving the shape(s) of the humerus and femur. Conversely, 
660 mass. The tibia seems to be equally affected by both, which is also the case for the fibula that 661 shows, in addition, an important intraspecific variation.

662 Despite the fact that we could not test the phylogenetic signal in our data because of the small 663 number of studied species (Adams, 2014), our observations tend to indicate an effect of 664 phylogenetic relations. It is accepted that the two African rhino C. simum and D. bicornis are 665 closely related (Tougard et al., 2001). They may belong to the same subfamily - called 666 Dicerotinae (Guérin, 1982; Gaudry, 2017) or Rhinocerotinae (Antoine, 2002; Becker, Antoine \& 667 Maridet, 2013), depending on the authors. The two species composing the genus Rhinoceros are 668 also closely related (Tougard et al., 2001), the bones of $R$. unicornis and $R$. sondaicus having 669 sometimes been confused with each other (Groves \& Leslie, 2011). Conversely, the phylogenetic 670 position of $D$. sumatrensis remains debated (Willerslev et al., 2009; Gaudry, 2017), this species 671 being considered alternately as sister taxon of the two African species (Antoine, Duranthon \& 672 Welcomme, 2003; Cappellini et al., 2018), of the two Rhinoceros species (Tougard et al., 2001; 673 Welker et al., 2017) or of all four other rhino species (Fernando et al., 2006; Piras et al., 2010). 674 Our analyses reveal equally contrasting relationship patterns, with D. sumatrensis more closely 675 resembling African species for some bones (radius, ulna and tibia) and other Asiatic ones for the 676 others (humerus, femur and fibula).

677 Some anatomical features seem strongly influenced by phylogenetic relationships, among which 678 some have previously been used as characters for cladistics analyses (Prothero, Manning \& 679 Hanson, 1986; Cerdeño, 1995; Antoine, 2002). On the humerus, the bicipital groove allows the 680 sliding of a large $m$. biceps brachii, a forearm flexor playing an important locomotor role in 681 coordinating the scapula and arm movements (Watson \& Wilson, 2007; Barone, 2010b). This 682 groove appears more closed by the greater tubercle for Asiatic rhinos, potentially indicating a 683 different length and shape for the transverse humeral ligament. Although most analyses 684 (Prothero, Manning \& Hanson, 1986; Antoine, 2002) have coded a few characters related to the 685 tubercles of the humerus, the complexity of the shape of this bone proximal epiphysis remains 686 generally underestimated in phylogenetic reconstructions. Moreover, the case of the greater 687 tubercle development observed on the humerus of Asiatic species, and mainly for $D$. 688 sumatrensis, is of particular interest (see Supplemental Figure S5). As mentioned by Hermanson 689 \& MacFadden (1992), the greater tubercle "increases mechanical advantages" for the $\mathrm{mm}$. 
690 pectoralis ascendens, supraspinatus and infraspinatus. D. sumatrensis displays the slenderest

691 humerus of all modern rhinos, with morphological traits qualitatively close to tapirs' (MacLaren

692 \& Nauwelaerts, 2016). The proximal epiphysis of $D$. sumatrensis resembles that of tapirs,

693 regarded by some authors as a plesiomorphic condition among Perissodactyla (Prothero,

694 Manning \& Hanson, 1986; Hermanson \& MacFadden, 1992; Antoine, 2002). This particular

695 shape may thus represent an evolutionary heritage and it is unclear whether and how functional

696 constraints may have also affected this shape. The greater tubercle being also an insertion area

697 for the $m$. supraspinatus, extension movements thus seem achieved differently between African

698 and Asiatic rhinos. Watson \& Wilson (2007) showed that the m. supraspinatus in horses acts

699 more as a shoulder stabilizer than as a true extensor of the shoulder. Given the qualitative

700 similarity of shape of this joint between African rhinos and equids, it is likely that this muscle

701 plays a similar role among these groups. The robustness of the lesser trochanter is consistent with

702 a development of the medial end of the m. supraspinatus, to increase the shoulder stabilisation.

703 The lever arm is medially deflected for C. simum and D. bicornis, and distributed both medially

704 and laterally for Rhinoceros species and D. sumatrensis. The role of the shoulder joint remains

705 crucial in weight bearing and locomotion, and its shape may be influenced by several factors.

706 The development of a massive greater tubercle is encountered among hippos (Fisher, Scott \&

707 Naples, 2007), a trait that could be interpreted as an indicator of semi-aquatic habits and

708 displacements into muddy swamps or riverbanks. However, this particular morphology is yet

709 also encountered among domestic bovids for example (Barone, 2010a), which are not semi-

710 aquatic. Conversely, extinct Amynodontidae, presumed to have been semi-aquatic Oligocene

711 rhinos (Averianov et al., 2017), did not display this greater tubercle development (Scott \&

712 Jepsen, 1941). The development of the greater tubercle can rather be interpreted as an indicator

713 of a powerful shoulder extension, as well as a feature increasing the resistance to displacement

714 on unstable substrates. However, only a comprehensive study of this convergent trait among

715 diverse artiodactyls and perissodactyls taxa could help to understand the functional role of this

716 anatomical region, and its potential link with the ecological habits. On the distal epiphysis,

717 characters related to the shape of the olecranon fossa have been used in phylogenies (Heissig,

718 1972; Antoine, 2002). Our results confirm that the shape and depth of this fossa do not seem

719 directly linked to the general bone robustness as observed in these studies. Moreover, this fossa

720 is proximodistally larger for the genus Rhinoceros than for Ceratotherium and Diceros. 
721 On the femur, the fovea capitis is extremely reduced in C. simum and absent in D. bicornis,

722 whereas it is well developed in Asiatic rhinos, especially in $R$. sondaicus, confirming previous

723 observations (Guérin, 1980; Antoine, 2002). This fovea provides an attachment for the accessory

724 ligament and the femoral head ligament (Hermanson \& Macfadden, 1996), acting as a hip

725 stabilizer. The absence or reduction of fovea capitis in African species may be both associated

726 with their phylogenetic proximity. This fovea is indeed present in many fossil rhinos (Antoine,

727 2002), regardless of the ecological preferences of these species. The shapes of the greater and of

728 the third trochanters also seem driven more by the phylogeny than by functional constraints,

729 supporting their use in phylogenies (Cerdeño, 1995; Antoine, 2002). On the distal epiphysis, the

730 medial trochlear ridge is more developed and inflated in all rhinos than in horses; this feature has

731 been previously interpreted as associated with "locking" the knee joint during long standing

732 periods in equids (Hermanson \& Macfadden, 1996) and considered as functionally equivalent in

733 rhinos (Shockey, 2001). Other authors saw in the development of this medial trochlear ridge an

734 adaptation to a more important degree of cursoriality, linked to openness of habitat (Janis et al.,

735 2012). But tapirs, yet able to gallop (Sanborn \& Watkins, 1950), do not display such an

736 enlargement of the medial ridge of the trochlea (Holbrook, 2001; C.M. pers. obs.). This trait may

737 thus be phylogenetically inherited between horses and rhinos only, or results of a convergence

738 towards a knee-locking apparatus (which has yet to be fully demonstrated for rhinos).

739 On the tibia, the massive development of the tibial tuberosity seems more pronounced among

740 African species than in Asiatic ones. The angle between the tibial plateau and the shaft axis is

741 interpreted as a functional character linked to the limb posture (Lessertisseur \& Saban, 1967); a

742 plateau caudally lowered may reflect an angled limb associated with a cursorial habit, whereas a

743 horizontal plateau tends to indicate more columnar limbs. Here, despite a slight change in the

744 plateau orientation between light and heavy rhino species, this trait seems more likely related to

745 phylogeny; African species have a more horizontal plateau than Asiatic ones. Similarly, on the

746 distal epiphysis, the rectangular shape of the articular surface for the talus is encountered mainly

747 in the three Asiatic species and not in African specimens.

\section{Role of ecology}

749 Phylogenetically related rhinos share ecologies with important similarities, making it difficult to 750 accurately assess the environmental effect on bone shape. Furthermore, as historical ranges and 
751 habitats of rhinos have been drastically reduced and modified under human pressure (Hillman-

752 Smith \& Groves, 1994; Dinerstein, 2011; Groves \& Leslie, 2011; Rookmaaker \& Antoine,

753 2013), ecological inferences must be assessed with caution regarding the current rhino habitats.

754 The related C. simum and D. bicornis both live in African savannas and display a common

755 general bone morphotype (see above). D. bicornis is a ubiquitous species, often visiting both

756 open savannas and clear forests and browsing various vegetal species, whereas C. simum is an

757 open grassland grazer (Dinerstein, 2011). The same assessment can be done for the two

758 Rhinoceros species, closely phylogenetically related and sharing an important part of their

759 historical geographic range. Despite their strong affinity with water, their ecological preferences

760 are quite different, $R$. unicornis feeding frequently in semi-open floodplains whereas $R$.

761 sondaicus prefers denser forests. $R$. sondaicus and D. sumatrensis share a similar lifestyle in

762 dense and closed forest habitats but only their humerus, femur and fibula tend to display slight

763 shape similarities. If long bone shape is affected by environmental factors, these constraints are

764 difficult to distinguish from the ones linked to phylogeny. This tends to confirm previous

765 observations indicating that rhino long bones can hardly be used as accurate environmental

766 markers (Guérin, 1980; Eisenmann \& Guérin, 1984).

\section{Shape variation, evolutionary allometry and functional implications}

768 Increase in body size and mass between the lightest and heaviest rhinos is associated with a

769 global broadening of the limb long bones, with a clear enlargement of both the diaphysis and

770 epiphyses, confirming previous general observations on different mammalian clades (Bertram \&

771 Biewener, 1990, 1992). However, this broadening is not uniform for all the bones. It is directed

772 both mediolaterally and craniocaudally for the humerus (especially for the proximal part), and

773 mainly mediolaterally for the radius and the femur. Conversely, for the ulna, tibia and fibula, we

774 rather observe a craniocaudal enlargement, particularly visible on the proximal part of the tibia.

\section{Forelimb bones}

776 The difference between high and low size among extant rhinos is expressed on the humerus by a general enlargement in both craniocaudal and mediolateral directions, particularly for the proximal first half. This may be related to the constraints exerted both by weight bearing and

779 braking role of the forelimb during locomotion (Dutto et al., 2006). The important development 
780 of the lesser tubercle at the expense of the greater tubercle in non-Dicerorhinus species allows

781 both a greater stability of the shoulder articulation, preventing hyperextension, and a larger

782 insertion area for the medial end of the $m$. supraspinatus, also considered as a shoulder stabilizer

783 (Fisher, Scott \& Naples, 2007; Watson \& Wilson, 2007). This muscle being one of the main

784 extensors of the forelimb (Barone, 2010b), the developed lesser tubercle acts as a strong medial

785 lever arm for extension movements. This configuration has been previously interpreted as

786 mechanically advantageous for the muscles inserting on the shoulder joint, while the lateral

787 reinforcement of the greater tubercle was supposed to help resisting the adduction of the arm

788 (Hermanson \& MacFadden, 1992). The development of the lesser tubercle may also help

789 supporting the scapula (more elongated among African rhinos, MacLaren, pers. com.) and be

790 associated with a lengthening of the $m$. subscapularis tendons. In addition, the lesser tubercle

791 also displays an important development in D. bicornis, more pronounced than in R. unicornis

792 and $R$. sondaicus, though these species are heavier and taller. This indicates a possible effect of

793 phylogenetic proximity or similar habitats between the African species (see above). The

794 development of the intermediate tubercle for some rhinos may be related to the presence of a

795 forelimb passive stay apparatus, as demonstrated in horses (Hermanson \& MacFadden, 1992;

796 Mihlbachler et al., 2014). Although less developed than in equids, the intermediate tubercle is

797 present in all rhinos at different degrees (well visible in African taxa, less developed in

798 Rhinoceros species and poorly developed in Dicerorhinus). This may indicate different degrees

799 of development of passive stay mechanism possibly linked to phylogeny and ecology (Shockey,

800 2001). On the distal epiphysis of the humerus, the mediolateral enlargement observed towards

801 high body mass ensures both a greater stability of the elbow articulation and larger insertion

802 areas for the different flexor and extensor muscles for the digits (Barone, 2010a). The distal

803 trochlea of the humerus is also subjected to a proximodistal compression and a mediolateral

804 extension, increasing the articular surface area to dissipate compressive forces, important for

805 maintaining posture at high body masses (Jenkins, 1973).

806 Forelimb paired zeugopodial bones seem to express complementary shape variations linked to

807 body mass. Whereas the radius broadens mainly mediolaterally with increasing body mass, the

808 ulna expands in the craniocaudal direction; they respond conjointly to the increase in body mass

809 and bone size to form a structure reinforced in all directions, as it has been observed on the

810 humerus. All rhinos have an ulnar proximal epiphysis situated caudal to the radius, while its 
811 shaft expands laterally, possibly allowing a mediolateral weight distribution. Moreover, almost

812 all the weight is borne by the proximal articular surface of the radius (Bertram \& Biewener, 813 1992), which expands medially and becomes asymmetrical for heavier rhinos. The concave

814 radial tuberosity shows a deep $m$. biceps brachii insertion delivering a strong forearm flexion

815 (Antoine, 2002) and the developed insertion lateral relief offers a greater surface for the $m$. 816 extensor digitorum communis (Guérin, 1980). As this relief is more developed in African species

817 than in Asiatic ones, this may suggest an effect of phylogeny or locomotion in different habitats

818 or both. On the ulna, the developed olecranon process constitutes a powerful lever arm for 819 forearm extensors such as the m. triceps brachii and the m. anconeus, also acting upon the bone 820 for gravitational support. The medial development of the olecranon process is related to larger 821 insertions for the mm. flexor carpi ulnaris, flexor digitorum profundus and flexor digitorum 822 superficialis, all essential to resist hyperextension of the wrist. The cranially reduced anconeal 823 process allows a greater extension of the forearm than in other taxa (e.g. bovids or equids) 824 (Hildebrand, 1974) but prevents a complete verticality of the member as observed in elephants 825 for example (Osborn, 1929). The distal epiphysis shows a reduction of both radial and ulnar 826 styloid processes towards high body mass, adding a mediolateral degree of freedom to the wrist 827 articulation. However, the proximally reduced articular surface for the scaphoid limits the 828 craniocaudal wrist flexion (Yalden, 1971). These morphological traits allow the foot to bear the 829 weight on different substrates while limiting the risk of wrist hyperflexion (Domning, 2002).

In the hind limb, the femur expands mainly in the mediolateral direction for rhinos with high body mass and bone size, tending to indicate a stronger resistance to constraints both linked to body propulsion and weight bearing (Lessertisseur \& Saban, 1967), exerted in the mediolateral direction (Hildebrand, 1974). The mediolateral reinforcement of the femur is mainly located under the head and the neck, responding to a concomitant enlargement of the medial condyle and epicondyle on the distal epiphysis, both indicating an increase of the body load near the sagittal plane. The more distal location of the lesser trochanter improves the lever arm of the mm. psoas major and iliacus, developing slower but stronger hip flexions (Hildebrand, 1974; Polly, 2007).

839 The same phenomenon is observed with the third trochanter, situated half way along shaft 840 contrary to in cursorial Perissodactyla like equids, where the third trochanter is more proximally 
841 situated (Hermanson \& Macfadden, 1996; Holbrook, 2001; Barone, 2010a). However, it has

842 been shown that the relative position of the third trochanter barely varies among extinct

843 rhinoceroses considered as "cursorial" or "semi-cursorial" (Prothero, 2005). This position along

844 the shaft may thus be influenced by both mechanical and phylogenetic constraints. The extreme

845 development of the third trochanter associated with a distolateral development of the greater

846 trochanter also creates a large lever arm for the fascia glutea, the mm. gluteus superficialis and

847 gluteus medius allowing strong hip flexion and abduction. This association appears the greatest

848 for R. unicornis, where the greater and third trochanters can be fused by a bony bridge.

849 Conversely, the greater trochanter is less proximally developed than in related groups like horses 850 and tapirs (Radinsky, 1965; Hermanson \& Macfadden, 1996; Holbrook, 2001); as this trochanter 851 is the insertion area for the m. gluteus medius, the main extensor of the hip, the extension in 852 rhinos seems less powerful than in cursorial perissodactyls. On the distal epiphysis, the lateral 853 torsion of the rotation axis of the trochlea in heavy rhinos also indicates a more laterally deviated 854 position of the knee. This conformation may improve weight bearing, shifting the body mass 855 laterally to the body, as previously observed on a study of pressure patterns of the feet in $C$. 856 simum (Panagiotopoulou, Pataky \& Hutchinson, 2019). No real difference in the bone curvature 857 related to body proportion was noticed, confirming previous observations on the independence of 858 femur curvature with regard to body mass increase in quadrupedal mammals (Bertram \& 859 Biewener, 1992).

860 On the hindlimb zeugopodial elements, when the proximal epiphysis of the tibia broadens 861 craniocaudally, the proximal fibular epiphysis is reduced in this direction, despite an increased 862 general robustness. The proximal epiphysis of the fibula is also oriented far more cranially than 863 in lighter specimens. The enlargement of the tibial plateau thus seems to involve a relative 864 reduction in size of the fibular head. The distal epiphyses of both bones covary too, with a 865 broadening mainly expressed in the craniocaudal direction. The medial condyle of the tibial 866 plateau enlarges strongly, resulting into an asymmetrical proximal epiphysis. Moreover, the 867 broadening of the tibial tuberosity correlates with a stronger and larger patellar ligament, 868 reinforcing the knee articulation and therefore the lever arm created by the patella (Hildebrand, 869 1974). On the distal epiphysis, the two malleoli are more mediolaterally inflated but less distally 870 expanded, allowing the tarsal articulation to move more freely in heavier rhinos (Lessertisseur \& 871 Saban, 1967). This trait is associated with a slightly shallower distal articular surface, conferring 
872 more important degrees of freedom to the ankle articulation for high body mass (Polly, 2007).

873 This observation is coherent with similar analyses conducted on rhino ankle bones (Etienne, 874 pers. com., 2019, showing notably that the talus bone is flattened and has a shallower groove 875 towards high body mass among rhinos).

876 In addition to the reduction of the proximal epiphysis, the fibula displays a straighter diaphysis

877 for large rhinos as opposed to the greatly curved one for lighter rhinos (see Supplemental Figure 878 S6 and S7). This is consistent with previous observations: although the fibula was not considered 879 in their study, Bertram \& Biewener (1992) noted a decrease of tibia curvature while body mass 880 increases among terrestrial mammals. In our rhino sample, the tibia shows a very slight 881 straightening of the diaphysis. However, this straightening, perhaps linked to load carrying 882 capacity, appears to be more pronounced on the fibula.

\section{Differences between body mass and body size}

884

885

886

887

888

889

890

891

892

893

894

895

896

897

898

899

900

901

As the exact body mass was only known for five specimens of our sample, we were not able to precisely express the shape variation regarding the animal's individual weight. However, theoretical bone shape obtained with mean body mass are very similar to the ones obtained with centroid size (see above). Comparing the values of the centroid size and mean body mass highlights some interspecific differences: if D. sumatrensis, the smallest rhino, has the lowest values for both centroid size and body mass, $R$. unicornis (the species with the highest values of shoulder height) displays the highest values of centroid size in most cases, which is coherent with its higher height at shoulder compared to other modern rhinos (Guérin, 1980; Dinerstein, $2011)$, despite a mean body mass $(2,000 \mathrm{~kg})$ lower than that of $C$. $\operatorname{simum}(2,300 \mathrm{~kg})$.

Furthermore, the centroid size of an isolated bone may neither reflect the actual global size of an animal, nor be strictly correlated with its body mass. This is particularly visible for taxa displaying brachypodial adaptation (i.e. shortening of limb length relatively to the height at the shoulder), as it is the case for modern hippos or some fossil rhinos like Brachypotherium or Teleoceras (Cerdeño, 1998). However, our results indicate that it does not seem to be the case with the long bones of modern rhinos. As bone size and body mass are intimately entangled (Berner, 2011), the centroid size of isolated bones may still constitute a useful body mass approximation when precise body mass remains unknown and if considered cautiously - this approximation depending on the number and placement of the landmarks on the bone. This is 
902 coherent with previous results obtained on cranial shape data indicating a marked correlation

903 between body mass and centroid size (both of the skull and mandible) for many mammalian

904 lineages, especially modern rhinos (Cassini, Vizcaíno \& Bargo, 2012). Another study focusing

905 on tapirs tend to highlight a good correlation between centroid size and body mass estimation

906 when using the forelimb elements (MacLaren et al., 2018).

907 Limb bone shape and graviportality

908 One of the criteria defining graviportality is straight and columnar limbs (Gregory, 1912;

909 Osborn, 1929; Biewener, 1989b). Rhino limb long bones do not display a true columnar

910 organisation (Osborn, 1900, 1929). Morphological changes between light and heavy rhino

911 species do not imply a clear change in the orientation of the articular facets: the elbow joint

912 remains unable to completely open like the elephant's one and the knee remains markedly

913 angled. Only the humeral proximal epiphysis displays a tenuous orientation change between light

914 and heavy rhinos, allowing a more slightly vertical orientation of this bone for $C$. simum and $R$.

915 unicornis.

916 Limb straightness can result from the reorientation of the trochlear notch of the ulna in the dorsal

917 direction, allowing an efficient support of the humerus (Gregory, 1912), as in proboscideans

918 (Christiansen, 1999). Our sample tends to indicate instead that the radius is the main support of

919 the body weight in the forelimb among modern rhinos. The shape of the radius becomes

920 gradually more robust from light to heavy rhinos, with a strong medial reinforcement of the

921 proximal epiphysis. The particular role of the radius was previously highlighted among a large

922 sample of mammal clades (Bertram \& Biewener, 1992), its vertical position being parallel to

923 ground reaction forces. This supportive role of the radius is widespread among ungulates and

924 remains of importance even in larger fossil rhinos like Elasmotheriinae (Antoine, 2002) and

925 Paraceratheriidae (Qiu \& Wang, 2007; Prothero, 2013). Unlike in elephants, increase in body

926 mass among rhinos is correlated with a more important supportive role of the radius. At the

927 opposite, the ulna's role has not been extensively explored in morphofunctional studies. Our

928 work underlines the complementary role of the ulna relative to the radius, providing more lateral

929 and caudal weight bearing by an enlargement in the dorsopalmar direction. In this regard, the

930 zeugopodial conformation in rhinos is close to the one encountered in hippos (Fisher, Scott \&

931 Naples, 2007).

Peer] reviewing PDF | (2019:05:37815:2:0:NEW 6 Aug 2019) 
932 Forelimb elements bear more weight than hind limb ones (Lessertisseur \& Saban, 1967;

933 Hildebrand, 1974; Polly, 2007) and play an additional braking role during locomotion,

934 particularly proximal elements (Dutto et al., 2006). Forelimb bones such as the humerus thus

935 need to be reinforced in all directions in order to support these higher masses in heavier animals.

936 Hind limb bone shape is affected differently than in forelimb by increases in body mass and size.

937 The hind limb bears relatively less weight than the forelimb in quadrupeds and plays an

938 additional propulsive role during locomotion (Lessertisseur \& Saban, 1967; Hildebrand, 1974;

939 Barone, 2010a). The femur displays important reinforcement and development of strong lever

940 arms in large rhino species, possibly to support increasing stress due to locomotion and body

941 mass, but the variations in shape of the tibia and the fibula seem driven as much by the body

942 mass as by the phylogenetic influence. The shape of the fibula is particularly variable within

943 several rhino species, questioning its functional role but also the factors driving this strong

944 intraspecific variation. It has been shown that the human fibula plays, in addition to its ankle

945 stabilizer role, a small but important weight bearing role, receiving one sixth of the load applied

946 to the knee (Lambert, 1971; Takebe et al., 1984). In horses, the diaphysis of the fibula is absent

947 and the malleolus is fused with the tibia, ensuring mainly ankle stabilization (Barone, 2010a).

948 The rhino fibula ensures a talus stabilization role (Polly, 2007) in addition to a potential weight

949 bearing due to the presence of the shaft. In addition, this bone often bears crests along the

950 diaphysis with no apparent correlation with weight bearing (see above). These crest

951 developments may be due to individual variations in bone development, without clear functional

952 implications, but this first analysis does not allow us to address this question.

953 Bertram \& Biewener (1990, 1992) and Polly (2007) previously called "allometry increase" the

954 tendency for body size and mass to rise among terrestrial mammals. Although reduced, this

955 allometry clearly affects our sample (Tables 6 and 7). In addition, robustness increase is

956 associated with a slight relative length reduction of the bone for larger rhinos such as

957 Ceratotherium (Guérin, 1980), a general trend observed among heavy mammals (Christiansen,

958 1999). Another trait associated with body mass augmentation among extant rhino species is the

959 expansion of the medial epiphyses of multiple bones (e.g., medial epicondyle and trochlear lip on

960 the humerus, medial glenoid cavity on the radius, medial condyle and trochlear lip on the femur,

961 medial condyle on the tibia). These medial reinforcements result in more asymmetrical bones,

962 potentially increasing parasagittal weight bearing (Barone, 2010a). This conformation is coherent 
963 with foot posture during walk: rhino forefeet are placed under the body, close to the sagittal

964 plane of the animal (Paul \& Christiansen, 2000). Hind feet are more spaced and oriented

965 laterally, especially for heavy rhinos (Pfistermüller, Walzer \& Licka, 2011; Panagiotopoulou,

966 Pataky \& Hutchinson, 2019), which seems to agree with our observations regarding the rotation

967 axis of the femoral trochlea, oriented more laterally as well. However, the distal articular surface

968 of the tibia displays a broader lateral groove and appears as a counterexample (Figure 5). This

969 lateral broadening of the ankle joint, also observed on the talus (Etienne, pers. com., 2019), may

970 be correlated with the hind limb posture of rhinos. As the pelvic bone is large and the feet are 971 placed under the body and oriented more laterally than forefeet, the legs are not parallel to the

972 sagittal plane (Paul \& Christiansen, 2000; C.M. pers. obs.). The vertical forces exerted by the

973 body mass may therefore cross the axis of the tibia. This appears in accordance with the fact that

974 the forces may be medially higher on the proximal plateau but laterally higher at the ankle joint;

975 this point would need to be tested more precisely in vivo. As studies of pressure patterns indicate

976 that foot pressure is more intense laterally (Pfistermüller, Walzer \& Licka, 2011;

977 Panagiotopoulou, Pataky \& Hutchinson, 2019), it will be crucial to explore relations that exist

978 between stylopodium, zeugopodium and autopodium organisation in the complete limb, as well

979 as the gait and posture of the rhinos.

\section{Conclusion}

981 This study conducted on the limb long bones among modern rhinos highlights the occurrence of

982 three distinct morphotypes. These reflect phylogenetic relationships, and the bone shape is

983 differently affected by body size and mass. The shape of the stylopodium bones, though affected

984 by body mass variation, remains highly constrained by phylogeny, whereas zeugopodial bones,

985 especially the radius and ulna, are more strongly affected by body mass, which highlights their

986 important role in weight bearing. The shape of the tibia is influenced by both body mass and

987 phylogeny. The unique pattern of the fibula reveals that, beyond significant intraspecific

988 variation, this bone may play a role in weight bearing. Comparisons with hippos and elephants

989 show clear differences and convergences and highlight the interest of investigating shape

990 variation in other heavy mammal taxa. This would enable description of the different ways to

991 sustain an increase of body mass in mammals and, eventually, to sharpen the concept of

992 "graviportality". 
993 Acknowledgments

994 The authors would like to warmly thank all the curators of the visited institutions for granting 995 access to the studied specimens: Catriona West, Rachel Jennings, Mike Cobb (Powell Cotton 996 Museum, Birchington-on-Sea, UK), Didier Berthet (Centre de Conservation et d'Étude des 997 Collections, Musée des Confluences, Lyon, France), Yves Laurent (Muséum d'Histoire Naturelle 998 de Toulouse, Toulouse, France), Joséphine Lesur, Aurélie Verguin, Salvador Bailon (Muséum 999 National d'Histoire Naturelle, Paris, France), Roberto Portela-Miguez (Natural History Museum, 1000 London, UK), Frank Zachos, Alexander Bibl (Naturhistorisches Museum Wien, Vienna, 1001 Austria), Olivier Pauwels, Sébastien Bruaux (Royal Belgian Institute of Natural Sciences, 1002 Brussels, Belgium), Emmanuel Gilissen (Royal Museum for Central Africa, Tervuren, Belgium), 1003 Anneke H. van Heteren (Zoologische Staatssammlung München, Munich, Germany) and John 1004 Hutchinson for providing us CT-scan data coming from the National Museums Scotland 1005 (Edinburgh, UK), the University of California Museum of Paleontology (Berkeley, USA) and the 1006 University Museum of Zoology Cambridge (Cambridge, UK). C.M. acknowledges Arnaud 1007 Delapré (MNHN, Paris, France) for significant help in 3D data reconstruction and management, 1008 Cyril Étienne, Rémi Lefebvre, Romain Pintore (MNHN, Paris, France) for constructive 1009 discussions and advices on R programming, data analyses and interpretations. We would also 1010 like to thank Jamie MacLaren (University of Antwerp, Antwerp, Belgium), Kelsey Stilson 1011 (University of Chicago, Chicago, USA) and Luke Holbrook (Rowan University, Glassboro, 1012 USA) for their constructive reviews that allowed us to significantly improve the quality of the 1013 manuscript. This work was funded by the European Research Council and is part of the 1014 GRAVIBONE project (ERC-2016-STG-715300).

\section{Author contributions}

1016 All authors designed the frame of the study. C.M. did most of the data acquisition with additions 1017 from A.H. C.M. performed the analyses under the guidance of R.C. C.M. drafted the manuscript. 1018 All authors reviewed and contributed to the final manuscript, read it and approved it. 


\section{References}

1020 Adams DC. 2014. A generalized K statistic for estimating phylogenetic signal from shape and other high-dimensional multivariate data. Systematic Biology 63:685-697. DOI:

1023 10.1093/sysbio/syu030.

Adams DC, Collyer M, Kaliontzopoulou A. 2018. Geometric Morphometric Analyses of 2D/3D Landmark Data.

Adams DC, Otárola-Castillo E. 2013. geomorph: an r package for the collection and analysis of geometric morphometric shape data. Methods in Ecology and Evolution 4:393-399. DOI: 10.1111/2041-210X.12035.

Adams DC, Rohlf FJ, Slice DE. 2004. Geometric morphometrics: Ten years of progress following the 'revolution.' Italian Journal of Zoology 71:5-16. DOI: $10.1080 / 11250000409356545$.

Agisoft. 2018. PhotoScan Professional Edition. Agisoft.

Alexander RMcN, Pond CM. 1992. Locomotion and bone strength of the white rhinoceros, Ceratotherium simum. Journal of Zoology 227:63-69. DOI: 10.1111/j.14697998.1992.tb04344.x.

Antoine P-O. 2002. Phylogénie et évolution des Elasmotheriina (Mammalia, Rhinocerotidae). Publications scientifiques du Muséum.

Antoine P-O, Duranthon F, Welcomme J-L. 2003. Alicornops (Mammalia, Rhinocerotidae) dans le Miocène supérieur des Collines Bugti (Balouchistan, Pakistan): implications phylogénétiques. Geodiversitas 25:575-603.

Artec 3D. 2018. Artec Studio Professional. Artec 3D. 
1041 Averianov A, Danilov I, Jin J, Wang Y. 2017. A new amynodontid from the Eocene of South

1042

1043

1044

1045

1046

1047

1048

1049

1050

1051

1052

1053

1054

1055

1056

1057

1058

1059

1060

1061

1062

1063

China and phylogeny of Amynodontidae (Perissodactyla: Rhinocerotoidea). Journal of Systematic Palaeontology 15:927-945. DOI: 10.1080/14772019.2016.1256914.

Baker J, Meade A, Pagel M, Venditti C. 2015. Adaptive evolution toward larger size in mammals. Proceedings of the National Academy of Sciences 112:5093-5098. DOI: 10.1073/pnas.1419823112.

Barone R. 2010a. Anatomie comparée des mammifères domestiques. Tome 1 : Ostéologie. Paris: Vigot Frères.

Barone R. 2010b. Anatomie comparée des mammifères domestiques. Tome 2 : Arthrologie et myologie. Paris: Vigot Frères.

Becker D. 2003. Paléoécologie et paléoclimats de la molasse du Jura (oligo-miocène). Université de Fribourg.

Becker D, Antoine P-O, Maridet O. 2013. A new genus of Rhinocerotidae (Mammalia, Perissodactyla) from the Oligocene of Europe. Journal of Systematic Palaeontology 11:947-972. DOI: 10.1080/14772019.2012.699007.

Becker D, Bürgin T, Oberli U, Scherler L. 2009. Diaceratherium lemanense (Rhinocerotidae) from Eschenbach (eastern Switzerland): systematics, palaeoecology, palaeobiogeography. Neues Jahrbuch für Geologie und Paläontologie-Abhandlungen 254:5-39. DOI: 10.1127/0077-7749/2009/0002.

Beddard FE, Treves F. 1889. On the Anatomy of Rhinoceros sumatrensis. Proceedings of the Zoological Society of London 57:7-25. DOI: 10.1111/j.1469-7998.1889.tb06740.x.

Berger J. 1994. Science, Conservation, and Black Rhinos. Journal of Mammalogy 75:298-308. DOI: $10.2307 / 1382548$. 
1064 Berner D. 2011. Size correction in biology: how reliable are approaches based on (common)

1065

1066

1067

1068

1069

1070

1071

1072

1073

1074

1075

1076

1077

1078

1079

1080

1081

1082

1083

1084

1085 principal component analysis? Oecologia 166:961-971. DOI: 10.1007/s00442-011-1934-

Bertram JEA, Biewener AA. 1990. Differential scaling of the long bones in the terrestrial carnivora and other mammals. Journal of Morphology 204:157-169. DOI: 10.1002/jmor.1052040205.

Bertram JEA, Biewener AA. 1992. Allometry and curvature in the long bones of quadrupedal mammals. Journal of Zoology 226:455-467. DOI: 10.1111/j.1469-7998.1992.tb07492.x.

Biewener AA. 1989a. Mammalian Terrestrial Locomotion and Size. BioScience 39:776-783. DOI: $10.2307 / 1311183$.

Biewener AA. 1989b. Scaling body support in mammals: limb posture and muscle mechanics. Science 245:45-48. DOI: 10.1126/science.2740914.

de Blainville H-MD, Nicard P. 1839. Ostéographie, ou Description iconographique comparée du squelette et du système dentaire des mammifères récents et fossiles pour servir de base à la zoologie et à la géologie. Tome 3. Paris: J.B. Baillère \& Fils.

Blanco RE, Gambini R, Fariña RA. 2003. Mechanical model for theoretical determination of maximum running speed in mammals. Journal of Theoretical Biology 222:117-125. DOI: 10.1016/S0022-5193(03)00019-5.

Bokma F, Godinot M, Maridet O, Ladevèze S, Costeur L, Solé F, Gheerbrant E, Peigné S, Jacques F, Laurin M. 2016. Testing for Depéret's Rule (Body Size Increase) in Mammals using Combined Extinct and Extant Data. Systematic Biology 65:98-108. DOI: 10.1093/sysbio/syv075. 
1086 Botton-Divet L, Cornette R, Fabre A-C, Herrel A, Houssaye A. 2016. Morphological Analysis of 1087 Long Bones in Semi-aquatic Mustelids and their Terrestrial Relatives. Integrative and 1088 Comparative Biology 56:1298-1309. DOI: 10.1093/icb/icw124.

1089 Bressou C. 1961. La myologie du tapir (Tapirus indicus L.). Mammalia 25:358-400. DOI:

1090 10.1515/mamm.1961.25.3.358.

1091

1092

1093

1094

1095

1096

1097

1098

1099

1100

1101

1102

1103

1104

1105

1106

Budras K-D, Sack WO, Röck S. 2009. Anatomy of the Horse. Schlütersche.

Campione NE, Evans DC. 2012. A universal scaling relationship between body mass and proximal limb bone dimensions in quadrupedal terrestrial tetrapods. BMC Biology 10:60. DOI: $10.1186 / 1741-7007-10-60$.

Cappellini E, Welker F, Pandolfi L, Madrigal JR, Fotakis A, Lyon D, Mayar VLM, Bukhsianidze M, Jersie-Christensen RR, Mackie M, Ginolhac A, Ferring R, Tappen M, Palkopoulou E, Samodova D, Ruther PL, Dickinson MR, Stafford T, Chan YL, Gotherstrom A, Nathan SK, Heintzman PD, Kapp JD, Kirillova I, Moodley Y, Agusti J, Kahlke R-D, Kiladze G, Martinez-Navarro B, Liu S, Velasco MS, Sinding M-HS, Kelstrup CD, Allentoft ME, Krogh A, Orlando L, Penkman K, Shapiro B, Rook L, Dalen L, Gilbert MTP, Olsen JV, Lordkipanidze D, Willerslev E. 2018. Early Pleistocene enamel proteome sequences from Dmanisi resolve Stephanorhinus phylogeny. bioRxiv:407692. DOI: 10.1101/407692.

Carrano MT. 1999. What, if anything, is a cursor? Categories versus continua for determining locomotor habit in mammals and dinosaurs. Journal of Zoology 247:29-42. DOI: 10.1111/j.1469-7998.1999.tb00190.x. 
1107 Cassini GH, Vizcaíno SF, Bargo MS. 2012. Body mass estimation in Early Miocene native

1108 South American ungulates: a predictive equation based on 3D landmarks. Journal of

1109 Zoology 287:53-64. DOI: 10.1111/j.1469-7998.2011.00886.x.

1110 Cerdeño E. 1995. Cladistic analysis of the family Rhinocerotidae (Perissodactyla). American Museum novitates 3143:1-25.

1112

1113

1114

1115

1116

1117

1118

1119

1120

1121

1122

1123

1124

1125

1126

1127

1128

1129

Cerdeño E. 1998. Diversity and evolutionary trends of the Family Rhinocerotidae (Perissodactyla). Palaeogeography, Palaeoclimatology, Palaeoecology 141:13-34. DOI: 10.1016/S0031-0182(98)00003-0.

Christiansen P. 1999. Scaling of mammalian long bones: small and large mammals compared. Journal of Zoology 247:333-348. DOI: 10.1111/j.1469-7998.1999.tb00996.x.

Cignoni P, Callieri M, Corsini M, Dellepiane M, Ganovelli F, Ranzuglia G. 2008. MeshLab: an Open-Source Mesh Processing Tool. The Eurographics Association. DOI: http://dx.doi.org/10.2312/LocalChapterEvents/ItalChap/ItalianChapConf2008/129-136.

Colyn M. 1980. Ostéologie descriptive de Ceratotherium simum cottoni Lydekker, 1908.

Coombs Walter P. 1978. Theoretical Aspects of Cursorial Adaptations in Dinosaurs. The Quarterly Review of Biology 53:393-418. DOI: 10.1086/410790.

Cuvier G. 1812. Recherches sur les ossements fossiles de quadrupèdes. Tome 2. Paris: Deterville.

Depéret C. 1907. Les transformations du monde animal. Paris: Flammarion.

Dinerstein E. 1991. Sexual Dimorphism in the Greater One-Horned Rhinoceros (Rhinoceros unicornis). Journal of Mammalogy 72:450-457. DOI: 10.2307/1382127.

Dinerstein E. 2011. Family Rhinocerotidae (Rhinoceroses). In: Handbook of the Mammals of the World. Barcelona: Don E. Wilson \& Russel A. Mittermeier, 144-181.

Peer) reviewing PDF | (2019:05:37815:2:0:NEW 6 Aug 2019) 
1130

1131

1132

1133

1134

1135

1136

1137

1138

1139

1140

1141

1142

1143

1144

1145

1146

1147

1148

1149

1150

Domning DP. 2002. The terrestrial posture of desmostylians. Smithsonian Contributions to Paleobiology 93:99-111.

Drake AG, Klingenberg CP. 2008. The pace of morphological change: historical transformation of skull shape in St Bernard dogs. Proceedings of the Royal Society B: Biological Sciences 275:71-76. DOI: 10.1098/rspb.2007.1169.

Dutto DJ, Hoyt DF, Clayton HM, Cogger EA, Wickler SJ. 2006. Joint work and power for both the forelimb and hindlimb during trotting in the horse. Journal of Experimental Biology 209:3990-3999. DOI: 10.1242/jeb.02471.

Eisenmann V, Guérin C. 1984. Morphologie fonctionnelle et environnement chez les périssodactyles. Geobios 17:69-74. DOI: 10.1016/S0016-6995(84)80158-8.

Fau M, Cornette R, Houssaye A. 2016. Photogrammetry for 3D digitizing bones of mounted skeletons: Potential and limits. Comptes Rendus Palevol 15:968-977. DOI: 10.1016/j.crpv.2016.08.003.

Fernando P, Polet G, Foead N, Ng LS, Pastorini J, Melnick DJ. 2006. Genetic diversity, phylogeny and conservation of the Javan rhinoceros (Rhinoceros sondaicus). Conservation Genetics 7:439-448. DOI: 10.1007/s10592-006-9139-4.

Fisher RE, Scott KM, Adrian B. 2010. Hind limb myology of the common hippopotamus, Hippopotamus amphibius (Artiodactyla: Hippopotamidae). Zoological Journal of the Linnean Society 158:661-682. DOI: 10.1111/j.1096-3642.2009.00558.x.

Fisher RE, Scott KM, Naples VL. 2007. Forelimb myology of the pygmy hippopotamus (Choeropsis liberiensis). The Anatomical Record 290:673-693. DOI: 10.1002/ar.20531. 
1151 Gaudry M. 2017. Molecular phylogenetics of the rhinoceros clade and evolution of UCP1

1152

1153

1154

1155

1156

1157

1158

1159

1160

1161

1162

1163

1164

1165

1166

1167

1168

1169

1170

1171

1172

transcriptional regulatory elements across the mammalian phylogeny. Master of Science Thesis. Winnipeg: University of Manitoba.

Goodall C. 1991. Procrustes Methods in the Statistical Analysis of Shape. Journal of the Royal Statistical Society: Series B (Methodological) 53:285-321. DOI: 10.1111/j.25176161.1991.tb01825.x.

Gower JC. 1975. Generalized procrustes analysis. Psychometrika 40:33-51. DOI: 10.1007/BF02291478.

Gregory WK. 1912. Notes on the Principles of Quadrupedal Locomotion and on the Mechanism of the Limbs in Hoofed Animals. Annals of the New York Academy of Sciences 22:267294. DOI: $10.1111 /$ j.1749-6632.1912.tb55164.x.

Groves CP. 1967a. Geographic variation in the black rhinoceros, Diceros bicornis (L, 1758). Zeitschrift fur Saugetierkunde 32:267-276.

Groves CP. 1967b. On the rhinoceroses of South-East Asia. Saugetierkundliche Mitteilungen $15: 221-237$.

Groves CP. 1972. Ceratotherium simum. Mammalian Species:1-6. DOI: 10.2307/3503966.

Groves CP. 1982. The skulls of Asian rhinoceroses: Wild and captive. Zoo Biology 1:251-261. DOI: 10.1002/zoo.1430010309.

Groves CP, Kurt F. 1972. Dicerorhinus sumatrensis. Mammalian Species:1-6. DOI: $10.2307 / 3503818$

Groves CP, Leslie DM. 2011. Rhinoceros sondaicus (Perissodactyla: Rhinocerotidae). Mammalian Species 43:190-208. DOI: 10.2307/mammalianspecies.43.1.190. 
1173 Guérin C. 1980. Les Rhinocéros (Mammalia, Perissodactyla) du Miocène terminal au

1174

1175

1176

1177

1178

1179

1180

1181

1182

1183

1184

1185

1186

1187

1188

1189

1190

1191

1192

1193
Pléistocène supérieur en Europe occidentale. Comparaison avec les espèces actuelles. Documents du Laboratoire de Géologie de l’Université de Lyon Thesis.

Guérin C. 1982. Les Rhinocerotidae (Mammalia, Perissodactyla) du Miocène terminal au Pleistocène supérieur d'Europe Occidentale comparés aux espèces actuelles: Tendances évolutives et relations phylogénétiques. Geobios 15:599-605. DOI: 10.1016/S00166995(82)80077-6.

Gunz P, Mitteroecker P. 2013. Semilandmarks: a method for quantifying curves and surfaces. Hystrix, the Italian Journal of Mammalogy 24:103-109.

Gunz P, Mitteroecker P, Bookstein FL. 2005. Semilandmarks in Three Dimensions. In: Modern Morphometrics in Physical Anthropology. Developments in Primatology: Progress and Prospects. Springer, Boston, MA, 73-98. DOI: 10.1007/0-387-27614-9_3.

Heissig K. 1972. Paläontologische und geologische Untersuchungen im Tertiär von Pakistan - 5. Rhinocerotidae (Mammalia) aus den unteren und mittleren Siwalik-Schichten. Abhandlungen der Bayerischen Akademie der Wissenschaften, Mathematischnaturwissenschaftliche Klasse, München 152:1-112.

Heissig K. 2012. Les Rhinocerotidae (Perissodactyla) de Sansan. In: Mammiferes de Sansan. Mémoires du Muséum national d'histoire naturelle. Paris, 317-485.

Hermanson JW, MacFadden BJ. 1992. Evolutionary and functional morphology of the shoulder region and stay-apparatus in fossil and extant horses (Equidae). Journal of Vertebrate Paleontology 12:377-386. DOI: 10.1080/02724634.1992.10011466. 
1194 Hermanson JW, Macfadden BJ. 1996. Evolutionary and functional morphology of the knee in 1195 fossil and extant horses (Equidae). Journal of Vertebrate Paleontology 16:349-357. DOI:

1196 10.1080/02724634.1996.10011321.

1197 Hildebrand M. 1974. Analysis of vertebrate structure. New York: John Wiley \& Sons.

1198

1199

1200

1201

1202

1203

1204

1205

1206

1207

1208

1209

1210

1211

1212

1213

1214

1215
Hillman-Smith AKK, Groves CP. 1994. Diceros bicornis. Mammalian Species:1-8. DOI: $10.2307 / 3504292$

Holbrook LT. 2001. Comparative osteology of early Tertiary tapiromorphs (Mammalia, Perissodactyla). Zoological Journal of the Linnean Society 132:1-54. DOI: 10.1111/j.1096-3642.2001.tb02270.x.

Janis CM, Shoshitaishvili B, Kambic R, Figueirido B. 2012. On their knees: distal femur asymmetry in ungulates and its relationship to body size and locomotion. Journal of Vertebrate Paleontology 32:433-445. DOI: 10.1080/02724634.2012.635737.

Jenkins FA. 1973. The functional anatomy and evolution of the mammalian humero-ulnar articulation. American Journal of Anatomy 137:281-297. DOI: 10.1002/aja.1001370304.

Klingenberg CP. 2016. Size, shape, and form: concepts of allometry in geometric morphometrics. Development Genes and Evolution 226:113-137. DOI: 10.1007/s00427016-0539-2.

Lambert KL. 1971. The weight-bearing function of the fibula. A strain gauge study. The Journal of Bone and Joint Surgery. American Volume 53:507-513.

Langman VA, Roberts TJ, Black J, Maloiy GM, Heglund NC, Weber JM, Kram R, Taylor CR. 1995. Moving cheaply: energetics of walking in the African elephant. Journal of Experimental Biology 198:629-632. 
1216 Laurie WA, Lang EM, Groves CP. 1983. Rhinoceros unicornis. Mammalian Species:1-6. DOI:

1217

1218

1219

1220

1221

1222

1223

1224

1225

1226

1227

1228

1229

1230

1231

1232

1233

1234

1235

1236 $10.2307 / 3504002$.

Lessertisseur J, Saban R. 1967. Le squelette. Squelette appendiculaire. In: Traité de Zoologie. Tome XVI, Fasicule 1: Mammifères. Paris: Grassé Pierre-Paul, 298-1123.

MacFadden BJ. 2005. Diet and habitat of toxodont megaherbivores (Mammalia, Notoungulata) from the late Quaternary of South and Central America. Quaternary Research 64:113124. DOI: $10.1016 /$ j.yqres.2005.05.003.

MacLaren JA, Hulbert Jr RC, Wallace SC, Nauwelaerts S. 2018. A morphometric analysis of the forelimb in the genus Tapirus (Perissodactyla: Tapiridae) reveals influences of habitat, phylogeny and size through time and across geographical space. Zoological Journal of the Linnean Society 20:1-17.

MacLaren JA, Nauwelaerts S. 2016. A three-dimensional morphometric analysis of upper forelimb morphology in the enigmatic tapir (Perissodactyla: Tapirus) hints at subtle variations in locomotor ecology. Journal of Morphology 277:1469-1485. DOI: 10.1002/jmor.20588.

Mallison H, Wings O. 2014. Photogrammetry in Paleontology - A practical guide. Journal of Paleontological Techniques.

Maynard Smith J, Savage RJG. 1956. Some locomotory adaptations in Mammals. Zoological Journal of the Linnean Society 42:603-622. DOI: 10.1111/j.1096-3642.1956.tb02220.x.

Mazza PPA. 2014. If hippopotamuses cannot swim, how did they colonize islands? Lethaia 47:494-499. DOI: 10.1111/let.12074.

Peer) reviewing PDF | (2019:05:37815:2:0:NEW 6 Aug 2019) 
1237 McMahon T. 1973. Size and Shape in Biology: Elastic criteria impose limits on biological

1238

1239

1240

1241

1242

1243

1244

1245

1246

1247

1248

1249

1250

1251

1252

1253

1254

1255

1256

1257

1258

1259

proportions, and consequently on metabolic rates. Science 179:1201-1204. DOI: 10.1126/science.179.4079.1201.

Mihlbachler MC, Lau T, Kapner D, Shockey BJ. 2014. Coevolution of the shoulder and knee in Ungulates: Implications of the evolution of locomotion and standing.

Osborn HF. 1900. The Angulation of the Limbs of Proboscidia, Dinocerata, and Other Quadrupeds, in Adaptation to Weight. The American Naturalist 34:89-94. DOI: $10.1086 / 277565$.

Osborn HF. 1929. The Titanotheres of ancient Wyoming, Dakota, and Nebraska. Government Printing Office.

Panagiotopoulou O, Pataky TC, Hutchinson JR. 2019. Foot pressure distribution in White Rhinoceroses (Ceratotherium simum) during walking. PeerJ 7:e6881. DOI: $10.7717 /$ peerj.6881.

Paradis E, Blomberg SP, Bolker B, Brown J, Claude J, Cuong HS, Desper R, Didier G, Durand B, Dutheil J, Ewing J, Gascuel O, Guillerme T, Heibl C, Ives A, Jones B, Krah F, Lawson D, Lefort V, Legendre P, Lemon J, Marcon E, McCloskey R, Nylander J, Opgen-Rhein R, Popescu A-A, Royer-Carenzi M, Schliep K, Strimmer K, de Vienne D. 2018. Ape: Analyses of Phylogenetics and Evolution.

Paul GS, Christiansen P. 2000. Forelimb posture in neoceratopsian dinosaurs: implications for gait and locomotion. Paleobiology 26:450-465. DOI: 10.1666/00948373(2000)026<0450:FPINDI >2.0.CO;2.

Petti FM, Avanzini M, Belvedere M, De Gasperi M, Ferretti P, Girardi S, Remondino F, Tomasoni R. 2008. Digital 3D modelling of dinosaur footprints by photogrammetry and 
1260

1261

1262

1263

1264

1265

1266

1267

1268

1269

1270

1271

1272

1273

1274

1275

1276

1277

1278

1279

1280

1281

1282

laser scanning techniques: integrated approach at the Coste dell'Anglone tracksite (Lower Jurassic, Southern Alps, Northern Italy). Studi Trentini di Scienze Naturali - Acta Geologia 83:303-315.

Pfistermüller R, Walzer C, Licka T. 2011. From Chitwan to Vienna - How do gait parameters change in a pair of Indian Rhinos (Rhinoceros unicornis) coming from semi-wild conditions to a European Zoo? In: Proceedings of the 2011 International Elephant and Rhino Conservation and Research Symposium. Rotterdam,.

Piras P, Maiorino L, Raia P, Marcolini F, Salvi D, Vignoli L, Kotsakis T. 2010. Functional and phylogenetic constraints in Rhinocerotinae craniodental morphology. Evolutionary Ecology Research 12:897-928.

Polly PD. 2007. Limbs in mammalian evolution. Chapter 15. In: Fins into Limbs: Evolution, Development, and Transformation. Chicago: Brian K. Hall, 245-268.

Prothero DR. 1998. Rhinocerotidae. In: Evolution of Tertiary Mammals of North America: Volume 1, Terrestrial Carnivores, Ungulates, and Ungulate Like Mammals. Cambridge University Press, 595-605.

Prothero DR. 2005. The Evolution of North American Rhinoceroses. Cambridge University Press.

Prothero DR. 2013. Rhinoceros Giants: The Paleobiology of Indricotheres. Indiana University Press.

Prothero DR, Manning EM, Hanson BC. 1986. The phylogeny of the Rhinocerotoidea (Mammalia, Perissodactyla). Zoological Journal of the Linnean Society 87:341-366.

Prothero DR, Schoch RM. 1989. The evolution of perissodactyls. New York: Oxford University Press. 
1283 Prothero DR, Sereno PC. 1982. Allometry and Paleoecology of Medial Miocene Dwarf

1284 Rhinoceroses from the Texas Gulf Coastal Plain. Paleobiology 8:16-30.

1285 Qiu Z-X, Wang B-Y. 2007. Paracerathere Fossils of China. Palaeontologia Sinica, newseries C $1286 \quad 29: 1-396$.

1287 R Core Team. 2014. R: a language and environment for statistical computing. Vienna: R $1288 \quad$ Foundation for Statistical Computing.

1289 Radinsky LB. 1965. Evolution of the tapiroid skeleton from Heptodon to Tapirus. Bulletin of the $1290 \quad$ Museum of Comparative Zoology 134:69-106.

1291 Raia P, Carotenuto F, Passaro F, Fulgione D, Fortelius M. 2012. Ecological Specialization in Fossil Mammals Explains Cope’s Rule. The American Naturalist 179:328-337. DOI:

1294 10.1086/664081.

Regnault S, Hermes R, Hildebrandt T, Hutchinson J, Weller R. 2013. Osteopathology in the feet

1297 1298

1299

1300 1301

1302 1303 1304 of rhinoceroses: lesion type and distribution. Journal of Zoo and Wildlife Medicine 44:918-927. DOI: 10.1638/2012-0277R1.1.

Remondino F, Rizzi A, Girardi S, Petti FM, Avanzini M. 2010. 3D Ichnology—recovering digital 3D models of dinosaur footprints. The Photogrammetric Record 25:266-282. DOI: $10.1111 / \mathrm{j} .1477-9730.2010 .00587 . x$.

Rohlf FJ, Slice D. 1990. Extensions of the Procrustes Method for the Optimal Superimposition of Landmarks. Systematic Biology 39:40-59. DOI: 10.2307/2992207.

Rookmaaker K, Antoine P-O. 2013. New maps representing the historical and recent distribution of the African species of rhinoceros: Diceros bicornis, Ceratotherium simum and Ceratotherium cottoni. Pachyderm 0:91-96. 
1305 Ross MD. 1984. The influence of gravity on structure and function of animals. Advances in 1306 Space Research 4:305-314. DOI: 10.1016/0273-1177(84)90575-1.

1307 Sanborn CC, Watkins AR. 1950. Notes on the Malay Tapir and Other Game Animals in Siam. $1308 \quad$ Journal of Mammalogy 31:430-433. DOI: 10.2307/1375112.

1309 Scherler L, Mennecart B, Hiard F, Becker D. 2013. Evolutionary history of hoofed mammals 1310 during the Oligocene-Miocene transition in Western Europe. Swiss Journal of 1311 Geosciences 106:349-369. DOI: 10.1007/s00015-013-0140-x.

Schlager S. 2018. Morpho: calculations and vizualisations related to Geometric Morphometrics.

1313

1314

1315

1316
Scott WB, Jepsen GL. 1941. The Mammalian Fauna of the White River Oligocene. Part V. Perissodactyla. Transactions of the American Philosophical Society, New Series 28:747975.

Shockey BJ. 2001. Specialized knee joints in some extinct, endemic, South American herbivores. Acta Palaeontologica Polonica 46:277-288.

Stein BR, Casinos A. 1997. What is a cursorial mammal? Journal of Zoology 242:185-192. DOI: 10.1111/j.1469-7998.1997.tb02939.x.

Stilson KT, Hopkins SSB, Davis EB. 2016. Osteopathology in Rhinocerotidae from 50 Million Years to the Present. PLOS ONE 11:e0146221. DOI: 10.1371/journal.pone.0146221.

Takebe K, Nakagawa A, Minami H, Kanazawa H, Hirohata K. 1984. Role of the Fibula in Weight-bearing. Clinical Orthopaedics and Related Research ${ }^{\circledR}$ 184:289.

Thermo Fisher Scientific. 2018. Avizo.

Tougard C, Delefosse T, Hänni C, Montgelard C. 2001. Phylogenetic Relationships of the Five Extant Rhinoceros Species (Rhinocerotidae, Perissodactyla) Based on Mitochondrial 
Cytochrome b and 12S rRNA Genes. Molecular Phylogenetics and Evolution 19:34-44. DOI: 10.1006/mpev.2000.0903.

1329

1330

1331

1332

1333

1334

1335

1336

1337

1338

1339

1340

1341

1342

1343

1344

1345

1346

1347

1348

Watson JC, Wilson AM. 2007. Muscle architecture of biceps brachii, triceps brachii and supraspinatus in the horse. Journal of Anatomy 210:32-40. DOI: 10.1111/j.14697580.2006.00669.x.

Welker F, Smith GM, Hutson JM, Kindler L, Garcia-Moreno A, Villaluenga A, Turner E, Gaudzinski-Windheuser S. 2017. Middle Pleistocene protein sequences from the rhinoceros genus Stephanorhinus and the phylogeny of extant and extinct Middle/Late Pleistocene Rhinocerotidae. PeerJ 5:e3033. DOI: 10.7717/peerj.3033.

Wiley DF, Amenta N, Alcantara DA, Ghosh D, Kil YJ, Delson E, Harcourt-Smith W, Rohlf FJ, St. John K, Hamann B. 2005. Evolutionary Morphing. In: Proceedings of IEEE Visualization 2005. Minneapolis, Minnesota,.

Willerslev E, Gilbert MTP, Binladen J, Ho SY, Campos PF, Ratan A, Tomsho LP, da Fonseca RR, Sher A, Kuznetsova TV, Nowak-Kemp M, Roth TL, Miller W, Schuster SC. 2009. Analysis of complete mitochondrial genomes from extinct and extant rhinoceroses reveals lack of phylogenetic resolution. BMC Evolutionary Biology 9:95. DOI: $10.1186 / 1471-2148-9-95$.

World Association of Veterinary Anatomists, International Committee on Veterinary Gross Anatomical Nomenclature. 2005. Nomina anatomica veterinaria. Hannover; Columbia [Mo.]; Ghent; Sapporo: The Editorial Committee.

Yalden DW. 1971. The functional morphology of the carpus in ungulate mammals. Cells Tissues Organs 78:461-487. DOI: 10.1159/000143609. 
1349 Zelditch ML, Swiderski DL, Sheets HD, Fink WL. 2012. Geometric morphometrics for

1350 biologists: A Primer. Academic Press.

1351 Zschokke S, Baur B. 2002. Inbreeding, outbreeding, infant growth, and size dimorphism in

1352 captive Indian rhinoceros (Rhinoceros unicornis). Canadian Journal of Zoology

1353 80:2014-2023. DOI: 10.1139/z02-183.

1354 


\section{Table $\mathbf{1}$ (on next page)}

Main characteristics of the five studied species.

Length, height and body mass data compiled and calculated after (Dinerstein, 2011) . Shoulder height is given at the withers. Ecological data compiled after (Becker, 2003) . Abbreviations: G: graviportal; M: mediportal. *: African species; **: Asiatic species. 


\begin{tabular}{cccccccc}
\hline Species name & $\begin{array}{c}\text { Total body } \\
\text { length } \mathbf{( c m )}\end{array}$ & $\begin{array}{c}\text { Shoulder } \\
\text { height } \\
\mathbf{( c m )}\end{array}$ & $\begin{array}{c}\text { Mean } \\
\text { body mass } \\
\mathbf{( k g )}\end{array}$ & Ecology & $\begin{array}{c}\text { (Gregory, 1912; } \\
\text { Osborn, 1929; } \\
\text { Coombs, 1978) }\end{array}$ & $\begin{array}{c}\text { (Eisenmann \& } \\
\text { Guérin, 1984) }\end{array}$ & $\begin{array}{c}\text { (Becker, } \\
\text { 2003) }\end{array}$ \\
\hline $\begin{array}{c}\text { Ceratotherium } \\
\text { simum* }\end{array}$ & $340-420$ & $150-180$ & 2,300 & Open savanna & $\mathrm{M}$ & $\mathrm{G}$ & $\mathrm{G}$ \\
\hline $\begin{array}{c}\text { Dicerorhinus } \\
\text { sumatrensis** }\end{array}$ & $236-318$ & $100-150$ & 775 & $\begin{array}{c}\text { Dense forests and } \\
\text { swampy lakes }\end{array}$ & $\mathrm{M}$ & $\mathrm{G}$ & $\mathrm{M}$ \\
\hline $\begin{array}{c}\text { Diceros } \\
\text { bicornis* }\end{array}$ & $300-380$ & $140-170$ & 1,050 & $\begin{array}{c}\text { Open savanna and } \\
\text { clear forest }\end{array}$ & $\mathrm{M}$ & $\mathrm{G}$ & $\mathrm{M}$ \\
\hline $\begin{array}{c}\text { Rhinoceros } \\
\text { sondaicus** }\end{array}$ & $305-344$ & $150-170$ & 1,350 & $\begin{array}{c}\text { Dense forests and } \\
\text { swampy areas }\end{array}$ & $\mathrm{M}$ & $\mathrm{G}$ & $\mathrm{G}$ \\
\hline $\begin{array}{c}\text { Rhinoceros } \\
\text { unicornis** }\end{array}$ & $335-346$ & $175-200$ & 2,000 & $\begin{array}{c}\text { Floodplains and } \\
\text { swamps }\end{array}$ & $\mathrm{M}$ & $\mathrm{G}$ & $\mathrm{M}$ \\
\hline
\end{tabular}




\section{Table 2 (on next page)}

List of the studied specimens with skeletal composition, sex, age class, condition and 3D acquisition details.

Abbreviations: Bones - H: humerus; R: radius; U: ulna; Fe: femur; T: tibia; Fi: fibula. Sex: F: female; M: male; U: unknown. Age - A: adult; Sa: sub-adult. Condition - W: wild; C: captive; U: unknown. 3D acquisition - SS: surface scanner; P: photogrammetry; CT: CTscan. Institutional codes: BICPC: Powell Cotton Museum, Birchington-on-Sea. CCEC: Centre de Conservation et d'Étude des Collections, Musée des Confluences, Lyon. MHNT: Muséum d'Histoire Naturelle de Toulouse, Toulouse. MNHN: Muséum National d'Histoire Naturelle, Paris. NHMUK: Natural History Museum, London. NHMW: Naturhistorisches Museum Wien, Vienna. NMS: National Museums Scotland, Edinburgh. RBINS: Royal Belgian Institute of Natural Sciences, Brussels. RMCA: Royal Museum for Central Africa, Tervuren. UCMP: University of California Museum of Paleontology, Berkeley. UMZC: University Museum of Zoology Cambridge, Cambridge. ZSM: Zoologische Staatssammlung München, Munich. * Specimens NHMUK ZD 2018.143 and NHMUK ZD 1972.822 were determined by ourselves during the visit of the collections on the basis of morphological observations and measurements on the post-cranial elements. These determinations were later confirmed by our shape analysis. ${ }^{* *}$ The specimen MNHN-ZM-AC-1885-734 was previously determined as Rhinoceros sondaicus based on a supposed Javan origin. The observations made on both long bones and tarsal elements led us to consider this individual as an Indian rhino (Rhinoceros unicornis). This attribution was later confirmed by our shape analysis. 


\begin{tabular}{|c|c|c|c|c|c|c|c|c|c|c|c|c|}
\hline Taxon & Institution & Specimen number & $\mathbf{H}$ & $\mathbf{R}$ & $\mathbf{U}$ & $\mathbf{F e}$ & $\mathbf{T}$ & $\mathbf{F i}$ & Sex & Age & Condition & $\begin{array}{c}\text { 3D } \\
\text { acquisition }\end{array}$ \\
\hline $\begin{array}{l}\text { Ceratotherium } \\
\text { simum * }\end{array}$ & NHMUK & ZD 2018.143 & $\mathrm{X}$ & $\mathrm{X}$ & $\mathrm{X}$ & $\mathrm{X}$ & $\mathrm{X}$ & $\mathrm{X}$ & $\mathrm{U}$ & A & $\mathrm{U}$ & SS \\
\hline Ceratotherium simum & NHMW & 3086 & $\mathrm{X}$ & $\mathrm{X}$ & $\mathrm{X}$ & $\mathrm{X}$ & $\mathrm{X}$ & $\mathrm{X}$ & $\mathrm{U}$ & $\mathrm{A}$ & W & $\mathrm{P}$ \\
\hline Ceratotherium simum & RBINS & 19904 & $\mathrm{X}$ & $\mathrm{X}$ & $\mathrm{X}$ & $\mathrm{X}$ & $\mathrm{X}$ & $\mathrm{X}$ & $\mathrm{M}$ & $\mathrm{S}$ & $\mathrm{W}$ & SS \\
\hline Ceratotherium simum & RBINS & 35208 & $\mathrm{X}$ & $\mathrm{X}$ & $\mathrm{X}$ & $\mathrm{X}$ & & $\mathrm{X}$ & $\mathrm{U}$ & $\mathrm{A}$ & $\mathrm{U}$ & SS \\
\hline Ceratotherium simum & RMCA & 1985.32-M-0001 & $\mathrm{X}$ & $\mathrm{X}$ & $\mathrm{X}$ & $\mathrm{X}$ & $\mathrm{X}$ & $\mathrm{X}$ & $\mathrm{U}$ & $\mathrm{A}$ & $\mathrm{W}$ & $\mathrm{SS}$ \\
\hline Ceratotherium simum & RMCA & RG35146 & $\mathrm{X}$ & $\mathrm{X}$ & $\mathrm{X}$ & $\mathrm{X}$ & $\mathrm{X}$ & $\mathrm{X}$ & $\mathrm{M}$ & A & W & SS \\
\hline Ceratotherium simum & UCMP & 125000 & & & & $\mathrm{X}$ & & & $\mathrm{U}$ & $\mathrm{A}$ & $\mathrm{U}$ & CT \\
\hline Ceratotherium simum & ZSM & $1912 / 4199$ & & & & $\mathrm{X}$ & & & $\mathrm{U}$ & $\mathrm{A}$ & $\mathrm{W}$ & SS \\
\hline Ceratotherium simum & BICPC & NH.CON.20 & $\mathrm{X}$ & $\mathrm{X}$ & $\mathrm{X}$ & $\mathrm{X}$ & $\mathrm{X}$ & $\mathrm{X}$ & $\mathrm{M}$ & $\mathrm{S}$ & W & SS \\
\hline Ceratotherium simum & $\mathrm{BICPC}$ & NH.CON.32 & $\mathrm{X}$ & $\mathrm{X}$ & $\mathrm{X}$ & $\mathrm{X}$ & $\mathrm{X}$ & $\mathrm{X}$ & $\mathrm{F}$ & $\mathrm{S}$ & $\mathrm{W}$ & SS \\
\hline Ceratotherium simum & $\mathrm{BICPC}$ & NH.CON.37 & $\mathrm{X}$ & $\mathrm{X}$ & & $\mathrm{X}$ & $\mathrm{X}$ & $\mathrm{X}$ & $\mathrm{F}$ & $\mathrm{A}$ & $\mathrm{W}$ & SS \\
\hline Ceratotherium simum & $\mathrm{BICPC}$ & NH.CON.40 & $\mathrm{X}$ & $\mathrm{X}$ & $\mathrm{X}$ & $\mathrm{X}$ & $\mathrm{X}$ & $\mathrm{X}$ & $\mathrm{F}$ & $\mathrm{S}$ & $\mathrm{W}$ & $\mathrm{SS}$ \\
\hline Ceratotherium simum & BICPC & NH.CON.110 & $\mathrm{X}$ & $\mathrm{X}$ & $\mathrm{X}$ & $\mathrm{X}$ & $\mathrm{X}$ & $\mathrm{X}$ & $\mathrm{M}$ & $\mathrm{A}$ & $\mathrm{W}$ & SS \\
\hline Ceratotherium simum & $\mathrm{BICPC}$ & NH.CON.112 & $\mathrm{X}$ & $\mathrm{X}$ & $\mathrm{X}$ & $\mathrm{X}$ & $\mathrm{X}$ & $\mathrm{X}$ & $\mathrm{M}$ & $\mathrm{A}$ & $\mathrm{W}$ & SS \\
\hline Ceratotherium simum & NMS & NMS.Z.2010.44 & $\mathrm{X}$ & & & $\mathrm{X}$ & & & $\mathrm{F}$ & $\mathrm{A}$ & $\mathrm{U}$ & CT \\
\hline Ceratotherium simum & MNHN & ZM-MO-2005-297 & $\mathrm{X}$ & & & $\mathrm{X}$ & $\mathrm{X}$ & $\mathrm{X}$ & $\mathrm{M}$ & $\mathrm{A}$ & $\mathrm{C}$ & $\mathrm{SS}$ \\
\hline $\begin{array}{c}\text { Dicerorhinus } \\
\text { sumatrensis }\end{array}$ & MNHN & ZM-AC-1903-300 & $\mathrm{X}$ & $\mathrm{X}$ & $\mathrm{X}$ & $\mathrm{X}$ & $\mathrm{X}$ & $\mathrm{X}$ & $\mathrm{M}$ & A & W & SS \\
\hline $\begin{array}{c}\text { Dicerorhinus } \\
\text { sumatrensis }\end{array}$ & MNHN & ZM-AC-A7967 & $\mathrm{X}$ & $\mathrm{X}$ & $\mathrm{X}$ & & & & $\mathrm{F}$ & A & W & SS \\
\hline $\begin{array}{c}\text { Dicerorhinus } \\
\text { sumatrensis }\end{array}$ & NHMUK & ZD 1879.6.14.2 & $\mathrm{X}$ & $\mathrm{X}$ & $\mathrm{X}$ & $\mathrm{X}$ & $\mathrm{X}$ & $\mathrm{X}$ & $\mathrm{M}$ & A & $\mathrm{W}$ & SS \\
\hline $\begin{array}{c}\text { Dicerorhinus } \\
\text { sumatrensis }\end{array}$ & NHMUK & ZD 1894.9.24.1 & $\mathrm{X}$ & $\mathrm{X}$ & $\mathrm{X}$ & $\mathrm{X}$ & $\mathrm{X}$ & $\mathrm{X}$ & $\mathrm{U}$ & A & W & SS \\
\hline $\begin{array}{c}\text { Dicerorhinus } \\
\text { sumatrensis }\end{array}$ & NHMUK & ZD 1931.5.28.1 & $\mathrm{X}$ & $\mathrm{X}$ & $\mathrm{X}$ & $\mathrm{X}$ & $\mathrm{X}$ & $\mathrm{X}$ & $\mathrm{M}$ & $\mathrm{S}$ & W & SS \\
\hline $\begin{array}{c}\text { Dicerorhinus } \\
\text { sumatrensis }\end{array}$ & NHMUK & ZE 1948.12.20.1 & $\mathrm{X}$ & $\mathrm{X}$ & $\mathrm{X}$ & $\mathrm{X}$ & $\mathrm{X}$ & $\mathrm{X}$ & $\mathrm{U}$ & A & $\mathrm{U}$ & SS \\
\hline $\begin{array}{c}\text { Dicerorhinus } \\
\text { sumatrensis }\end{array}$ & NHMUK & ZE 1949.1.11.1 & $\mathrm{X}$ & $\mathrm{X}$ & $\mathrm{X}$ & $\mathrm{X}$ & $\mathrm{X}$ & $\mathrm{X}$ & $\mathrm{U}$ & A & W & SS \\
\hline $\begin{array}{c}\text { Dicerorhinus } \\
\text { sumatrensis }\end{array}$ & NHMUK & ZD 2004.23 & $\mathrm{X}$ & & & $\mathrm{X}$ & $\mathrm{X}$ & $\mathrm{X}$ & $\mathrm{U}$ & A & W & SS \\
\hline $\begin{array}{c}\text { Dicerorhinus } \\
\text { sumatrensis }\end{array}$ & NHMW & 1500 & & & & $\mathrm{X}$ & $\mathrm{X}$ & $\mathrm{X}$ & $\mathrm{M}$ & A & $\mathrm{U}$ & $\mathrm{P}$ \\
\hline $\begin{array}{c}\text { Dicerorhinus } \\
\text { sumatrensis }\end{array}$ & NHMW & 3082 & $\mathrm{X}$ & $\mathrm{X}$ & $\mathrm{X}$ & $\mathrm{X}$ & $\mathrm{X}$ & $\mathrm{X}$ & $\mathrm{U}$ & A & $\mathrm{U}$ & $\mathrm{P}$ \\
\hline $\begin{array}{c}\text { Dicerorhinus } \\
\text { sumatrensis }\end{array}$ & NHMW & 29568 & & $\mathrm{X}$ & $\mathrm{X}$ & $\mathrm{X}$ & & $\mathrm{X}$ & $\mathrm{U}$ & $\mathrm{S}$ & $\mathrm{U}$ & $\mathrm{P}$ \\
\hline $\begin{array}{c}\text { Dicerorhinus } \\
\text { sumatrensis }\end{array}$ & RBINS & 1204 & $\mathrm{X}$ & $\mathrm{X}$ & $\mathrm{X}$ & $\mathrm{X}$ & $\mathrm{X}$ & $\mathrm{X}$ & $\mathrm{M}$ & A & W & SS \\
\hline $\begin{array}{c}\text { Dicerorhinus } \\
\text { sumatrensis }\end{array}$ & UMZC & Н.6392 & $\mathrm{X}$ & & & & & & $\mathrm{U}$ & A & $\mathrm{U}$ & $\mathrm{CT}$ \\
\hline $\begin{array}{c}\text { Dicerorhinus } \\
\text { sumatrensis }\end{array}$ & ZSM & $1908 / 571$ & $\mathrm{X}$ & $\mathrm{X}$ & & $\mathrm{X}$ & $\mathrm{X}$ & $\mathrm{X}$ & $\mathrm{M}$ & A & $\mathrm{U}$ & SS \\
\hline Diceros bicornis & CCEC & 50002040 & $\mathrm{X}$ & & & $\mathrm{X}$ & $\mathrm{X}$ & $\mathrm{X}$ & $\mathrm{U}$ & $\mathrm{A}$ & $\mathrm{W}$ & SS \\
\hline Diceros bicornis & CCEC & 50002044 & & $\mathrm{X}$ & & $\mathrm{X}$ & & & $\mathrm{U}$ & $\mathrm{S}$ & $\mathrm{U}$ & $\mathrm{SS}$ \\
\hline Diceros bicornis & CCEC & 50002045 & & & & $\mathrm{X}$ & & & $\mathrm{U}$ & $\mathrm{S}$ & W & $\mathrm{SS}$ \\
\hline Diceros bicornis & CCEC & 50002046 & $\mathrm{X}$ & $\mathrm{X}$ & $\mathrm{X}$ & & $\mathrm{X}$ & $\mathrm{X}$ & $\mathrm{U}$ & $\mathrm{S}$ & $\mathrm{U}$ & $\mathrm{SS}$ \\
\hline Diceros bicornis & CCEC & 50002047 & & $\mathrm{X}$ & $\mathrm{X}$ & & $\mathrm{X}$ & $\mathrm{X}$ & $\mathrm{U}$ & $\mathrm{A}$ & $\mathrm{U}$ & $\mathrm{SS}$ \\
\hline Diceros bicornis & MNHN & ZM-AC-1936-644 & $\mathrm{X}$ & $\mathrm{X}$ & $\mathrm{X}$ & $\mathrm{X}$ & $\mathrm{X}$ & $\mathrm{X}$ & $\mathrm{F}$ & $\mathrm{S}$ & $\mathrm{U}$ & $\mathrm{SS}$ \\
\hline Diceros bicornis & MNHN & ZM-AC-1944-278 & $\mathrm{X}$ & & & $\mathrm{X}$ & $\mathrm{X}$ & $\mathrm{X}$ & $\mathrm{M}$ & $\mathrm{A}$ & $\mathrm{C}$ & $\mathrm{SS}$ \\
\hline Diceros bicornis & MNHN & ZM-AC-1974-124 & & & & $\mathrm{X}$ & $\mathrm{X}$ & $\mathrm{X}$ & $\mathrm{F}$ & $\mathrm{A}$ & $\mathrm{C}$ & $\mathrm{SS}$ \\
\hline Diceros bicornis & RBINS & 9714 & $\mathrm{X}$ & $\mathrm{X}$ & $\mathrm{X}$ & $\mathrm{X}$ & $\mathrm{X}$ & $\mathrm{X}$ & $\mathrm{F}$ & $\mathrm{A}$ & $\mathrm{W}$ & SS \\
\hline Diceros bicornis & RMCA & RG2133 & $\mathrm{X}$ & $\mathrm{X}$ & $\mathrm{X}$ & $\mathrm{X}$ & $\mathrm{X}$ & $\mathrm{X}$ & $\mathrm{M}$ & $\mathrm{S}$ & W & $\mathrm{SS}$ \\
\hline Diceros bicornis & UCMP & 9856 & & & & & $\mathrm{X}$ & & $\mathrm{U}$ & $\mathrm{A}$ & $\mathrm{U}$ & $\mathrm{CT}$ \\
\hline Diceros bicornis & ZSM & $1961 / 186$ & $\mathrm{X}$ & $\mathrm{X}$ & $\mathrm{X}$ & $\mathrm{X}$ & $\mathrm{X}$ & $\mathrm{X}$ & $\mathrm{M}$ & $\mathrm{S}$ & $\mathrm{U}$ & SS \\
\hline Diceros bicornis & ZSM & $1961 / 187$ & $\mathrm{X}$ & $\mathrm{X}$ & $\mathrm{X}$ & $\mathrm{X}$ & $\mathrm{X}$ & $\mathrm{X}$ & $\mathrm{M}$ & $\mathrm{S}$ & $\mathrm{U}$ & $\mathrm{SS}$ \\
\hline
\end{tabular}




\begin{tabular}{|c|c|c|c|c|c|c|c|c|c|c|c|c|}
\hline Diceros bicornis & ZSM & $1962 / 166$ & $X$ & $X$ & $X$ & $X$ & $\mathrm{X}$ & & $F$ & $\mathrm{~S}$ & $\mathrm{U}$ & SS \\
\hline Rhinoceros sondaicus & CCEC & 50002041 & $\mathrm{X}$ & $\mathrm{X}$ & $\mathrm{X}$ & $\mathrm{X}$ & $\mathrm{X}$ & $\mathrm{X}$ & $\mathrm{U}$ & $\mathrm{A}$ & $\mathrm{W}$ & $\mathrm{SS}$ \\
\hline Rhinoceros sondaicus & CCEC & 50002043 & $\mathrm{X}$ & $\mathrm{X}$ & $\mathrm{X}$ & $\mathrm{X}$ & & & $\mathrm{U}$ & $\mathrm{A}$ & $\mathrm{W}$ & $\mathrm{SS}$ \\
\hline Rhinoceros sondaicus & MNHN & ZM-AC-A7970 & $\mathrm{X}$ & $\mathrm{X}$ & $\mathrm{X}$ & $\mathrm{X}$ & $\mathrm{X}$ & $\mathrm{X}$ & $\mathrm{U}$ & $\mathrm{A}$ & $\mathrm{U}$ & SS \\
\hline Rhinoceros sondaicus & MNHN & ZM-AC-A7971 & $\mathrm{X}$ & $\mathrm{X}$ & $\mathrm{X}$ & $\mathrm{X}$ & $\mathrm{X}$ & $\mathrm{X}$ & $\mathrm{U}$ & $\mathrm{A}$ & $\mathrm{W}$ & $\mathrm{SS}$ \\
\hline Rhinoceros sondaicus & NHMUK & ZD 1861.3.11.1 & $\mathrm{X}$ & $X$ & $\mathrm{X}$ & $\mathrm{X}$ & $\mathrm{X}$ & $\mathrm{X}$ & $\mathrm{U}$ & $\mathrm{S}$ & $\mathrm{W}$ & SS \\
\hline Rhinoceros sondaicus & NHMUK & ZD 1871.12.29.7 & $\mathrm{X}$ & $\mathrm{X}$ & $\mathrm{X}$ & $\mathrm{X}$ & $\mathrm{X}$ & $\mathrm{X}$ & $\mathrm{M}$ & $\mathrm{A}$ & $\mathrm{W}$ & SS \\
\hline Rhinoceros sondaicus & NHMUK & ZD 1921.5.15.1 & $\mathrm{X}$ & $\mathrm{X}$ & $\mathrm{X}$ & $\mathrm{X}$ & $\mathrm{X}$ & $\mathrm{X}$ & $\mathrm{F}$ & $\mathrm{S}$ & $\mathrm{W}$ & $\mathrm{SS}$ \\
\hline Rhinoceros sondaicus & RBINS & $1205 \mathrm{~F}$ & $\mathrm{X}$ & $\mathrm{X}$ & $\mathrm{X}$ & $\mathrm{X}$ & $\mathrm{X}$ & $\mathrm{X}$ & $\mathrm{U}$ & $\mathrm{S}$ & $\mathrm{W}$ & $\mathrm{SS}$ \\
\hline $\begin{array}{l}\text { Rhinoceros } \\
\text { unicornis** }\end{array}$ & MNHN & ZM-AC-1885-734 & $\mathrm{X}$ & $X$ & $\mathrm{X}$ & $\mathrm{X}$ & $\mathrm{X}$ & & $\mathrm{U}$ & A & W & SS \\
\hline Rhinoceros unicornis & MNHN & ZM-AC-1932-49 & $X$ & & & & $\mathrm{X}$ & $\mathrm{X}$ & $\mathrm{U}$ & $\mathrm{S}$ & $\mathrm{U}$ & $\mathrm{SS}$ \\
\hline Rhinoceros unicornis & MNHN & ZM-AC-1960-59 & $\mathrm{X}$ & $\mathrm{X}$ & $\mathrm{X}$ & $\mathrm{X}$ & $\mathrm{X}$ & $\mathrm{X}$ & $\mathrm{M}$ & $\mathrm{A}$ & $\mathrm{C}$ & $\mathrm{SS}$ \\
\hline Rhinoceros unicornis & MNHN & ZM-AC-1967-101 & $\mathrm{X}$ & $\mathrm{X}$ & $\mathrm{X}$ & $\mathrm{X}$ & $\mathrm{X}$ & & $\mathrm{F}$ & $\mathrm{A}$ & $\mathrm{C}$ & $\mathrm{SS}$ \\
\hline Rhinoceros unicornis & NHMUK & ZD 1884.1.22.1.2 & $\mathrm{X}$ & $\mathrm{X}$ & $\mathrm{X}$ & $\mathrm{X}$ & $\mathrm{X}$ & $\mathrm{X}$ & $\mathrm{F}$ & $\mathrm{A}$ & $\mathrm{W}$ & $\mathrm{SS}$ \\
\hline Rhinoceros unicornis & NHMUK & ZE 1950.10.18.5 & $\mathrm{X}$ & $\mathrm{X}$ & $\mathrm{X}$ & $\mathrm{X}$ & $\mathrm{X}$ & $\mathrm{X}$ & $\mathrm{M}$ & $\mathrm{A}$ & $\mathrm{W}$ & $\mathrm{SS}$ \\
\hline Rhinoceros unicornis & NHMUK & ZE 1961.5.10.1 & $\mathrm{X}$ & $\mathrm{X}$ & $\mathrm{X}$ & $\mathrm{X}$ & $\mathrm{X}$ & $\mathrm{X}$ & $\mathrm{M}$ & $\mathrm{A}$ & $\mathrm{W}$ & SS \\
\hline Rhinoceros unicornis* & NHMUK & ZD 1972.822 & $\mathrm{X}$ & $\mathrm{X}$ & $\mathrm{X}$ & $\mathrm{X}$ & $\mathrm{X}$ & $\mathrm{X}$ & $\mathrm{U}$ & $\mathrm{A}$ & $\mathrm{U}$ & $\mathrm{SS}$ \\
\hline Rhinoceros unicornis & RBINS & 1208 & $\mathrm{X}$ & $X$ & $\mathrm{X}$ & $\mathrm{X}$ & $\mathrm{X}$ & $\mathrm{X}$ & $\mathrm{F}$ & $\mathrm{A}$ & $\mathrm{C}$ & $\mathrm{SS}$ \\
\hline Rhinoceros unicornis & RBINS & 33382 & $\mathrm{X}$ & $\mathrm{X}$ & $\mathrm{X}$ & $\mathrm{X}$ & $\mathrm{X}$ & $\mathrm{X}$ & $\mathrm{U}$ & $\mathrm{A}$ & $\mathrm{U}$ & SS \\
\hline
\end{tabular}

1 


\section{Table 3 (on next page)}

Results of the Pearson's correlation tests between the log-transformed centroid size and the two first principal components for each bone.

$r$ : Pearson's correlation coefficient value; t: Student distribution value; dF: degrees of freedom; P: p-value. Significant results are indicated in bold. 
1

2

\begin{tabular}{|c|c|c|c|c|c|}
\hline Bone & Component & $\mathbf{r}$ & $\mathbf{t}$ & $\mathbf{d F}$ & $\mathbf{P}$ \\
\hline \multirow{2}{*}{ Humerus } & PC1 & -0.38 & -2.93 & 51 & 0.01 \\
\hline & PC2 & 0.43 & 3.44 & 51 & $<0.01$ \\
\hline \multirow{2}{*}{ Radius } & PC1 & -0.64 & -5.77 & 47 & $<0.01$ \\
\hline & PC2 & 0.22 & 1.58 & 47 & 0.12 \\
\hline \multirow{2}{*}{ Ulna } & PC1 & -0.79 & -8.44 & 44 & $<0.01$ \\
\hline & PC2 & 0.02 & 0.11 & 44 & 0.91 \\
\hline \multirow{2}{*}{ Femur } & PC1 & -0.56 & -5.01 & 54 & $<0.01$ \\
\hline & PC2 & 0.30 & -2.34 & 54 & 0.02 \\
\hline \multirow{2}{*}{ Tibia } & PC1 & -0.58 & -5.05 & 51 & $<0.01$ \\
\hline & PC2 & 0.08 & 0.58 & 51 & 0.57 \\
\hline \multirow{3}{*}{ Fibula } & PC1 & -0.36 & -2.69 & 48 & $<0.01$ \\
\hline & PC2 & -0.34 & -2.47 & 48 & 0.02 \\
\hline & PC 3 & 0.16 & 1.12 & 48 & 0.27 \\
\hline
\end{tabular}




\section{Table 4 (on next page)}

Main anatomical differences observed between theoretical shapes associated with minimal and maximal centroid size for each bone of the forelimb.

B: Bone; H: Humerus; R: Radius; U: Ulna. 


\begin{tabular}{|c|c|c|c|}
\hline B & $\begin{array}{c}\text { Anatomical } \\
\text { feature }\end{array}$ & Centroid size minimum & Centroid size maximum \\
\hline \multirow{20}{*}{$\mathbf{H}$} & General aspect & Gracile & Robust \\
\hline & Head & Rounded, overhanging the shaft & $\begin{array}{l}\text { Rounded, overhanging poorly } \\
\text { the shaft }\end{array}$ \\
\hline & Lesser tubercle & Developed & Poorly developed \\
\hline & $\begin{array}{l}\text { Intermediate } \\
\text { tubercle }\end{array}$ & Almost absent & Poorly developed \\
\hline & Greater tubercle & Developed & Strongly developed \\
\hline & Bicipital groove & Asymmetrical and closed & $\begin{array}{l}\text { Almost symmetrical and } \\
\text { widely open }\end{array}$ \\
\hline & $\begin{array}{l}\text { M. infraspinatus } \\
\text { insertion }\end{array}$ & $\begin{array}{c}\text { Diamond-shaped and strongly } \\
\text { developed }\end{array}$ & Ovoid and less developed \\
\hline & Deltoid tuberosity & $\begin{array}{l}\text { Poorly laterally deviated and } \\
\text { caudally sharp }\end{array}$ & $\begin{array}{l}\text { Laterally deviated and } \\
\text { caudally smooth }\end{array}$ \\
\hline & Distal epiphysis & Medio-laterally compressed & Medio-laterally extended \\
\hline & $\begin{array}{l}\text { Supracondylar } \\
\text { crest }\end{array}$ & Smooth & Very smooth \\
\hline & Lateral epicondyle & Poorly extended laterally & Strongly extended laterally \\
\hline & Medial epicondyle & Overhanging the olecranon fossa & $\begin{array}{l}\text { Not overhanging the olecranon } \\
\text { fossa }\end{array}$ \\
\hline & Olecranon fossa & Triangular and deep & Rectangular and deep \\
\hline & Trochlea & Sharp lips and deep groove & $\begin{array}{l}\text { Smooth lips and shallow } \\
\text { groove }\end{array}$ \\
\hline & Capitulum & Extremely reduced & Extremely reduced \\
\hline & General aspect & Gracile & Robust \\
\hline & $\begin{array}{c}\text { Proximal articular } \\
\text { surface }\end{array}$ & $\begin{array}{l}\text { Open and little concave; medial } \\
\text { glenoid cavity slightly larger } \\
\text { than the lateral one }\end{array}$ & $\begin{array}{l}\text { Concave; medial glenoid } \\
\text { cavity twice as large as the } \\
\text { lateral one }\end{array}$ \\
\hline & Radial tuberosity & Poorly developed & Poorly developed \\
\hline & $\begin{array}{l}\text { Lateral insertion } \\
\text { relief }\end{array}$ & Poorly developed & Knob-shaped \\
\hline & $\begin{array}{c}\text { Lateral synovial } \\
\text { articulation surface }\end{array}$ & Trapezoid and laterally extended & $\begin{array}{l}\text { Trapezoid and laterally } \\
\text { reduced }\end{array}$ \\
\hline \multirow[t]{6}{*}{$\mathbf{R}$} & $\begin{array}{c}\text { Medial synovial } \\
\text { articulation surface }\end{array}$ & Thin and rectangular & Thin and rectangular \\
\hline & $\begin{array}{l}\text { Proximal articular } \\
\text { surface for the ulna }\end{array}$ & $\begin{array}{l}\text { Triangular, wide and proximo- } \\
\text { distally short }\end{array}$ & $\begin{array}{l}\text { Triangular, slender and } \\
\text { proximo-distally long }\end{array}$ \\
\hline & Interosseous crest & Smooth & Sharp \\
\hline & $\begin{array}{l}\text { Interosseous space } \\
\text { position }\end{array}$ & Mid-shaft & $\begin{array}{l}\text { First proximal third of the } \\
\text { shaft }\end{array}$ \\
\hline & $\begin{array}{c}\text { Distal articular } \\
\text { surface for the ulna }\end{array}$ & Long and slender triangle & Short and wide triangle \\
\hline & $\begin{array}{l}\text { Articular surface } \\
\text { for the carpal bones }\end{array}$ & Broad in dorso-palmar direction & $\begin{array}{l}\text { Compressed in dorso-palmar } \\
\text { direction }\end{array}$ \\
\hline
\end{tabular}




\begin{tabular}{ccc}
\hline \hline $\begin{array}{c}\text { Articular surface } \\
\text { for the scaphoid }\end{array}$ & Proximally extended & Poorly extended proximally \\
\hline $\begin{array}{c}\text { Articular surface } \\
\text { for the semilunar }\end{array}$ & Trapezoid and narrow & Trapezoid and wide \\
\hline $\begin{array}{c}\text { Radial styloid } \\
\text { process }\end{array}$ & Short & Long \\
\hline \hline General aspect & Gracile & Robust \\
\hline Olecranon & Medio-laterally compressed & Medio-laterally large \\
\hline $\begin{array}{c}\text { Olecranon } \\
\text { tuberosity }\end{array}$ & $\begin{array}{c}\text { Oriented medially with a medial } \\
\text { tubercle pointing in the medio- } \\
\text { palmar direction }\end{array}$ & $\begin{array}{c}\text { Oriented laterally with a } \\
\text { medial tubercle pointing in the } \\
\text { medio-dorsal direction }\end{array}$ \\
\hline Anconeus process & Developed in dorsal direction & Little developed dorsally \\
\hline $\begin{array}{c}\text { Articular surface } \\
\text { for the humerus }\end{array}$ & $\begin{array}{c}\text { Medio-laterally reduced, lateral } \\
\text { lip developed in proximal } \\
\text { direction }\end{array}$ & $\begin{array}{c}\text { Medio-laterally broad with an } \\
\text { important development of the } \\
\text { medial part }\end{array}$ \\
\hline $\begin{array}{c}\text { Interosseous crest } \\
\text { Distal epiphysis }\end{array}$ & Irregular and sharp & Smooth \\
\hline $\begin{array}{c}\text { Articular surface } \\
\text { for the triquetrum }\end{array}$ & Narrow and concave & $\begin{array}{c}\text { Large and extending largely in } \\
\text { lateral and dorsal directions }\end{array}$ \\
\hline $\begin{array}{c}\text { Articular surface } \\
\text { for the pisiform }\end{array}$ & $\begin{array}{c}\text { Extended in proximal direction } \\
\text { Wide and slightly concave }\end{array}$ \\
\hline
\end{tabular}




\section{Table 5 (on next page)}

Main anatomical differences observed between theoretical shapes associated with minimal and maximal centroid size for each bone of the hind limb.

B: Bone; Fe: Femur; Fi: Fibula; T: Tibia. 


\begin{tabular}{|c|c|c|c|}
\hline B & $\begin{array}{c}\text { Anatomical } \\
\text { feature }\end{array}$ & Centroid size minimum & Centroid size maximum \\
\hline \multirow{10}{*}{$\mathbf{F e}$} & General aspect & Gracile & Robust \\
\hline & Head & $\begin{array}{l}\text { Rounded, well separated from } \\
\text { the shaft by a narrow neck }\end{array}$ & $\begin{array}{l}\text { Massive and flattened, } \\
\text { surmounting a large neck }\end{array}$ \\
\hline & Fovea capitis & $\begin{array}{l}\text { Formed by a simple shallow } \\
\text { notch on the border head in } \\
\text { medio-caudal direction }\end{array}$ & $\begin{array}{l}\text { Small and shallow, oriented } \\
\text { more medially }\end{array}$ \\
\hline & Greater trochanter & $\begin{array}{l}\text { Small and developed in the } \\
\text { cranial direction }\end{array}$ & $\begin{array}{l}\text { Large and developed in the } \\
\text { latero-distal direction }\end{array}$ \\
\hline & Lesser trochanter & $\begin{array}{l}\text { Thin and bordering the caudal } \\
\text { border of the shaft medial side }\end{array}$ & $\begin{array}{l}\text { Thick, occupying the whole } \\
\text { width of the medial side }\end{array}$ \\
\hline & $\begin{array}{l}\text { Lines on the } \\
\text { cranial side }\end{array}$ & $\begin{array}{l}\text { Medial line running straight } \\
\text { along the side }\end{array}$ & $\begin{array}{l}\text { Medial line strongly concave } \\
\text { along the side }\end{array}$ \\
\hline & Third trochanter & Rounded and poorly developed & $\begin{array}{l}\text { Strong and developed towards } \\
\text { the greater trochanter }\end{array}$ \\
\hline & Trochlea & $\begin{array}{c}\text { Oriented medially with a } \\
\text { shallow groove and developed } \\
\text { medial lip }\end{array}$ & $\begin{array}{l}\text { Oriented cranially with a deep } \\
\text { groove and an extremely } \\
\text { developed medial lip }\end{array}$ \\
\hline & Condyles & Almost of the same size & $\begin{array}{c}\text { Medial condyle more } \\
\text { developed than the lateral one }\end{array}$ \\
\hline & $\begin{array}{l}\text { Intercondylar } \\
\text { space }\end{array}$ & Wide & Narrow \\
\hline \multirow{12}{*}{$\mathbf{T}$} & General aspect & Gracile & Robust \\
\hline & $\begin{array}{l}\text { Proximal } \\
\text { condyles }\end{array}$ & $\begin{array}{c}\text { Nearly equal surface areas; } \\
\text { lateral condyle more developed } \\
\text { caudally with a sliding surface } \\
\text { for the } m \text {. popliteus }\end{array}$ & $\begin{array}{l}\text { Medial condyle surface twice } \\
\text { as wide as the lateral one and } \\
\text { more developed caudally }\end{array}$ \\
\hline & $\begin{array}{l}\text { Intercondylar } \\
\text { tubercles }\end{array}$ & Nearly of equal height & $\begin{array}{l}\text { Medial tubercle higher than } \\
\text { the lateral one }\end{array}$ \\
\hline & $\begin{array}{l}\text { Central } \\
\text { intercondylar area }\end{array}$ & Wide & Narrow \\
\hline & Tibial tuberosity & Laterally deviated & $\begin{array}{l}\text { Massive and oriented in lateral } \\
\text { direction }\end{array}$ \\
\hline & Tuberosity groove & Deep & Shallow \\
\hline & Extensor sulcus & Shallow & Shallow \\
\hline & $\begin{array}{l}\text { Proximal articular } \\
\text { surface for the } \\
\text { fibula }\end{array}$ & Nail-shaped & Triangular \\
\hline & Interosseous crest & Sharp & Smooth \\
\hline & $\begin{array}{l}\text { Distal articular } \\
\text { surface for the } \\
\text { fibula }\end{array}$ & Narrow and triangular & Wide and triangular \\
\hline & $\begin{array}{l}\text { Articular surface } \\
\text { for the talus }\end{array}$ & $\begin{array}{l}\text { Rectangular, slightly tilted } \\
\text { laterally }\end{array}$ & $\begin{array}{l}\text { Squared, slightly oriented } \\
\text { medially }\end{array}$ \\
\hline & Medial groove for & Deep and narrow & Deep and narrow \\
\hline
\end{tabular}




\begin{tabular}{|c|c|c|c|}
\hline & $\begin{array}{l}\text { Lateral groove for } \\
\text { the talus } \\
\end{array}$ & Shallow and wide & Shallow and wide \\
\hline \multirow{7}{*}{$\mathbf{F i}$} & General aspect & Gracile & Robust \\
\hline & Head & $\begin{array}{l}\text { Flat and large, oriented cranio- } \\
\text { medially }\end{array}$ & Small and oriented cranially \\
\hline & $\begin{array}{l}\text { Proximal articular } \\
\text { surface for the } \\
\text { tibia }\end{array}$ & Nail-shaped & Triangular \\
\hline & Shaft & $\begin{array}{l}\text { Thin and slightly concave, with } \\
\text { two sharp crests running along } \\
\text { the lateral side }\end{array}$ & $\begin{array}{l}\text { Broad and straight, with two } \\
\text { smooth crests running along } \\
\text { the lateral side }\end{array}$ \\
\hline & $\begin{array}{l}\text { Distal articular } \\
\text { surface for the } \\
\text { tibia }\end{array}$ & Triangular, narrow and long & Triangular, wide and short \\
\hline & Lateral malleolus & $\begin{array}{c}\text { Two well-developed tubercles } \\
\text { caudally oriented and separated } \\
\text { by a deep groove }\end{array}$ & $\begin{array}{l}\text { Two flat tubercles laterally } \\
\text { oriented, with the cranial one } \\
\text { being more developed, and } \\
\text { separated by a shallow groove }\end{array}$ \\
\hline & $\begin{array}{l}\text { Articular surface } \\
\text { for the talus }\end{array}$ & $\begin{array}{l}\text { Kidney-shaped, broad in } \\
\text { proximo-distal direction }\end{array}$ & $\begin{array}{l}\text { Triangular, proximo-distally } \\
\text { compressed }\end{array}$ \\
\hline
\end{tabular}

1 


\section{Table 6(on next page)}

Results of the Procrustes ANOVA performed on shape data and log-transformed centroid size (Cs.) taking into account species (Sp.) affiliation.

$\mathrm{R}^{2}$ : determination coefficient value; F: Fisher distribution value; Z: Normal distribution value; P: p-value. Significant results are indicated in bold. 


\begin{tabular}{cccccc} 
& & $\mathbf{R}^{\mathbf{2}}$ & $\mathbf{F}$ & $\mathbf{Z}$ & $\mathbf{P}(>\mathbf{F})$ \\
\hline \multirow{2}{*}{ Humerus } & Cs. & 0.13 & 17.38 & 5.13 & $\mathbf{0 . 0 0 1}$ \\
\cline { 2 - 6 } & Sp. & 0.53 & 17.72 & 8.50 & $\mathbf{0 . 0 0 1}$ \\
\hline \multirow{2}{*}{ Radius } & Cs. & 0.18 & 15.72 & 5.74 & $\mathbf{0 . 0 0 1}$ \\
\cline { 2 - 6 } & Sp. & 0.32 & 7.07 & 8.83 & $\mathbf{0 . 0 0 1}$ \\
\hline \multirow{2}{*}{ Ulna } & Cs. & 0.16 & 12.94 & 6.19 & $\mathbf{0 . 0 0 1}$ \\
\cline { 2 - 6 } Femur & Sp. & 0.36 & 7.31 & 9.27 & $\mathbf{0 . 0 0 1}$ \\
\cline { 2 - 6 } & Cs. & 0.14 & 14.41 & 6.07 & $\mathbf{0 . 0 0 1}$ \\
\hline \multirow{2}{*}{ Tibia } & Cs. & 0.37 & 9.56 & 10.08 & $\mathbf{0 . 0 0 1}$ \\
\cline { 2 - 6 } & Sp. & 0.36 & 8.06 & 9.03 & $\mathbf{0 . 0 0 1}$ \\
\hline \multirow{2}{*}{ Fibula } & Cs. & 0.10 & 6.61 & 3.77 & $\mathbf{0 . 0 0 1}$ \\
\cline { 2 - 6 } & Sp. & 0.26 & 4.47 & 5.61 & $\mathbf{0 . 0 0 1}$ \\
\hline
\end{tabular}




\section{Table 7 (on next page)}

Results of the Procrustes ANOVA performed on shape data and cube root of the mean body mass.

$\mathrm{R}^{2}$ : determination coefficient value; F: Fisher distribution value; Z: Normal distribution value; P: p-value. Significant results are indicated in bold. 
1

2

\begin{tabular}{ccccc}
\cline { 2 - 5 } & $\mathbf{R}^{\mathbf{2}}$ & $\mathbf{F}$ & $\mathbf{Z}$ & $\mathbf{P}(>\mathbf{F})$ \\
\hline Humerus & 0.33 & 25.664 & 5.73 & $\mathbf{0 . 0 0 1}$ \\
\hline Radius & 0.29 & 18.77 & 6.06 & $\mathbf{0 . 0 0 1}$ \\
\hline Ulna & 0.21 & 11.22 & 5.57 & $\mathbf{0 . 0 0 1}$ \\
\hline Femur & 0.26 & 18.61 & 6.39 & $\mathbf{0 . 0 0 1}$ \\
\hline Tibia & 0.18 & 11.16 & 5.50 & $\mathbf{0 . 0 0 1}$ \\
\hline Fibula & 0.11 & 5.91 & 3.40 & $\mathbf{0 . 0 0 1}$
\end{tabular}




\section{Table 8(on next page)}

Mean centroid size and standard deviation by bone for each species. 
1

\section{C. simum D. sumatrensis $\quad$ D. bicornis $\quad R$. sondaicus $\quad R$. unicornis}

\begin{tabular}{cccccc}
\hline Humerus & $723 \pm 34$ & $626 \pm 24$ & $660 \pm 49$ & $749 \pm 39$ & $812 \pm 26$ \\
\hline Radius & $501 \pm 19$ & $403 \pm 14$ & $485 \pm 19$ & $463 \pm 28$ & $520 \pm 21$ \\
\hline Ulna & $512 \pm 18$ & $408 \pm 14$ & $492 \pm 18$ & $478 \pm 28$ & $530 \pm 22$ \\
\hline Femur & $724 \pm 37$ & $613 \pm 18$ & $657 \pm 28$ & $686 \pm 22$ & $822 \pm 34$ \\
\hline Tibia & $471 \pm 17$ & $398 \pm 15$ & $442 \pm 25$ & $451 \pm 39$ & $535 \pm 28$ \\
\hline Fibula & $279 \pm 14$ & $233 \pm 7$ & $269 \pm 14$ & $254 \pm 8$ & $327 \pm 16$ \\
\hline
\end{tabular}

2

3 


\section{Figure 1}

Results of the PCA performed on morphometric data of the humerus.

A: distribution of the specimens along the two first axes of the PCA; B to I: theoretical shapes associated with the minimum and maximum values of $\mathrm{PC1}$ : caudal $(\mathrm{B}, \mathrm{C})$, lateral $(\mathrm{D}, \mathrm{E})$, proximal $(F, G)$ and distal $(H, I)$ views for $P C 1$ minimum $(B, D, F, H)$ and $P C 1$ maximum $(C, E$, G, I). Abbreviations - B.g.: Bicipital groove; C.: Capitulum; D.t.: Deltoid tuberosity; E.c.: Epicondylar crest; G.t.: Greater tubercle; G.t.c.: Greater tubercle convexity; H.: Head; I.t.: Intermediate tubercle; L.e.: Lateral epicondyle; L.I.b.: Lateral lip border; L.t.: Lesser tubercle; L.t.c.: Lesser tubercle convexity; M.e.: Medial epicondyle; M.i.i.: M. infraspinatus insertion; M.I.b.: Medial lip border; M.t.m.t.: M. teres major tuberosity; N.: Neck; O.f.: Olecranon fossa; T.: Trochlea; T.g.: Trochlear groove. 

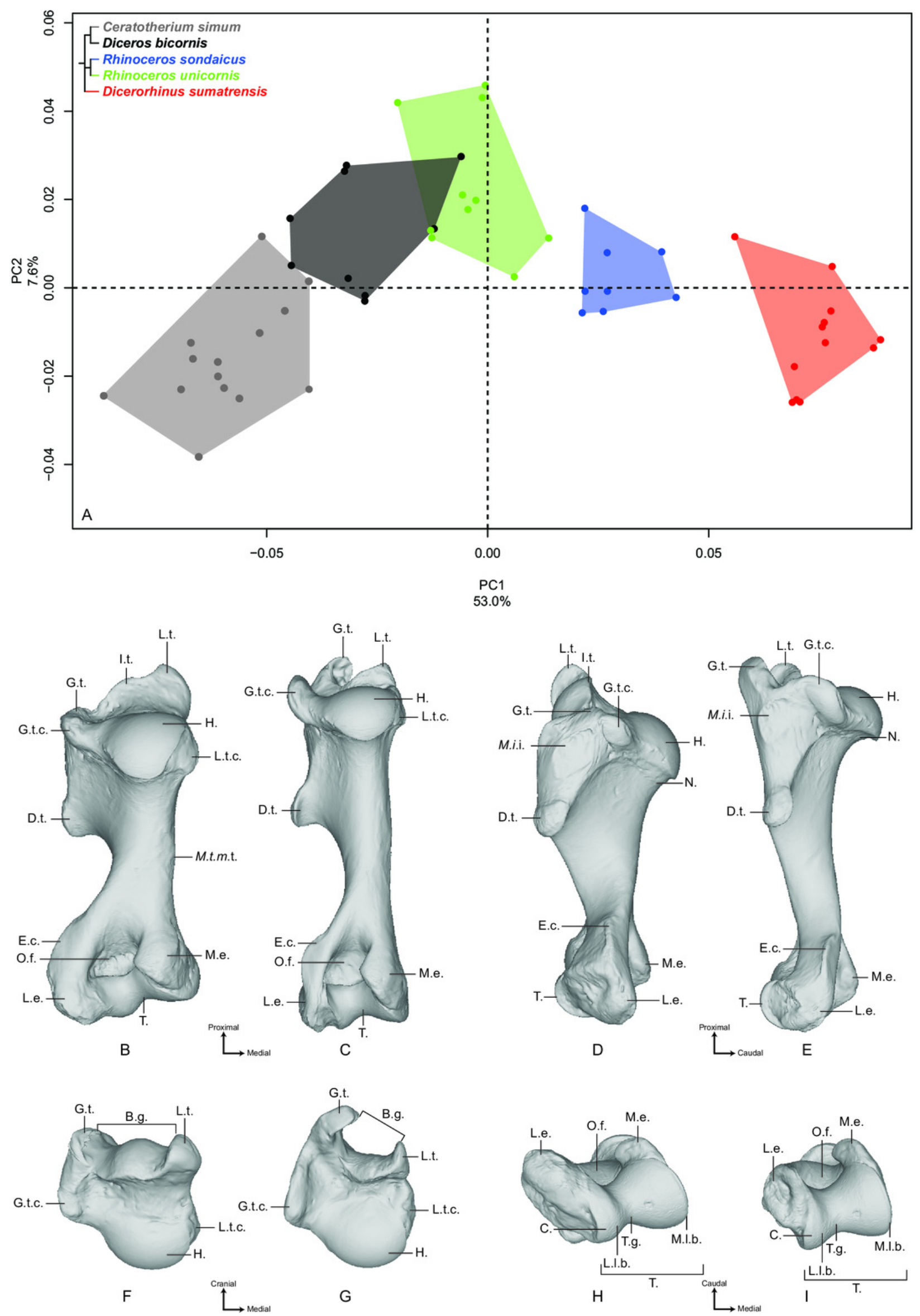


\section{Figure 2}

Results of the PCA performed on morphometric data of the radius.

A: distribution of the specimens along the two first axes of the PCA; B to I: theoretical shapes associated with the minimum and maximum values of $\mathrm{PC} 1$ : dorsal $(B, C)$, palmar $(D, E)$, proximal $(F, G)$ and distal $(H, I)$ views for $P C 1$ minimum $(B, D, F, H)$ and $P C 1$ maximum $(C, E$, G, I). Abbreviations - A.s.s.: Articular surface for the scaphoid; A.s.sl.: Articular surface for the semilunar; C.p.: Coronoid process; D.a.s.u.: Distal articular surface for the ulna; I.c.: Interosseous crest; I.s.: Interosseous space; L.g.c.: Lateral glenoid cavity; L.i.r.: Lateral insertion relief; L.s.a.s.: Lateral synovial articular surface; M.g.c.: Medial glenoid cavity; M.s.a.s.: Medial synovial articular surface; P.a.s.u.: Proximal articular surface for the ulna; P.p.: Palmar process; R.s.p.: Radial styloid process; R.t.: Radial tuberosity. 

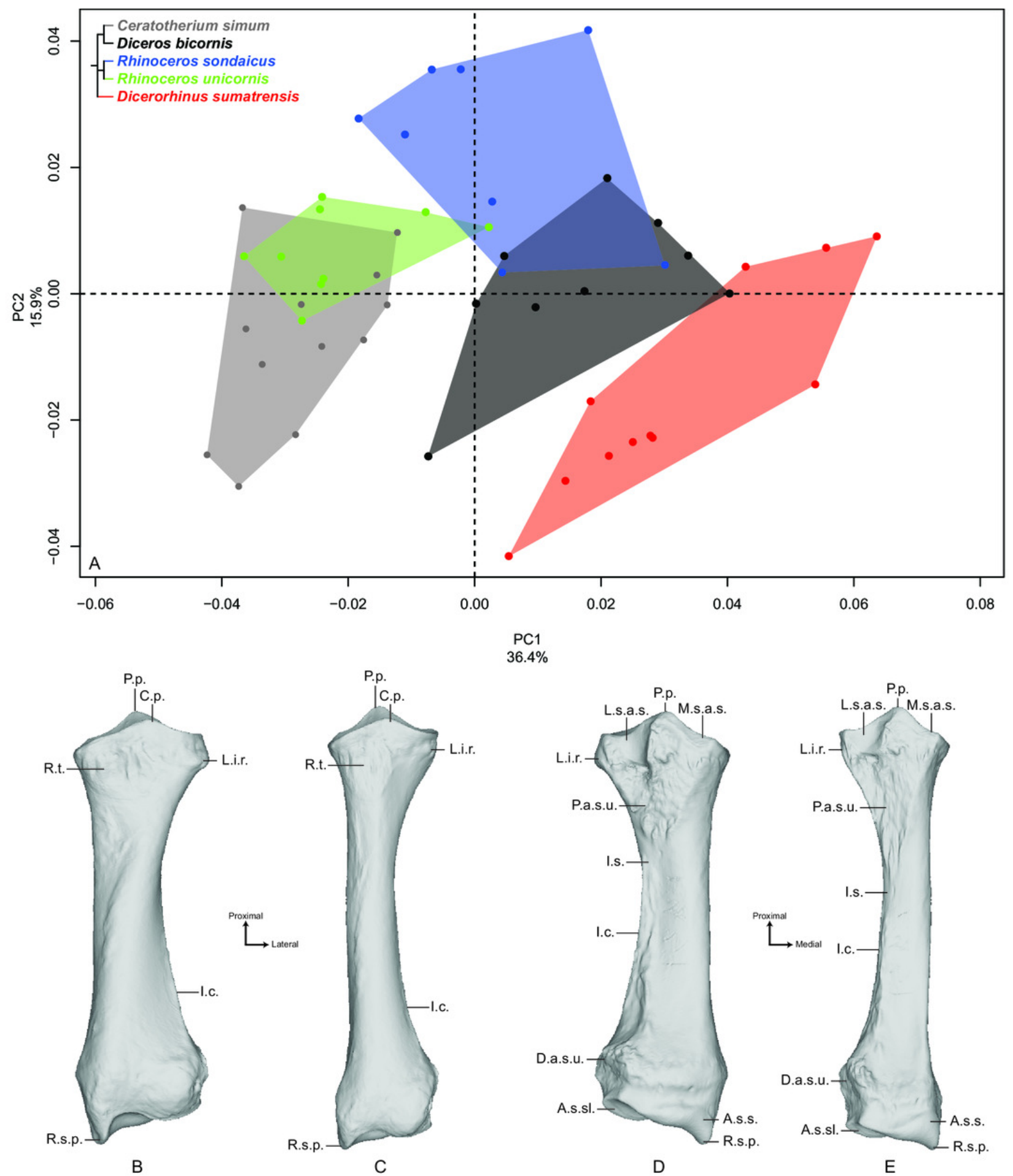

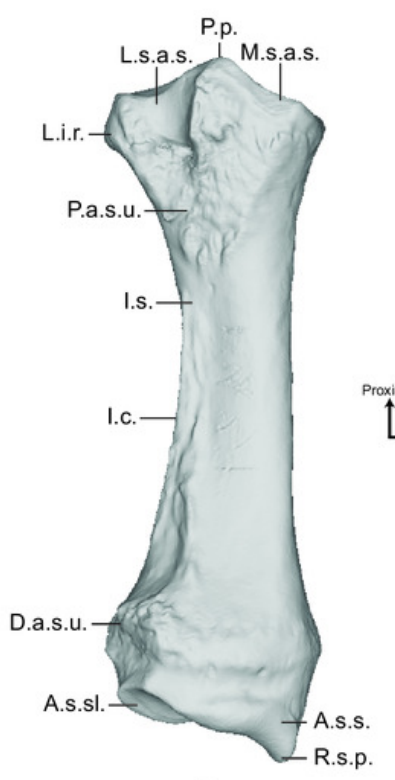

D

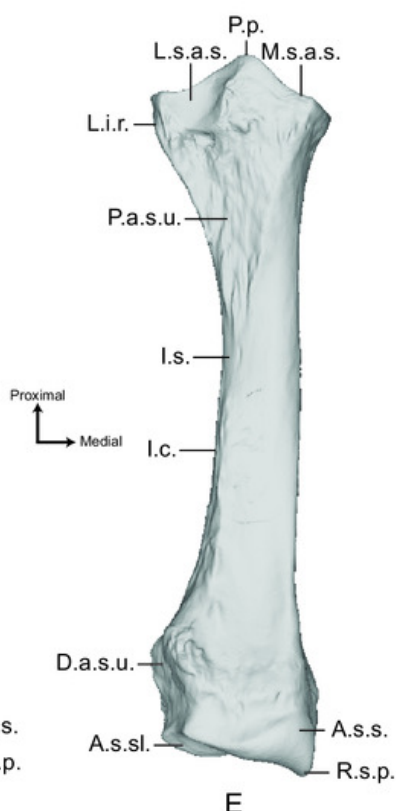

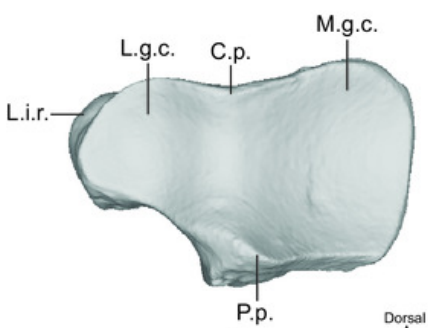

F $\stackrel{\text { Dorsal }}{\longrightarrow \text { Medial }}$

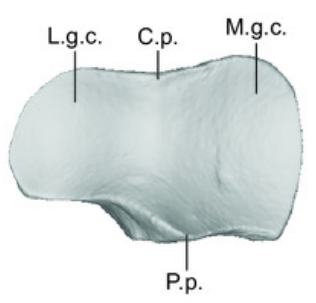

G

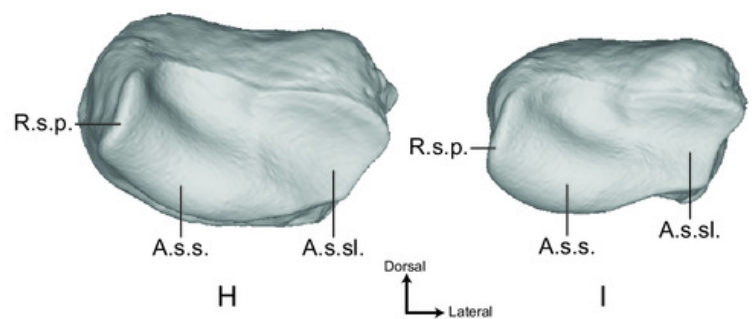

Peer) reviewing PDF | (2019:05:37815:2:0:NEW 6 Aug 2019) 


\section{Figure 3}

Results of the PCA performed on morphometric data of the ulna.

A: distribution of the specimens along the two first axes of the PCA; B to I: theoretical shapes associated with the minimum and maximum values of $P C 1$ : dorsal $(B, C)$, medial $(D, E)$, proximal $(F, G)$ and distal $(H, I)$ views for $P C 1$ minimum $(B, D, F, H)$ and $P C 1$ maximum $(C, E$, G, I). Abbreviations - A.p.: Anconeal process; A.s.h.: Articular surface for the humerus; A.s.p.: Articular surface for the pisiform; A.s.sl.: Articular surface for the semilunar; A.s.t.: Articular surface for the triquetrum; D.a.s.r.: Distal articular surface for the radius; I.c.: Interosseous crest; I.s.: Interosseous space; M.t.o.: Medial tuberosity of the olecranon; 0.t.: Olecranon tuberosity; P.b.: palmar border; U.s.p.: Ulnar styloid process. 


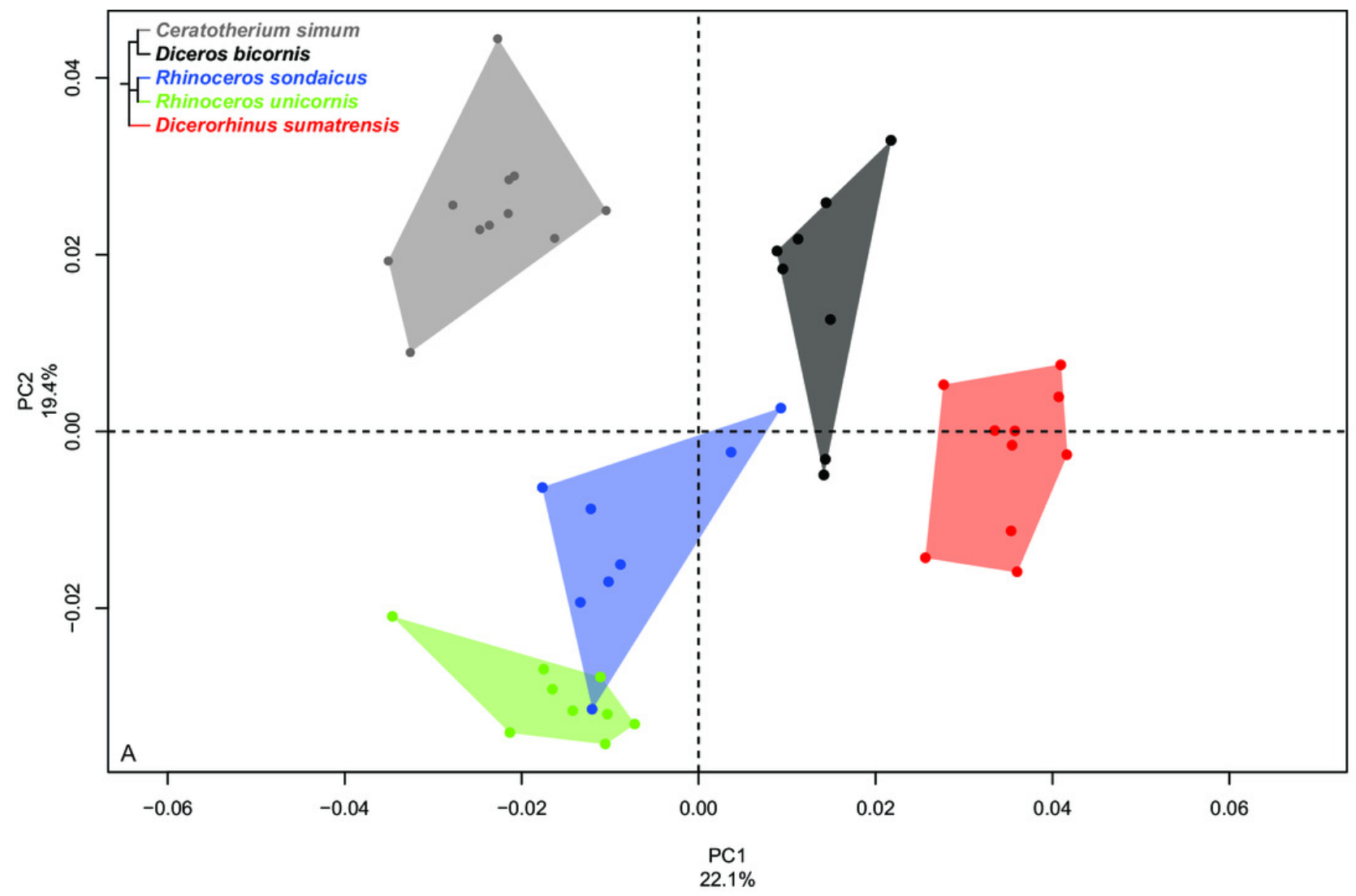

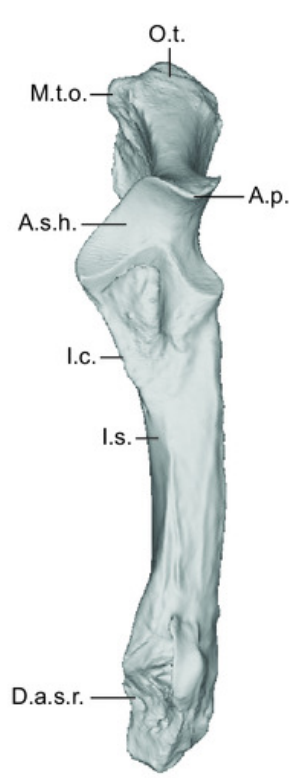

B

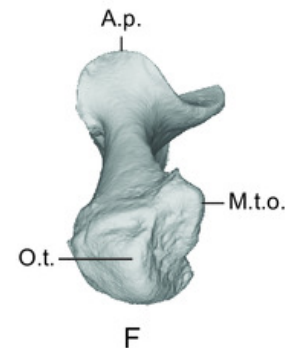

F
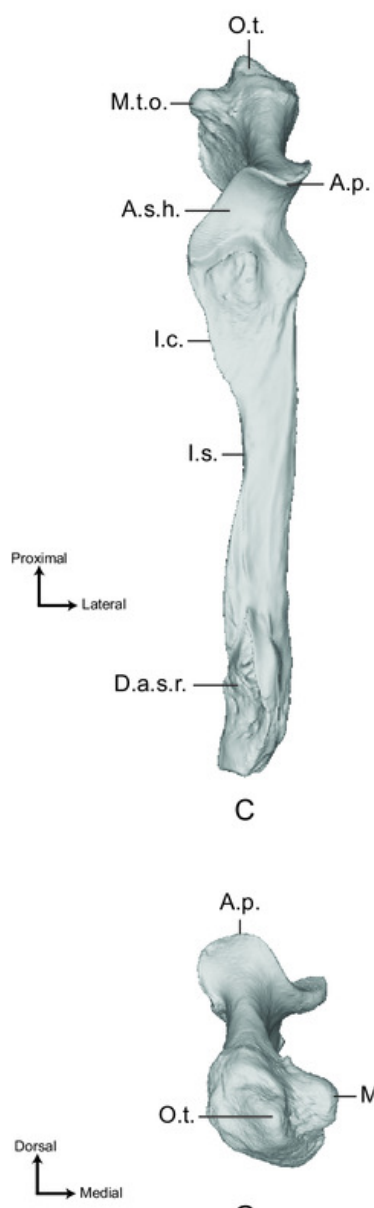

C

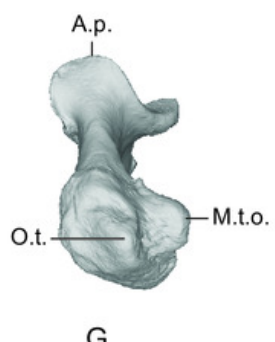

G

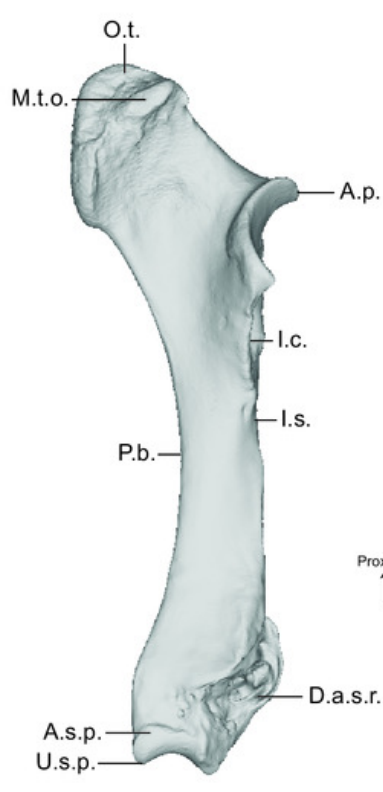

D

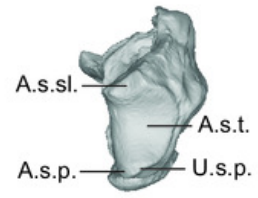

$\mathrm{H}$

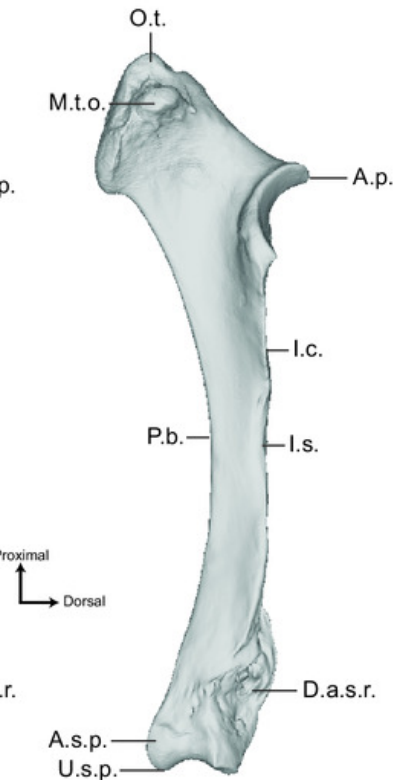

E
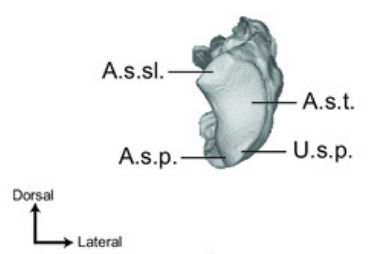

I 


\section{Figure 4}

Results of the PCA performed on morphometric data of the femur.

A: distribution of the specimens along the two first axes of the PCA; B to I: theoretical shapes associated with the minimum and maximum values of $P C 1$ : cranial $(B, C)$, medial $(D, E)$, proximal $(F, G)$ and distal $(H, I)$ views for $P C 1$ minimum $(B, D, F, H)$ and $P C 1$ maximum $(C, E$, G, I). Abbreviations - F.c.: Fovea capitis; G.t.: Greater trochanter; G.t.c.: Greater trochanter convexity; G.t.t.: Greater trochanter top; H.: Head; I.s.: Intercondylar space; L.c.: Lateral condyle; L.e.: Lateral epicondyle; L.t.r.: Lateral trochlear ridge; L.t.: Lesser trochanter; M.c.: Medial condyle; M.e.: Medial epicondyle; M.t.r.: Medial trochlear ridge; N.: Neck; S.f.:

supracondylar fossa; T.: Trochlea; T.f.: Trochanteric fossa; T.g.: Trochlear groove; T.t.: Third trochanter. 


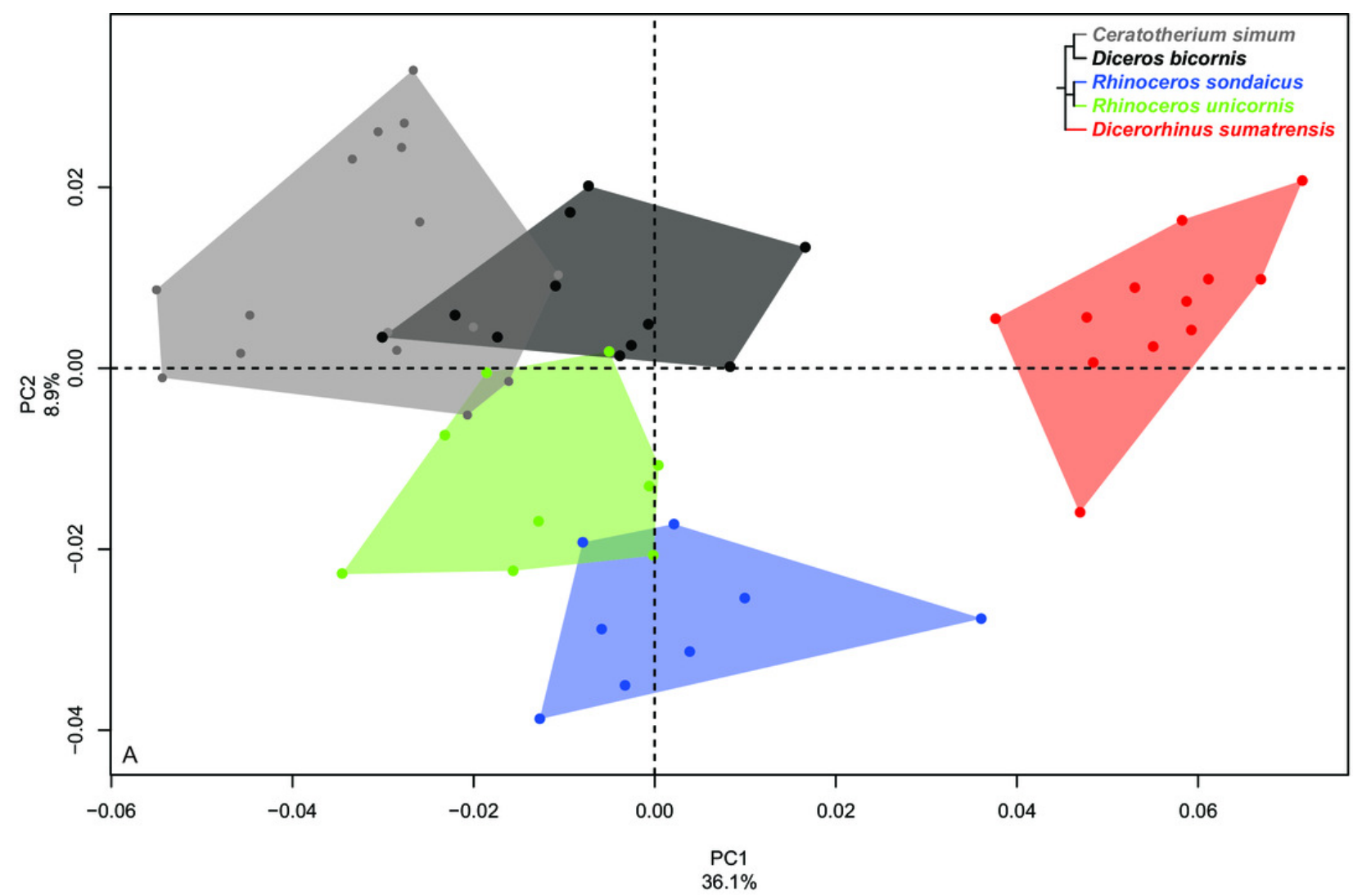

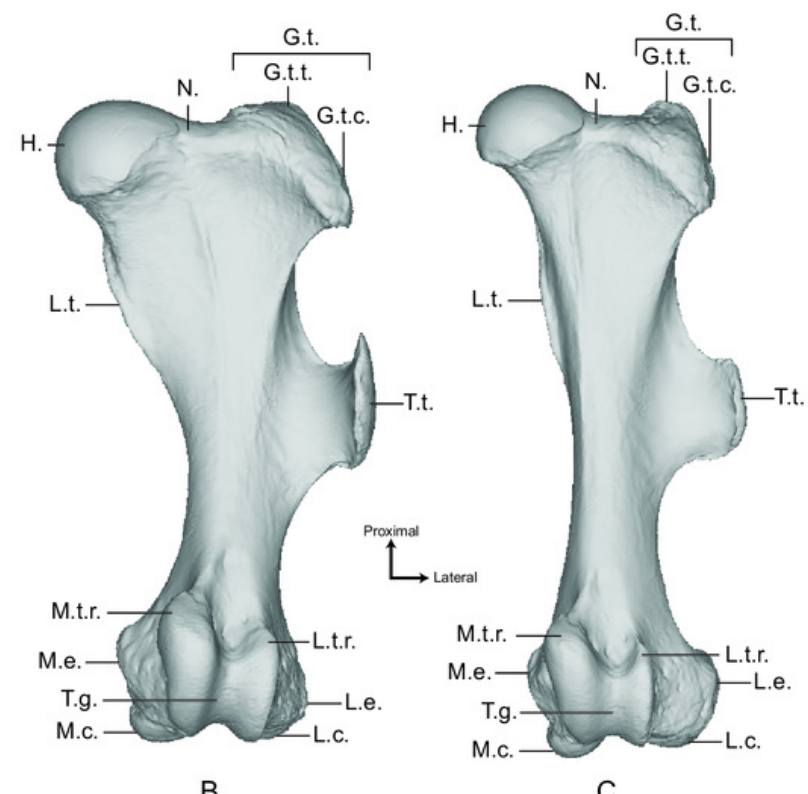

B

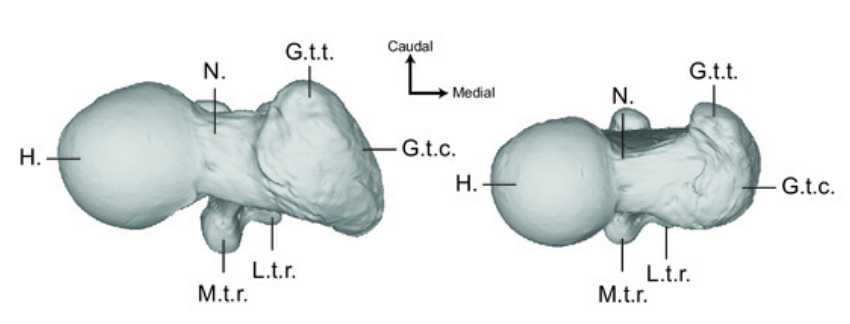

F

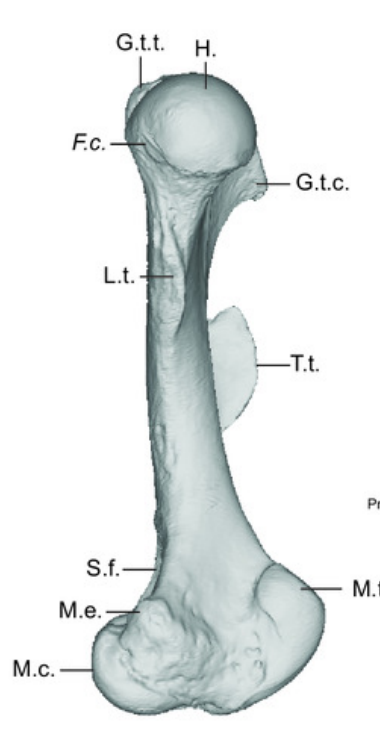

D

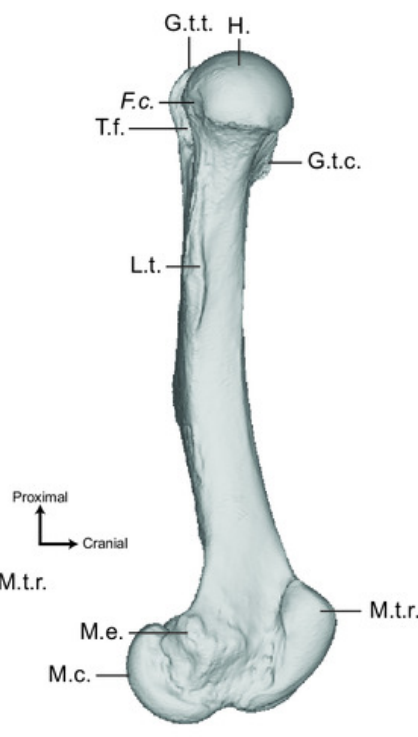

E

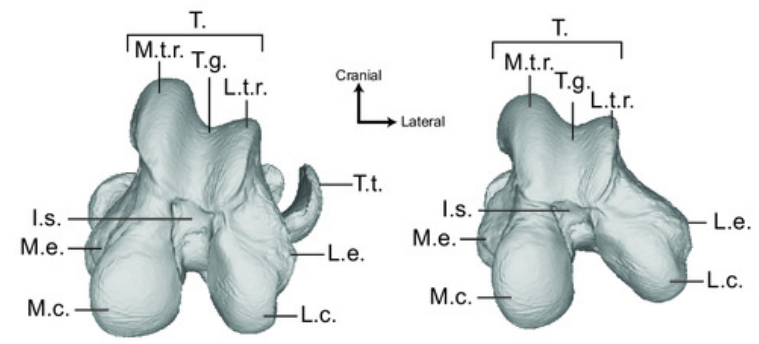

$\mathrm{H}$

I 


\section{Figure 5}

Results of the PCA performed on morphometric data of the tibia.

A: distribution of the specimens along the two first axes of the PCA; B to I: theoretical shapes associated with the minimum and maximum values of $\mathrm{PC} 1$ : cranial $(B, C)$, lateral $(D, E)$, proximal $(F, G)$ and distal $(H, I)$ views for $P C 1$ minimum $(B, D, F, H)$ and $P C 1$ maximum $(C, E$, G, I). Abbreviations - A.s.t.: Articular surface for the talus; C.a.: Caudal apophysis; Ce.i.a.: Central intercondylar area; Cr.i.a.: Cranial intercondylar area; D.a.s.f.: Distal articular surface for the fibula; E.g.: Extensor groove; I.c.: Interosseous crest; L.a.s.: Lateral articular surface; L.c.: Lateral condyle; L.g.: Lateral groove; L.i.t.: Lateral intercondylar tubercle; M.a.s.: Medial articular surface; M.c.: Medial condyle; M.g.: Medial groove; M.i.t.: Medial intercondylar tubercle; M.m.: Medial malleolus; P.a.s.f.: Proximal articular surface for the fibula; P.n.: Popliteal notch; S.s.m.p.: Sliding surface for the m. popliteus; T.c.: Tibial crest; T.g.: Tuberosity groove; T.t.: Tibial tuberosity. 

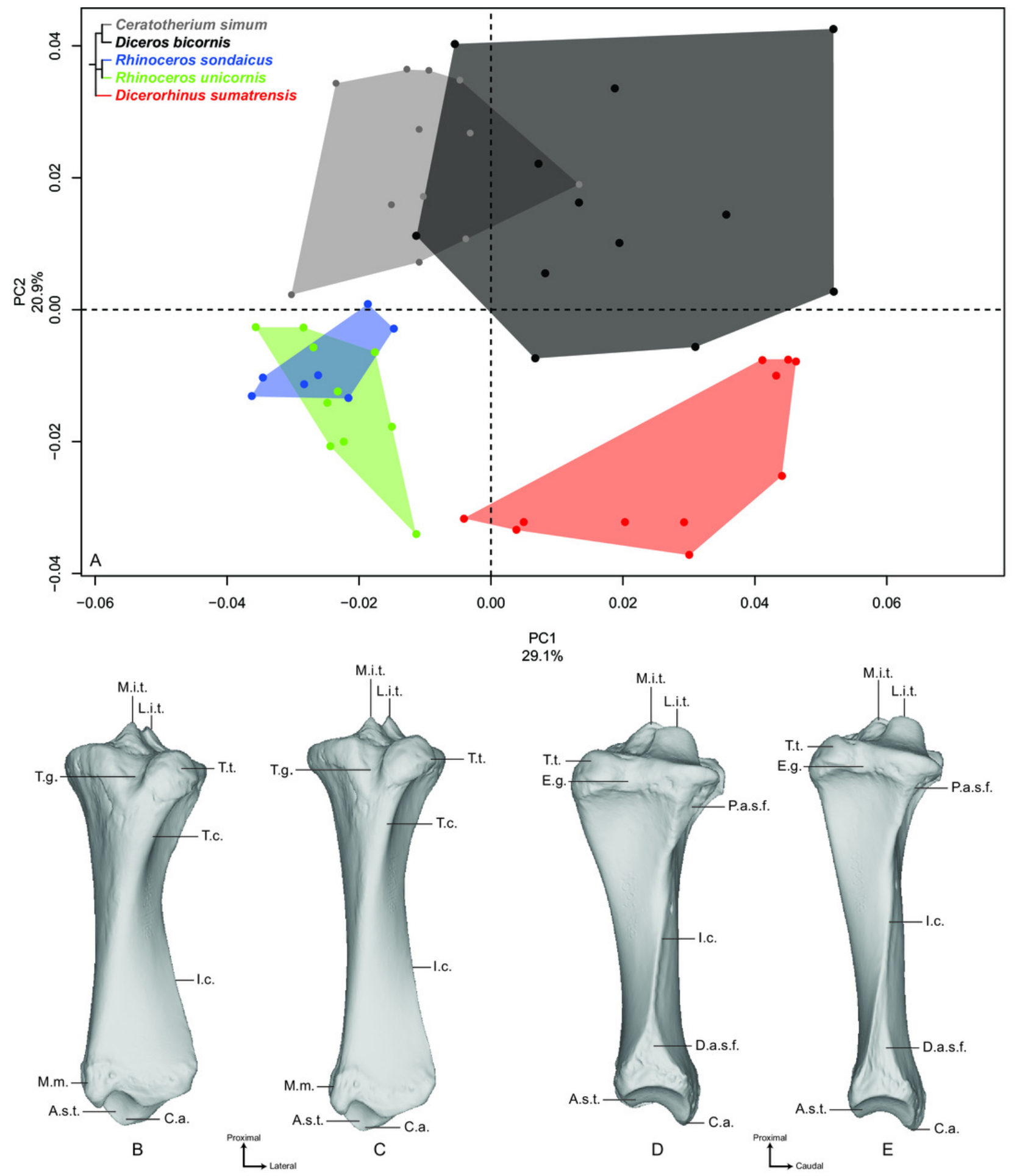

$29.1 \%$
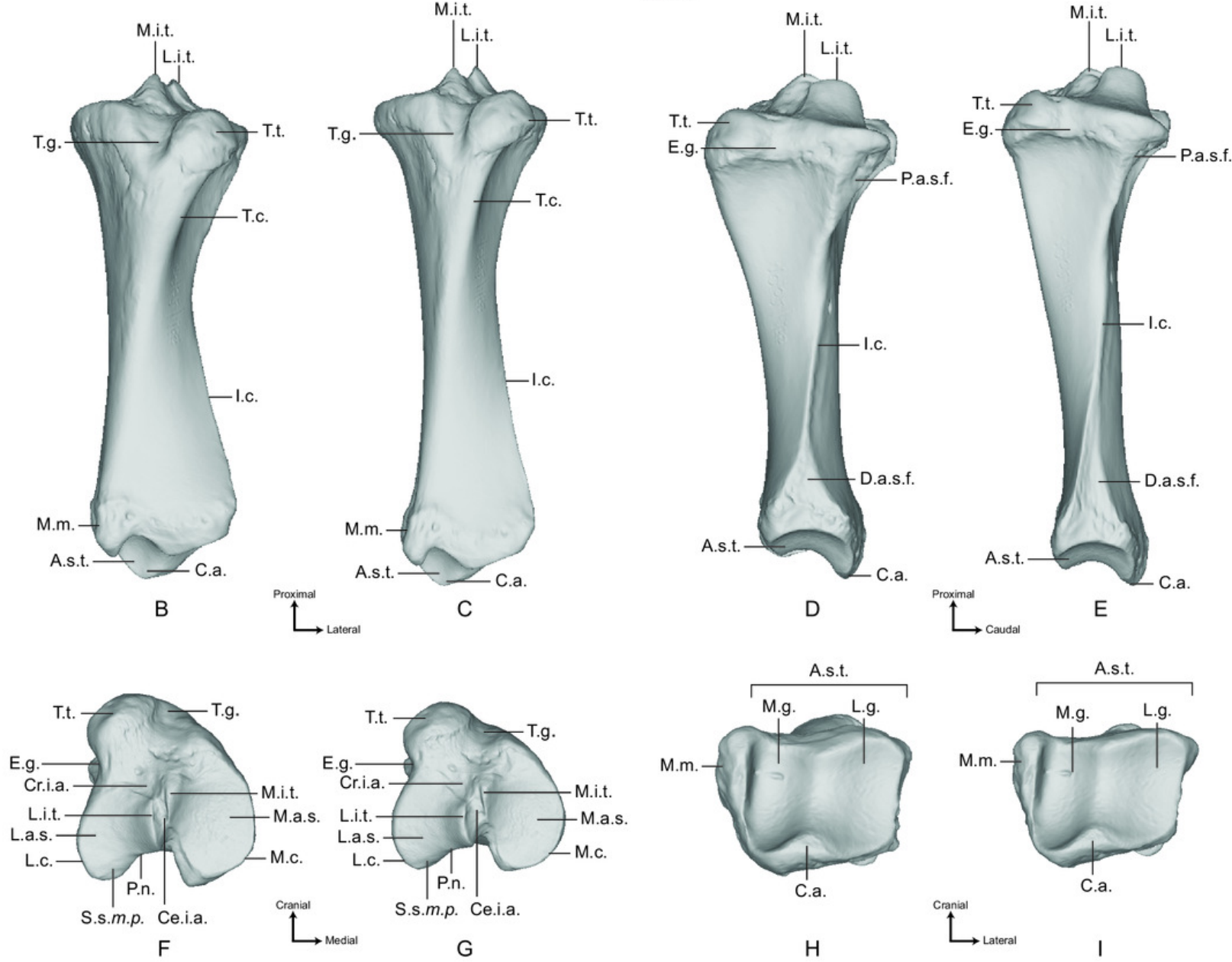

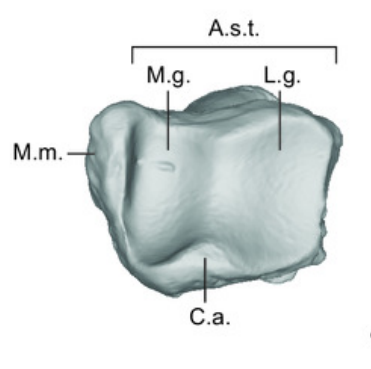

$\mathrm{H}$

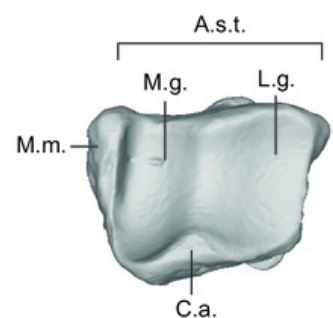

$\stackrel{\text { Cranial }}{\longrightarrow}$ Lateral 


\section{Figure 6}

Results of the PCA performed on morphometric data of the fibula.

Distribution of the specimens along the two first axes of the PCA, taking into account the age class and the sex of each specimen. Square: female; Triangle: male; Circle: unknown; Empty symbol: subadult; Filled symbol: adult.

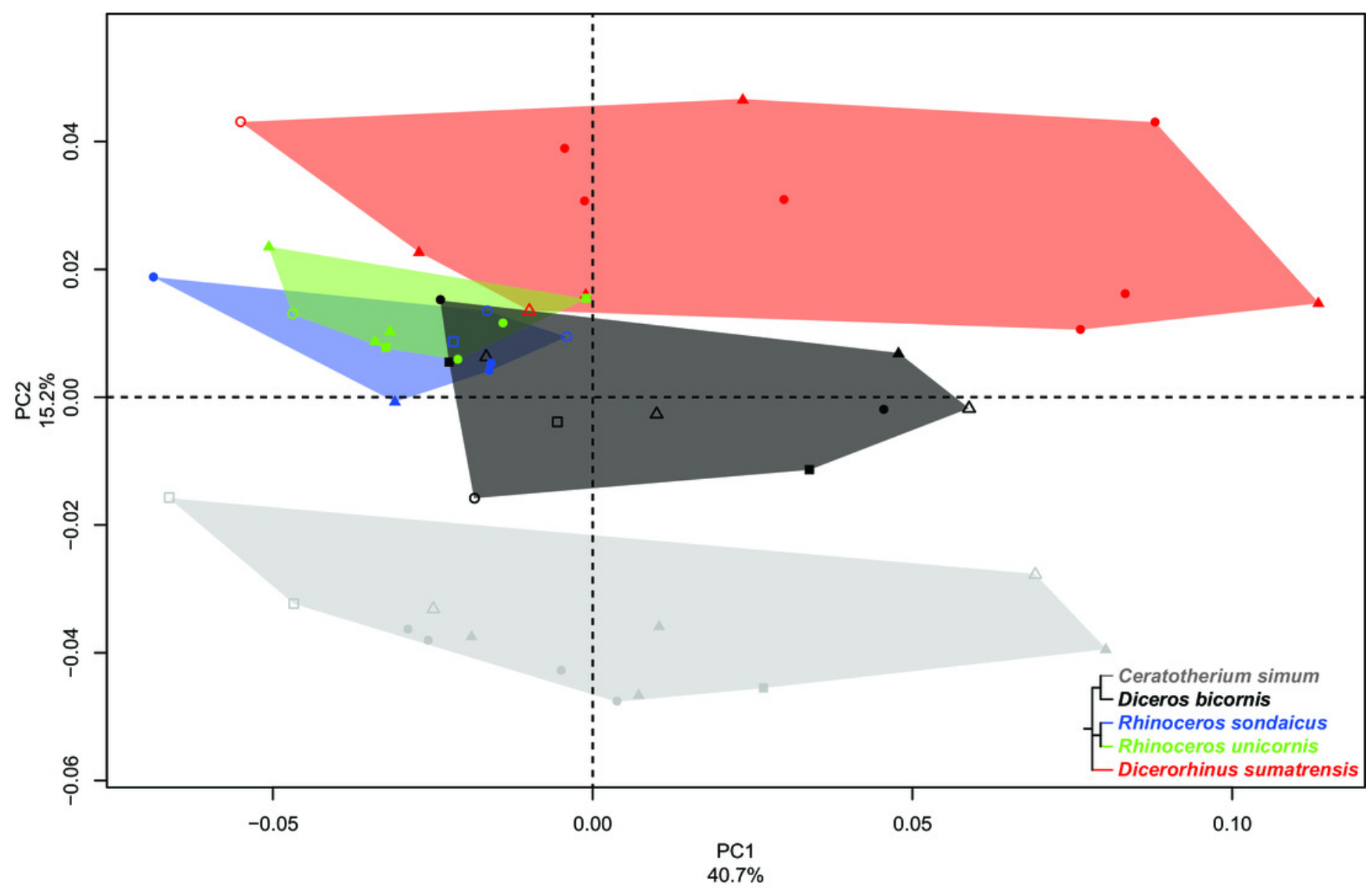




\section{Figure 7}

Results of the PCA performed on morphometric data of the fibula (second and third axes).

A: distribution of the specimens along the second and third axes of the PCA; B to K:

theoretical shapes associated with the minimum and maximum values of PC2: lateral $(B, C)$, cranial $(D, E)$, medial $(F, G)$, proximal $(H, I)$ and distal $(J, K)$ views for PC2 minimum $(B, D, F$, H, J) and PC2 maximum (C, E, G, I, K). Abbreviations - A.s.t.: Articular surface for the talus;

Ca.I.: Caudo-lateral line; Ca.t.I.m.: Caudal tubercle of the lateral malleolus; Cr.I.: Craniolateral line; Cr.t.I.m.: Cranial tubercle of the lateral malleolus; D.a.s.t.: Distal articular surface for the tibia; D.g.m.: Distal groove of the malleolus; H.: Head; I.c.: Interosseous crest; L.g.: Lateral groove; P.a.s.t.: Proximal articular surface for the tibia. 

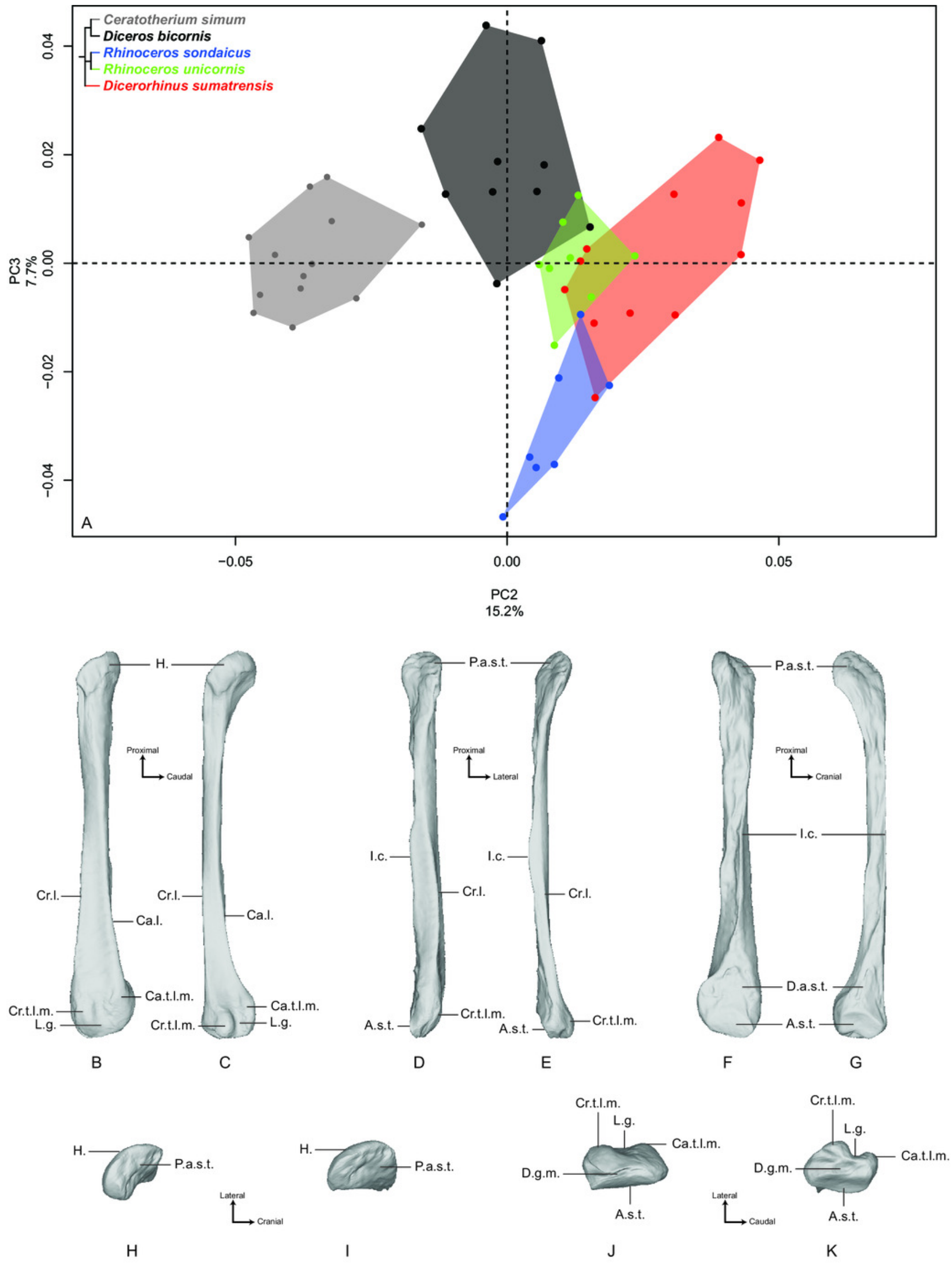


\section{Figure 8}

Landmark conformations associated with minimal and maximal centroid size and mean mass for each bone.

A, B: Humerus (caudal view); C, D: Radius (dorsal view); E, F: Ulna (dorsal view); G, H: Femur (cranial view); I, J: Tibia (cranial view); K, L: Fibula (lateral view). Red dots: landmark conformation associated with the mean mass. Blue dots: landmark conformation associated with the centroid size. A, C, E, G, I, K: landmark conformation associated with the minimum of both parameters; $B, D, F, H, J$, L: landmark conformation associated with the maximum of both parameters. 

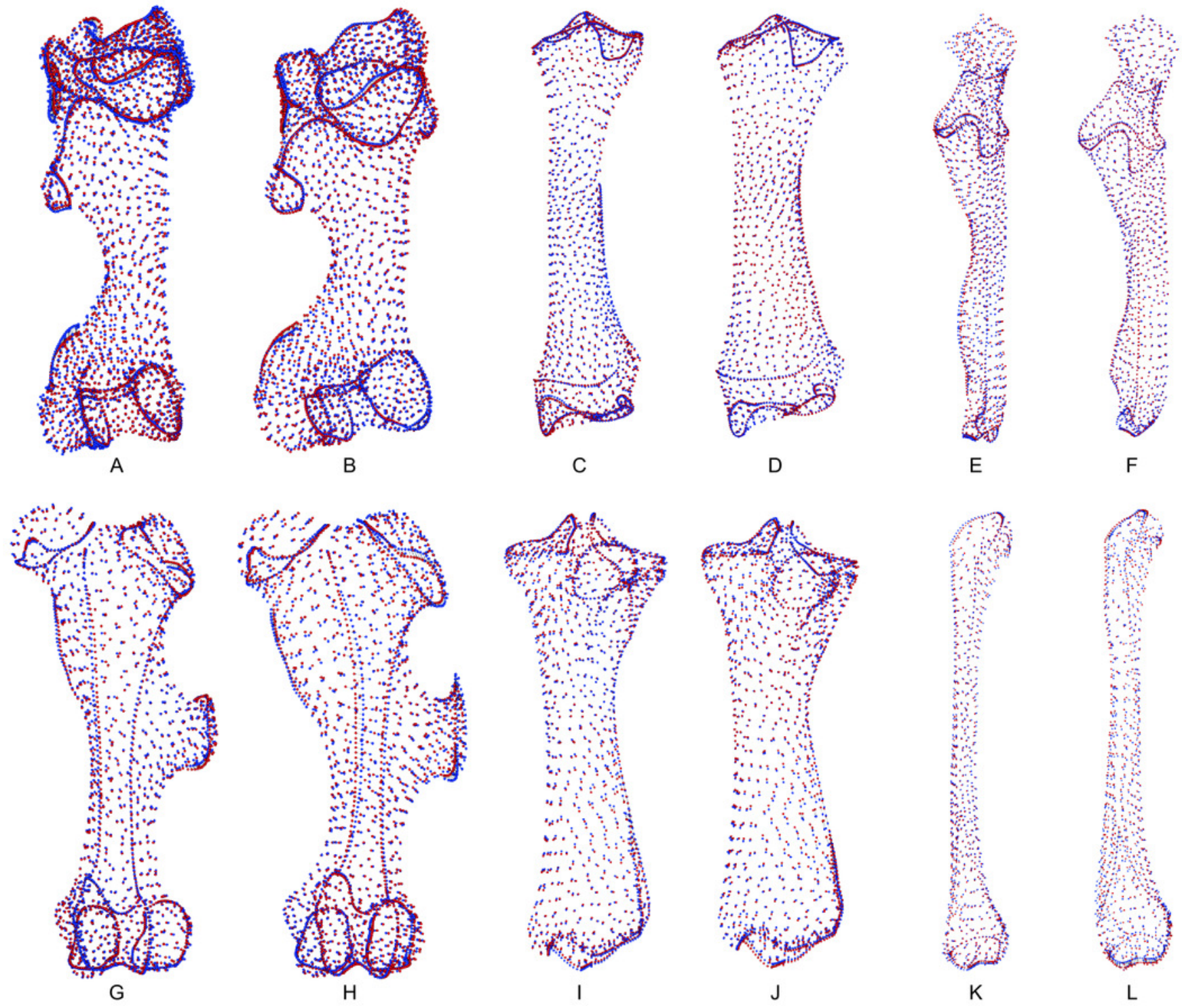
Figure 9

Multivariate regression plots performed on shape data and log-transformed centroid size. 

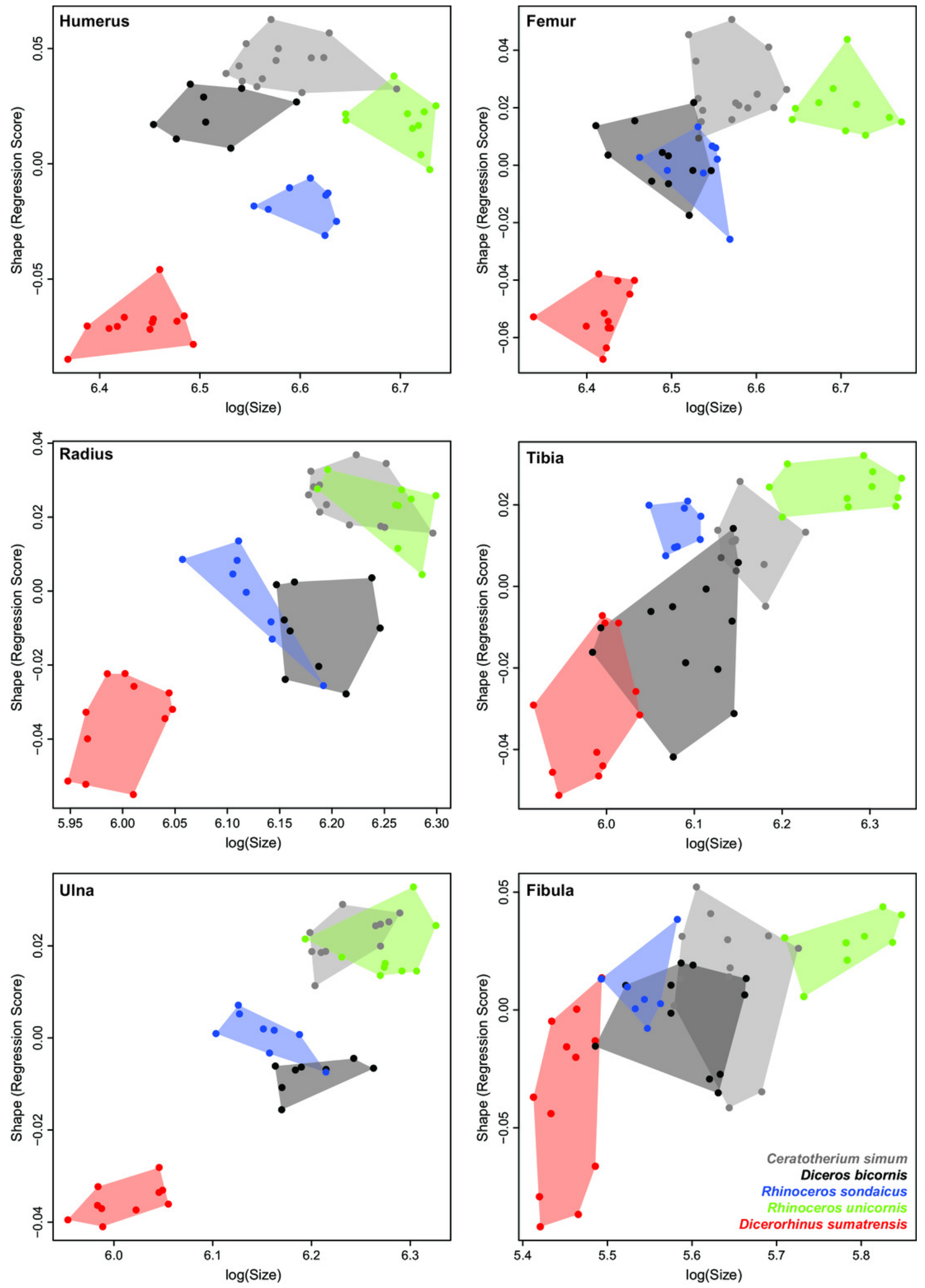

Peer) reviewing PDF | (2019:05:37815:2:0:NEW 6 Aug 2019) 